\title{
WestVirginiaUniversity
}

THE RESEARCH REPOSITORY @ WVU

Graduate Theses, Dissertations, and Problem Reports

2018

\section{Three Essays Using Natural Experiments to Measure Causal Effects on Education}

\author{
Patrick A Reilly
}

Follow this and additional works at: https://researchrepository.wvu.edu/etd

\section{Recommended Citation}

Reilly, Patrick A, "Three Essays Using Natural Experiments to Measure Causal Effects on Education" (2018). Graduate Theses, Dissertations, and Problem Reports. 7237.

https://researchrepository.wvu.edu/etd/7237

This Dissertation is protected by copyright and/or related rights. It has been brought to you by the The Research Repository @ WVU with permission from the rights-holder(s). You are free to use this Dissertation in any way that is permitted by the copyright and related rights legislation that applies to your use. For other uses you must obtain permission from the rights-holder(s) directly, unless additional rights are indicated by a Creative Commons license in the record and/ or on the work itself. This Dissertation has been accepted for inclusion in WVU Graduate Theses, Dissertations, and Problem Reports collection by an authorized administrator of The Research Repository @ WVU.

For more information, please contact researchrepository@mail.wvu.edu. 


\title{
Three Essays Using Natural Experiments to Measure Causal Effects on Education
}

\author{
Patrick A. Reilly \\ Dissertation submitted to the \\ College of Business and Economics \\ at West Virginia University \\ in partial fulfillment of the requirements for the degree of \\ Doctor of Philosophy \\ in \\ Economics
}

Brad R. Humphreys, Ph.D., Chair

Arabinda Basistha, Ph.D.

Joshua Hall, Ph.D.

Daniel Grossman, Ph.D.

Jack Dorminey, Ph.D.

Department of Economics

Morgantown, West Virginia

2018

Keywords: bank branching, conference realignment, credit constraints, education, higher education, intercollegiate athletics

Copyright 2018 Patrick A. Reilly 


\begin{abstract}
Three Essays Using Natural Experiments to Measure Causal Effects on Education
\end{abstract}

Patrick A. Reilly

This dissertation covers two topics. The first in two essays, each using variation in the timing of statewide deregulation of bank branching to estimate causal effects of credit availability on high school graduation. Between 1970 and 1999, 39 states reduced legal geographic restrictions on the location of bank branches. These bank branching deregulations represent quasi-random increases in credit availability to residents of the deregulating state relative to residents of regulated states. In the first essay, using data on state of residence and educational attainment from the Current Population Survey March Supplement, I estimate bank branching deregulation's impact on high school graduation by regressing a binary indicator of high school attainment on a treatment variable. This treatment variable indicates whether an individual's graduation from high school was plausibly affected by bank branching deregulation. I find bank branching deregulation significantly increases the likelihood of graduating high school by 1 percentage point. In the second essay, I continue to investigate how bank branching deregulation affects high school graduation. In place of the CPS data, I use National Longitudinal Survey of Youth 1979 data to mitigate both measurement error introduced when identifying treatment and omitted variable bias. I also use the differencein-discontinuities method, which should improve similarity of unobservable characteristics by finding the local average treatment effect. I again find positive and significant effects of bank branching deregulation on high school graduation. The third essay comprises the second topic covered in this dissertation, namely, does big-time college football promote other university outcomes. Football Bowl Subdivision colleges and universities support their athletics departments to the tune of $\$ 20$ million per university per year. Advocates of university sponsored athletics suggest there are large advertising effects of fielding big-time college football and men's basketball teams. Using athletic success to measure changes in the advertising effect fails to control for unobservable, institution-specific factors that influence university outcomes.Therefore, we use conference changes to represent quasi-random shocks to the aforementioned advertising effect. Using difference-in-differences methods we estimate average treatment effects of conference switching with Integrated Postsecondary Education Data System (IPEDS) data for 90 NCAA D1 FBS universities over the years 2000 to 2015. Difference-in-differences estimations provide weak evidence that conference switching reduces applications and ACT scores of incoming students and increases state appropriations, calling into question the subsidization of these athletics programs. 


\section{Acknowledgements}

In the last five years at West Virginia University I have grown as a scholar and as a person. I am indebted to Dr. Brad Humphreys for his time, knowledge, counsel, and for reassuring me in times of doubt.

I am also grateful for all I learned from Dr. Arabinda Basistha and Dr. Joshua Hall, for their open doors, encouraging attitude, and insightful advice.

I also thank Dr. Dan Grossman and Dr. Jack Dorminey who each improved this dissertation with their curiosity and unique viewpoints.

Finally, I want to acknowledge all the support and love from the friends I made in my time at this program. Masha, Juan, Danko, Zach, Golnaz, Amir, Pyun, Yang, and all the rest, thank you all.

I dedicate this dissertation to Francene. "When I walked into your house/I knew I'd never want to leave." 


\section{Contents}

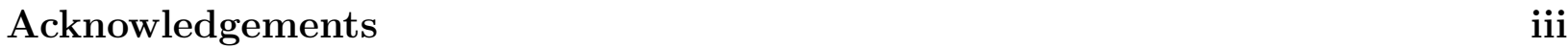

List of Figures $\quad$ vi

List of Tables $\quad$ vii

1 Introduction 1

2 Bank Branching Deregulation and High School Graduation 4

2.1 Background on Bank Branching Deregulation . . . . . . . . . . . . 6

2.2 Discussion of Mechanisms . . . . . . . . . . . . . . . . . . . 8

2.3 Data and Methods . . . . . . . . . . . . . . . . . . . . 10

2.3.1 Empirical Method . . . . . . . . . . . . . . . . . . . . . 10

2.3.2 Identifying the Treatment Group . . . . . . . . . . . . . . . . . 13

2.3 .3 CPS Data . . . . . . . . . . . . . . . . . . . . . . 15

2.4 Results . . . . . . . . . . . . . . . . . . . . . . . . . . . . . 17

2.5 Robustness . . . . . . . . . . . . . . . . . . . . . . . . . 20

2.6 Conclusion . . . . . . . . . . . . . . . . . . . . . . . . . . . . . . 21

3 Bank Branching Deregulation and High School Graduation: A Regression Discontinuity Approach 35

3.1 Background: Bank Branching Deregulation . . . . . . . . . . . . . . . 37

3.2 Theoretical Foundations . . . . . . . . . . . . . . . . . . . . . . . 38

3.3 Data and Methods . . . . . . . . . . . . . . . . . . 40

3.3 .1 Data . . . . . . . . . . . . . . . . . . . . . 40

3.3 .2 Identifying Treated Individuals . . . . . . . . . . . . . . . . 42

3.3 .3 State Selection . . . . . . . . . . . . . . . . . . . . . 44

3.3 .4 Regression Model . . . . . . . . . . . . . . . . . . . . . . . . 45

3.3.5 Regression Discontinuity Validity Checks . . . . . . . . . . . . 46

3.3.6 Differences-in-Discontinuity Design . . . . . . . . . . . . . . 46

3.4 Results . . . . . . . . . . . . . . . . . . . . . . . . 47

3.5 Robustness Checks and Falsification Tests . . . . . . . . . . . . . 51

3.6 Conclusion . . . . . . . . . . . . . . . . . . . . . . . . 52 
4 The Impact of Big-Time Sports on University Outcomes: Evidence from $\begin{array}{ll} & 67\end{array}$

4.1 Context . . . . . . . . . . . . . . . . . . . . 70

4.1.1 Previous Literature on Athletics and Academic Outcomes . . . . . . . 70

4.1.2 Conference Realignment in Big-Time College Sports . . . . . . . . . . 75

4.2 Data . . . . . . . . . . . . . . . . . . . . . . 77

4.2.1 Changes to Conference Membership . . . . . . . . . . . . . 78

4.2 .2 IPEDS Data . . . . . . . . . . . . . . . . . . . . . . . . . . . . . . . . 79

4.2 .3 REIS Data . . . . . . . . . . . . . . . . . . . . . . . . 82

4.3 Empirical Analysis . . . . . . . . . . . . . . . . . . . . . . . . . 82

4.3 .1 Identification . . . . . . . . . . . . . . . . . . 83

4.3 .2 Baseline Empirical Model . . . . . . . . . . . . . . . . . . . . . . . 84

4.3.3 Propensity Score Matching . . . . . . . . . . . . . . . . . . . . . 85

4.3.4 Analyzing Realignment Clusters . . . . . . . . . . . . . . . . 87

4.4 Results . . . . . . . . . . . . . . . . . . . . . . . . . . . 89

$4.4 .1 \quad$ Full Sample Results . . . . . . . . . . . . . . . . . . . . . . . . . . . 89

4.4.2 Propensity Score Based Control Group Selection . . . . . . . . . . . . 91

4.4 .3 Investigating Realignment Clusters . . . . . . . . . . . . . . . . 92

4.5 Conclusion . . . . . . . . . . . . . . . . . . . . . . . . . 94 


\section{List of Figures}

2.1 Dates of US Bank Branching Deregulation . . . . . . . . . . . . . . . . . 23

2.2 Intent to Treat Strategy, Two States . . . . . . . . . . . . . . . . . . . . . 24

2.3 Bank Branching Deregulation's Effect on HSG by Age at BBD . . . . . . . . 25

3.1 High School Graduation Regression Discontinuity Pre- and Post-Deregulation 54

3.2 Placebo Test for Cutoff, Cuttoff $=-20 \ldots \ldots$. . . . . . . . . . 55

4.1 Conference Changes by Year, First Time Switchers . . . . . . . . . . . . . 96

4.2 Propensity Score Distribution: Power 5 Conference Changes . . . . . . . . . 121 


\section{List of Tables}

2.1 Bank Branching Deregulation Dates, by Year . . . . . . . . . . . . . 26

2.2 Summary Statistics . . . . . . . . . . . . . . . . . . . . . . 27

2.3 Effect of BBD on High School Graduation by Race and Gender . . . . . . . 28

2.4 Identification Validity: College Attendance and Attainment . . . . . . . . . . 29

2.5 Comparison of Unit Banking vs Limited Branching Groups . . . . . . . . . . 30

2.6 Comparison of Treatment Group by Age at BBD . . . . . . . . . . . . . . . 31

2.7 Robustness Checks . . . . . . . . . . . . . . . . . . . . . . . 32

2.8 Placebo Test, False BBD Dates . . . . . . . . . . . . . . . . . . . . . . . . . . . . . . . . . 33

2.9 False BBD Dates, by Year . . . . . . . . . . . . . . . . . . . . 34

3.1 Borders of Interest . . . . . . . . . . . . . . . . . . . . . 56

3.2 Summary Statistics, All Counties Sample, Age 22 . . . . . . . . . . . . 57

3.3 Summary Statistics, Border County Sample, Age 22 . . . . . . . . . . . . . 58

3.4 Mean Comparison Test: Are Border Counties more Homogenous? . . . . . . 59

3.5 Effect of BBD on High School Graduation by Race and Gender . . . . . . . 60

3.6 Effect of BBD on High School Graduation, Split at AFQT $=50$. . . . . . . 61

3.7 Difference-in-Discontinuities Method, Local Average Treatment Effect of BBD on Educational Outcomes . . . . . . . . . . . . . . . . . . . 62

3.8 Difference-in-Discontinuities Method, Local Average Treatment Effect of BBD on Grade Completion by Age . . . . . . . . . . . . . . . . . . . . 63

3.9 Effect of BBD on Educational Attainment, Income-BBD Interaction . . . . . 64

3.10 Effect of BBD on College Attendance Grouped by Income Level . . . . . . . 65

3.11 Robustness Estimations . . . . . . . . . . . . . . . . 66

4.1 Summary Statistics, Full Sample . . . . . . . . . . . . . . . . . . 97

4.2 PSM Treated and Control Pairs . . . . . . . . . . . . . . . . . . . 98

4.3 Admissions Outcomes and Conference Changes, Full Sample . . . . . . . . . 99

4.4 Graduation and Retention Rates and Conference Changes, Full Sample . . . 100

4.5 ACT Composite Scores and Conference Changes, Full Sample . . . . . . . . 101

4.6 ACT Verbal Scores and Conference Changes, Full Sample . . . . . . . . . . . 102

4.7 ACT Math Scores and Conference Changes, Full Smaple . . . . . . . . . . . 103

4.8 SAT Critical Reading Scores and Conference Changes, Full Smaple . . . . . 104

4.9 SAT Math Scores and Conference Changes, Full Smaple . . . . . . . . . . . . 105

4.10 Instructional Expenditures and Conference Changes, Full Smaple . . . . . . 106 
4.11 Research Expenditures and Conference Changes, Full Smaple . . . . . . . . . 107

4.12 State and Local Funding and Conference Changes, Full Smaple . . . . . . . . 108

4.13 Private and Federal Funding and Conference Changes, Full Smaple . . . . . 109

4.14 Diff-in-Diff Estimates: Universities PS Matched on Switch Power 5 . . . . . 110

4.15 Applications, Retention, Graduation, and Conference Changes: 04/05 Cluster 111

4.16 ACT Scores and Conference Changes: 04/05 Cluster . . . . . . . . . . . . . 112

4.17 SAT Scores and Conference Changes: 04/05 Cluster . . . . . . . . . . . . . 113

4.18 University Funding and Conference Changes: 04/05 Cluster . . . . . . . . . 114

4.19 Research, Instructional Expenditures, and Conference Changes: 04/05 Cluster 115

4.20 Admissions, Student Outcomes, and Conference Changes: 11/12/13 Cluster . 116

4.21 ACT Scores and Conference Changes: 11/12/13 Cluster . . . . . . . . . . . . 117

4.22 SAT Scores and Conference Changes: 11/12/13 Cluster . . . . . . . . . . . . 118

4.23 University Funding and Conference Changes: 11/12/13 Cluster . . . . . . . . 119

4.24 University Expenditures and Conference Changes: 11/12/13 Cluster . . . . . 120

4.25 Summary Statistics, 2004/05 Clusters . . . . . . . . . . . . . . . . . . . 122

4.26 Admissions and Enrollment and Realignment, No Institutional Groupings . . 123

4.27 ACT Composite Scores and Realignment, No Institutional Groupings . . . . 124

4.28 ACT Verbal Scores and Realignmen, No Institutional Groupingst . . . . . . 125

4.29 ACT Math Scores and Realignment, No Institutional Groupings . . . . . . . 126

4.30 SAT Critical Reading Scores and Realignment, No Institutional Groupings . 127

4.31 SAT Math Scores and Realignment, No Institutional Groupings . . . . . . . 128

4.32 Graduation and Retention Rates and Realignment, No Institutional Groupings 129

4.33 Instructional Expenditures and Realignment, No Institutional Groupings . . 130

4.34 Research Expenditures and Realignment, No Institutional Groupings . . . . 131

4.35 State and Local Funding and Realignment, No Institutional Groupings . . . 132

4.36 Private and Federal Funding and Realignment, No Institutional Groupings . 133

4.37 Log Odds of Joining a Power 5 Conference . . . . . . . . . . . . . . . . . . . 134

4.38 PSM with Rutgers and Maryland . . . . . . . . . . . . . . . . . 135 


\section{Chapter 1}

\section{Introduction}

Education is an outcome of interest for any economic change because of its association with future benefits. In this dissertation, I use causal inference methods to assess the educational impact of two separate natural experiments. In the first two essays, I use commercial bank branching deregulation during the 1970s, 1980s, and 1990s as an exogenous indicator of increased credit availability and assess the impact on education, namely high school graduation. In the last essay, jointly with Brad Humphreys, we use changes to NCAA Division 1 Football Bowl Subdivision conferences to assess whether or not big-time college sports support universities' academic goals.

I study how increased competition in credit markets impact individuals' ability and desire to graduate high school in chapters 2 and 3. More specifically, I empirically evaluate the impact of states legally removing restrictions for the geographic location of bank branches, known as bank branching deregulation (BBD), on individual attainment of high school graduation. Thirty-nine states removed these restrictions at different times between 1970 and 1999. The variation in timing allows me to identify treated individuals, those who were likely too young to have graduated high school when their state deregulated, and non-treated individuals. By identifying these two groups, I am able to estimate the average effect of BBD on the likelihood of graduating high school.

In Chapter 2, I estimate linear probability models of an indicator of high school graduation using data from the Current Population Survey (CPS) March Supplement from 1977 to 1999. I find both white males and white females were more likely to graduate high 
school when treated. In Chapter 3, I estimate a type of regression discontinuity model called difference-in-discontinuities, which controls for differences between states prior to BBD. These models use National Longitudinal Survey of Youth 1979 geocoded data, which provide county of residence along with many individual specific predictors of educational attainment such as family income. Although only three out of the 39 states are viable for the difference-in-discontinuities estimation, I find significant increases in the likelihood of high school graduation for treated individuals.

In Chapter 4, a joint work with Brad Humphreys, we analyze whether or not big-time college athletics, directly or indirectly, impacts non-athletic outcomes at the university. The marriage of athletics and academics is unique to the US. In fact, universities subsidize athletics programs at FBS schools at an average rate of $\$ 20$ million per year. For this to make economic sense for each university, this funding must benefit the university's mission as much as $\$ 20$ million spent elsewhere. Proponents of this subsidization believe in advertising effects, where more prominent athletics teams attract applicants, donations, and state funding.

If these effects exist, we expect improvements in university outcomes to follow these conference improvements. We use movements to more prestigious football conferences as quasi-random improvements to potential advertising effects. Using panel data for 90 universities from 2000 to 2015, we employ a difference-in-differences method to estimate the effects of switching conferences. In the full model, and also in models limiting control groups in order to better match unobservable aspects of universities changing conferences, we find conference changes in general negatively affect applications, and switching to power 5 conferences have weak negative effects or no effect on university outcomes.

This dissertation has two main contributions. First, by demonstrating bank branching deregulation increased the likelihood of high school graduation, I provide evidence that credit markets indirectly affect secondary education. Since high school attendance does not have monetary costs, this relationship cannot derive from secondary students and their families needing to borrow money to afford high school. Rather, access to credit must change circumstances surrounding high school graduation through either changes to labor market outcomes of dropouts relative to graduates or greater stability for families.

Second, together with Brad Humphreys, we improve the causal method used to study 
the relationship between big-time athletics and university academics by using conference changes as a source of quasi-random increase in athletic program prestige. Previous studies used athletic success to measure variation in athletic program prestige when assessing how that prestige impacts university outcomes. However, this branch of research typically fails to account for institution-specific unobservable factors related to athletic success and university outcomes. Additionally, even if athletic success positively affects the university overall, this cannot justify why big-time athletics is subsidized by universities because in the long run success is zero-sum. No university can expect prolonged success in a system where all teams subsidize their athletics programs. We believe using conference changes mitigates these issues For a few reasons. First, teams cannot simply chose their conference at will. Next, conference expansions allow more teams to join prestigious conferences so it is not zerosum. And finally, reasons for conference changes are revenue based and exogenous to other university outcomes. 


\section{Chapter 2}

\section{Bank Branching Deregulation and High School Graduation}

Credit markets affect the real economy. Rules and regulations of the banking industry constrain credit markets. Bank branching is one such regulation. Most states initiated intrastate bank branching deregulation of commercial banks (hereafter BBD) over the period 1970 to 1994. Several issues influenced BBD: low profits for small commercial banks caused by usury laws acting as interest rate ceilings during a time of high nominal interest rates, and higher profits from larger banks due to banking innovations such as the Automated Teller Machine (ATM). ${ }^{1}$

BBD allowed commercial banks to compete with geographically unconstrained money market mutual funds and increased the size of banks, allowing them to take advantage of economies of scale. BBD also decreased the market power of local banks by lowering barriers to entry. These decreases in costs and increases in competition reduced interest rates for loans, stimulating the economy.

Jayaratne and Strahan (1996) and Clarke (2004) find economic growth positively related to BBD. In fact, the same BBD is shown to have many real effects. Some effects are direct, for instance an increase in commercial banking industry competition (Stiroh and Strahan, 2003). Other effects have a more indirect link. As an example, Beck et al. (2010) find

\footnotetext{
${ }^{1}$ For a review of the political economy surrounding bank branching deregulation, see Kroszner and Strahan (1999) or Kroszner and Strahan (2014)
} 
Patrick A. Reilly Chapter 2. Bank Branching Deregulation and High School Graduation 5 decreases in income inequality due to BBD. This chapter focuses on indirect consequences of BBD on educational attainment.

In related work, both Levine and Rubinstein (2013) and Teng Sun and Yannelis (2016) identify a relationship between BBD and college enrollment. Both papers concluded increased postsecondary enrollment resulting from BBD via improved credit availability. Levine and Rubinstein focused on how intellectually able but financially constrained individuals were affected by BBD. Teng Sun and Yannelis concentrate on financial constraints, used multiple data sets, and found increases in both postsecondary school attendance, completion of postsecondary education, and college loans, especially in low- and middle-income families.

This chapter examines BBD's effect on education in the absence of a direct credit market channel. Focusing on secondary school outcomes mitigates credit's role in education. Any effects of BBD on high school graduation provide evidence that other channels, more complex than a direct credit channel, impact educational outcomes. The most likely alternative is a labor market channel transmitted via older siblings, friends, and parents revealing the relative labor market conditions for high school degree earners post-BBD.

Although other researchers focus on college attendance and BBD, policy impacts on high school graduation are as, if not more, important than college attendance. First, high school graduation is compulsory for college enrollment, so any negative effects on high school graduation are compounded by a reduction in future educational opportunities. Additionally, students and their families initially reduce wealth via student loans, limiting any gains to welfare from improved postsecondary educational outcomes. No such burden exists for secondary education. Finally, the negative consequences of failing to receive a high school diploma are far worse than the negative consequences of failing to attend college. Bridgeland et al. (2006) estimate the negative consequences of dropping out of high school, which included $\$ 9,200$ less income per year on average, greater rates of unemployment, and a smaller likelihood of reporting good health. Also, high school dropouts needed and received more public assistance than graduates. Oreopoulos (2007) reports similar findings.

With this in mind, focusing on high school graduation in addition to college attendance, a la Levine and Rubinstein (2013) or Teng Sun and Yannelis (2016), provides a more comprehensive picture of the impact of BBD on education. 
Patrick A. Reilly Chapter 2. Bank Branching Deregulation and High School Graduation 6

This chapter estimates linear probability models explaining whether or not individuals achieved specific levels of education using data from the March Current Population Survey (CPS). Variation in dates of state-level BBD identifies treatment. Analysis reveals positive impacts of $\mathrm{BBD}$ on high school graduation along with increases in postsecondary attendance and bachelor's degree achievement. The parameter estimates for postsecondary outcomes are on par with results from Teng Sun and Yannelis (2016) and Levine and Rubinstein (2013), which suggests validity of identification strategy and data used. The results provide no evidence of heterogeneity by gender. However, nonwhite individuals (unlike white individuals) are not significantly affected by BBD.

\subsection{Background on Bank Branching Deregulation}

Deregulation of geographic bank branching restrictions is a widely analyzed policy change. Throughout the 1970s, 1980s, and 1990s most states removed geographic restrictions on bank branching. In 1969, thirty-nine states had regulations on intrastate (within-state) branching and all fifty states had regulations on interstate (across-state) bank branching. By 1994, every state except Iowa had deregulated their intrastate branching in some form and only Hawaii continued to prohibit interstate bank branching. ${ }^{2}$

Why were there restrictions on bank branching? One reason comes from the rent seeking/rent extraction literature. Taxes on bank profits were originally a large part of states' revenues (Sylla et al., 1987). To maximize revenue, states maximized bank profits. States increased monopoly power by passing laws restricting bank branching. Separating banks geographically, especially in an era without electronic banking, allowed banks to set prices higher than competition would dictate.

Depositors and borrowers in the 18th and 19th and even 20th centuries chose not to switch banks because of the high cost of locating and traveling to competing banks. Thus, demand for bank services was price inelastic, so banks charged more for loans and paid less to depositors to maximize profits. Therefore, by restricting competition through limiting bank

\footnotetext{
${ }^{2}$ Deregulation dates from Amel (1993) and Kroszner and Strahan (1999). See Table 2.1.
} 


\section{Patrick A. Reilly Chapter 2. Bank Branching Deregulation and High School Graduation 7}

branching, banks maximized profits and states maximized revenues. ${ }^{3}$ This rent extraction relationship became less important overtime as state governments found alternative sources of revenue. Nevertheless, incumbent banks lobbied state governments to keep the laws intact in order to protect monopoly rents. ${ }^{4}$

Interstate regulations originated because, in order to charter in a state, a bank incorporated in that state must pay a fee; whereas, a bank incorporated in a different state need not pay (Kroszner and Strahan, 2014). Once again, regulations acted to maximize state revenue.

Kroszner and Strahan (1999) suggest that these rents decreased, particularly for small banks, in the 1970s and into the 1980s because of high nominal interest rates combined with the usury law ceiling for rates charged on commercial bank loans. Creation of demand deposit substitutes such as money market mutual funds also directly hurt small banks' profits.

During the same time period, ATMs, use of credit scores, and improvements in information technology all benefit large banks disproportionately with respect to small banks. Thus, BBD should increase bank profits from these innovations as well as reduce risk by geographically spreading assets. In a rent seeking framework, large banks eventually outbid the incumbent small banks and BBD laws passed (Kroszner and Strahan, 2014). ${ }^{5}$

The literature identifies three types of BBD. First, intrastate BBD through mergers and acquisitions; next full intrastate or de novo branching deregulation, and third, interstate BBD. This chapter focuses on mergers and acquisitions. Mergers and acquisitions allowed Multibank Holding Companies (MBHC) to consolidate their subsidiaries into branches of a single bank. ${ }^{6}$

After each BBD, banks grew larger and spread their risk geographically. Geographic

\footnotetext{
${ }^{3}$ This relationship falls within the rent extraction literature a la McChesney (1987).

${ }^{4}$ If states are no longer extracting, we can still expect some sort of rent seeking by incumbent banks a la Tullock (1967) and Krueger (1974).

${ }^{5}$ Some small commercial banks and thrifts initiated a last ditch loan scheme to cover their losses from high interest rates and regulation. Armed with deregulation and moral hazard created by federal insurance of many Savings and Loans, some Savings and Loan institutions took on very risky assets to make back losses. The failure of these junk assets led directly to the Savings and Loan Crisis in the 1980s. See Kroszner and Strahan (2014) or White (1991)

${ }^{6}$ However, banks could not open up a branch anywhere after merger and acquisition BBD. They had to acquire or merge with an existing bank in order to add branches. The ability to add non-preexisting branches was the last step of intrastate BBD. This, de novo branching, completed the intrastate BBD. The last type of BBD discussed here is interstate. This allowed MBHCs to own banks in states other than where they were headquartered.
} 
Patrick A. Reilly Chapter 2. Bank Branching Deregulation and High School Graduation 8 spread of risk decreased the likelihood of a bank failure due to economic weakness in a certain region of a state. Bank size can reduce costs through economies of scale. If banks pass on this cost saving to depositors and borrowers BBDs could have had a positive influence on real economic variables.

The use of merger and acquisition $\mathrm{BBD}$ is the norm in the literature because it has the greatest effect on other real variables and a larger variation in policy timing (Jayaratne and Strahan, 1996; Beck et al., 2010; Levine and Rubinstein, 2013). Table 2.1 and Figure 2.1, using dates from Amel (1993) and Kroszner and Strahan (1999), present the years BBD occurred for each state.

\subsection{Discussion of Mechanisms}

Bank branching deregulation increased credit availability. This could directly affect the purchasing power of students and their families resulting in changes in educational opportunities. Indirectly, BBD promotes economic growth, increasing demand for employment. The labor market influences educational decisions in a number of ways. Additionally, increased credit availability can stabilize families and businesses when negative shocks occur. Holding all else constant, a more stable family will benefit children's educations. What follows is a discussion of these possible channels by which BBD may affect high school graduation.

If $\mathrm{BBD}$ relaxes credit constraints and if education is a normal good, then parents should make a greater investment in their child's education, along with young adults increasing investment in their own education. Additionally, relaxing geographic restrictions could influence the labor market by changing the relative wages and availability of jobs for dropouts, high school grads, college attendees, and college degree earners. The overall effect depends on both channels.

Relaxing branching regulations increases college attendance through credit availability (Teng Sun and Yannelis, 2016; Levine and Rubinstein, 2013). However, credit availability should not affect high school graduation in the same way. One might posit students change behaviors based on postsecondary school becoming more affordable. However, this is unlikely to cause any significant effects on high school graduation. In order to take advantage of more 
Patrick A. Reilly Chapter 2. Bank Branching Deregulation and High School Graduation 9

affordable college educations, students must possess the skills to succeed academically. If a student has the potential to earn a college degree, the cost of graduating high school is low. That is not to say that every high school dropout is incapable of graduating college. But those dropouts who are capable face some constraint. And if they cannot overcome said constraint to avoid dropping out of high school (a publicly provided good) then that must be a non-financial constraint, or a financial constraint much larger than a marginal increase in credit availability can alleviate. So, even if credit is made more available via BBD, the constraint remains.

Over time, however, reduced cost of credit may affect educational outcomes. Caucutt and Lochner (2012) find differences in returns to educational investment in younger versus older students. They split parental investment on child's education into "early" (investment in young children) and "late" (investment in adolescents) categories and found early investment is of greater importance than late. Without the early investment, the individual will be of lower ability and cannot take advantage of additional subsidies for later education. Thus, younger individuals at the time of BBD may benefit from increased early educational investment improving ability. This reduces the overall cost of education, leading to increases in both high school and college attainment.

In a theory that combines labor market and credit channels, Bedard (2001) demonstrates that relaxing credit constraints on high-ability high school students (or their families) enables them to signal those abilities to employers by earning a postsecondary degree. If these highability individuals earn a college degree ex-post, they reduce the average (expected) ability level of someone earning a high school diploma. In this case, employers decrease their expectation of ability signaled by high school diploma earners.

Thus, firms reduce the relative wage and employment opportunities provided to individuals with high school degrees but no college degree. Individuals on the margin will drop out because the relative benefits of graduating high school decrease. Therefore, this theory suggests BBD could lower high school graduation outcomes.

BBD is linked to labor market outcomes. Benmelech et al. (2011) and Beck et al. (2010) find decreases in unemployment rates following BBD. Results in Boustanifar (2014) demonstrate a positive association between BBD and employment growth. These labor market 
Patrick A. Reilly Chapter 2. Bank Branching Deregulation and High School Graduation 10 changes should affect educational attainment. The direction of this effect depends on the reactions of both earnings forgone and changes in potential for future earnings. If BBD benefits a certain skill level of worker relatively more than other skill levels, then I expect BBD caused changes to high school graduation patterns. Specifically, I expect more dropouts if low skilled workers enjoy relatively greater benefit or more high school graduates if medium/high skilled workers enjoy relatively greater benefits.

Prior research demonstrate this exact sentiment. Black et al. (2005) study how changes in labor markets, specifically, a coal boom in the 1970s and subsequent bust in the 1980s, caused changes in high school enrollment decisions in Pennsylvania and Kentucky. Enrollment decreased during the boom and increased in the subsequent bust. Evans and Kim (2006) investigate changes in education decisions after casinos opened on Native American reservations. They found opening a casino increased employment and wages of low-skilled workers. Students responded by dropping out of high school more often and attending college less often. Additionally, Rees and Mocan (1997) find worse labor market conditions (higher school district unemployment rates) reduced high school dropout rates in New York State.

Some evidence of disproportionate labor market changes from BBD come from Beck et al. (2010), who find that BBD raised the income and employment hours of low skilled individuals. This means increased returns for low skill jobs relative to high or medium skilled jobs. It follows that, on the margin, individuals would lower educational investment since low skilled jobs became relatively better paying and more available after BBD.

Jerzmanowski and Nabar (2013), however, find opposing results. They found that wages of skilled labor increased and wages of unskilled labor decreased following BBD. Thus, on the margin, educational attainment would increase as individuals try and earn those heightened wages at high skilled jobs.

Additionally, over a long time horizon, increased economic growth due to bank branching deregulation could improve the home lives of children. One of the most important determinants of high school graduation is social and emotional development (Murnane, 2013). Both Murnane (2013) and Caucutt and Lochner (2012) demonstrate a better home life during formative years can improve this development and increase the chances that an individual graduates high school by increasing her cognitive or social/emotional abilities. Thus, in the 
Patrick A. Reilly Chapter 2. Bank Branching Deregulation and High School Graduation 11 long run, there may be increases in high school graduation associated with BBD via better home life.

\subsection{Data and Methods}

\subsubsection{Empirical Method}

The typical approach in the literature identifies the year when BBD occurred in a state and employs a difference-in-differences approach based on this timing to explain observed variation in data aggregated to the state level. This study differs in several ways. First, I analyze individual level data, not statewide aggregate data. However, I do not follow individuals through time. Because of the bivariate nature of the educational attainment variables, I estimate linear probability models (LPMs). ${ }^{7}$ I estimate the following LPM using ordinary least squares (OLS):

$$
Y_{i s t}=\alpha+\phi B B D_{i s t}+\beta X_{i t}+A_{i t}+\theta_{s}+\tau_{t}+\epsilon_{i s t}
$$

where $Y_{i s t}$ is an educational attainment indicator variable of interest. The variable of interest, $B B D_{i s t}$, indicates whether or not BBD plausibly affects an individual's ability or desire to graduate high school. $B B D_{i s t}=1$ if individual $i$ is of an age when surveyed, year $t$, that suggests he or she was 17 or under when state $s$, the state of residence of individual $i$ when surveyed, first deregulated bank branching. $B B D_{i s t}=0$ otherwise. I discuss this identification at length in section 2.3.2. $X_{i t}$ is a vector of individual specific variables of central city ( $i$ lives in city center in year $t)$, MSA ( $i$ lives in a MSA but not in the central city in year $t)$, nonwhite ( $i$ is nonwhite), and male ( $i$ is male). $A_{i t}$ picks up a cohort effect. It is a vector of indicator variables for survey ages $(21,22,23, \ldots, 29)$ to control for nonlinearity in high school graduation by age. ${ }^{8} \theta_{s}$ is a state specific indicator to control for time-invariant state-specific unobservable characteristics, $\tau_{t}$ is the year specific indicator to control for yearspecific unobservable determinants of educational attainment common to all states. $\epsilon_{i s t}$ is the

\footnotetext{
${ }^{7} \mathrm{LPMs}$ are also used in Teng Sun and Yannelis (2016).

${ }^{8}$ Since I cannot differentiate between high school graduates and GED earners this could be a real concern if GED earning is prevalent among, say, 20 to 24 year olds but not 25 to 29 year olds
} 
Patrick A. Reilly Chapter 2. Bank Branching Deregulation and High School Graduation 12 normally distributed random error term with mean zero for individual $i$. In each estimation, the error terms are cluster-corrected by state to address potential serial correlation.

$\phi$ represents the estimated effect of BBD on educational outcomes. This is true as long as the timing of $\mathrm{BBD}$ is not related to other state/year specific policies. For example, financial equalization court rulings changes school funding for some states during this time period, however the timing of these rulings does not correspond closely to the branching deregulations (Card and Payne, 2002).

Another potential policy affecting high school graduation via increased bank branching is the Community Reinvestment Act (CRA), which starting 1977 made it necessary for banks to prove they helped meet the credit needs of their entire community, especially lower income neighborhoods. Banks adhering to the CRA positively impact poorer communities including education of those community members. Banks in states with fewer bank branching restrictions had greater incentive to adhere to the CRA as compliance is taken into account when approving branching. Additionally, having more branching increases the geographic domain of a bank. This increases the likelihood that it serves both poor and wealthy communities, which compels the bank to change its lending to comply. This channel is not demonstrated by the data as nonwhite individuals, who typically live in poor areas, do not see relatively larger increases in high school graduation.

To account for heterogeneous effects of $\mathrm{BBD}$ on race and gender, the sample is split into four subsamples: nonwhite females, nonwhite males, white females, and white males. Regression models for these subsamples are estimated separately using Equation (1) with race and gender variables omitted. Separating into sub samples ensures we do not restrict parameter estimates to be common for each sub-sample. For instance, there is likely large changes in the difference between white-male and white-female graduation likelihood in 1975 versus 1999, or in New York versus West Virginia.

Similar models are used to identify the difference in effects of BBD on residents of unit banking states versus states with other levels of branching restrictions. I split the sample for individuals living in unit banking states and those not and estimate separate models.

Error terms of LPM may suffer from non-normality and heteroskedasticity because of the bivariate nature of the dependent variable. To address this issue, the Probit estimator 
Patrick A. Reilly Chapter 2. Bank Branching Deregulation and High School Graduation 13

is used as a robustness check:

$$
P\left(Y_{i}=1 \mid \theta_{s}, \tau_{t}, B B D_{i s t}, X_{i} t, A_{i} t\right)=\Phi\left(a+\theta_{s}+\tau_{t}+\phi B B D_{i s t}+\beta X_{i s t}+A_{i t}+\epsilon_{i s t}\right)
$$

Probit estimates whether or not the bivariate dependent variable, $Y_{\text {ist }}$, equals 1 using a maximum likelihood approach. $\Phi()$ is the cumulative distribution function of the unit-normal distribution.

\subsubsection{Identifying the Treatment Group}

$B B D_{s t}$ identifies individuals whose high school education was plausibly influenced by BBD. The data available can identify a treatment group under certain assumptions.

First, I must identify individuals who already reached the educational achievement of interest when $\mathrm{BBD}$ occurs as non-treated. For instance, if an individual graduates high school in 1980 but BBD occurred in 1981 in her state of residence, then the BBD could not have any effect on her ability to stay in school and graduate high school.

The March CPS does not identify the year each individual graduated high school. I instead use the fact that most individuals do not graduate high school before age 17 and use data on individuals' ages and states of residence to sort them into treated and control groups. I identify individuals as treated if they were 17 or under at the time their state of residence deregulated. I use this same identification when focused on postsecondary degree earners because most decisions about college attendance are made around the same time as (or before) high school graduation.

Therefore, $B B D_{s t}$ is an indicator variable intended to identifying the treatment group, namely, individuals exposed to BBD before graduating high school. $B B D_{s t}=1$ if individual $i$ was under the age of 18 when the state individual $i$ lives in deregulated branching. Otherwise, $B B D_{s t}=0 .^{9}$

\footnotetext{
${ }^{9}$ To create $B B D_{s t}$ I use information from the CPS on the age, $A G E_{i s t}$, of each individual, $i$, the year, $Y E A R_{i s t}$, and the state of residence, $\theta_{i s t}$. I create a variable called $B B D \_y e a r_{i s t}$, which takes the value of the year of $\mathrm{BBD}$ of state, $\theta_{i s t}$. I then create another variable called age_at_BBD $D_{s t}$, which takes the value of individual $i$ 's age in the year when state, $\theta_{\text {ist }}$, was deregulated: age_at_BBD $D_{\text {st }}=$ $\left(B B D_{-}\right.$year $\left._{i s t}-\left(Y E A R_{\text {ist }}-A G E_{\text {ist }}\right)\right)$. Then I create the BBD treatment variable, $B B D_{s t}$, which takes a value of 1 when age_at_BBD $D_{s t}<18,0$ otherwise, unless differently specified.
} 
Patrick A. Reilly Chapter 2. Bank Branching Deregulation and High School Graduation 14

To visually demonstrate the treatment criterion, Figure 2.2 depicts age-year combinations in two BBD states. The rows indicate a subset of survey years. The columns indicate ages observed in the survey. The shaded cells are treated cohorts. Notice, the diagonal boundary. Shaded cells on the boundary represent 17 -year-olds in the survey year. Any observations to the left/below this boundary are 17 or younger at the time their state deregulated, which is the definition of treated. Unshaded cells on the boundary represent 18-year-olds in the survey year. Any individuals to the right or above this boundary are 18 years old or older at the time their state deregulated, which is the definition of non-treated.

In this sample, $78.3 \%$ of 19 -year-olds graduated high school, $45.5 \%$ of 18 -year-olds have graduated high school, and $5.4 \%$ of 17 -year-olds have graduated high school. Because of the difficulty in sorting individuals aged 18 and 19 into "should have graduated" or "likely still in school" categories, I exclude them from estimation. Measurement error from graduation age is randomly created by differences in day and month of birth. However, most of this error is eliminated by excluding observations of those individuals aged 18 and 19 in the year of BBD.

There may be some systematic error remaining. It is likely that I improperly place low ability individuals in the control group, 20-year-olds or older still in high school. It is also likely that I improperly place high ability individuals treated group because they graduated before age 17. This could bias the BBD coefficient upward. However, this applies to such a small portion of the sample that the bias is likely inconsequential. ${ }^{10}$

A challenge with this identification strategy is that some individuals moved to another state after high school and were not influenced by BBD in their current state of residence. This unobserved migration across state lines introduces measurement error. This movement may be tied to educational attainment. Educated individuals are more able to move than less-educated individuals. Educated individuals more likely have experience away from home, e.g. going to college out of state/away from home. Also, higher educated individuals usually have greater means to move, both financial and time to search.

However, most migration decisions are likely uncorrelated with BBD. ${ }^{11}$ People are un-

\footnotetext{
${ }^{10}$ The effect of excluding 17-year-olds from the treatment group is addressed in robustness checks. Only $0.6 \%$ of 16 -year-olds graduated high school in this sample.

${ }^{11} \mathrm{BBD}$ is found to increase economic growth, so there may be some systematic movement toward dereg-
} 
Patrick A. Reilly Chapter 2. Bank Branching Deregulation and High School Graduation 15

likely to move to another state to gain access to banks with less branching regulation. Therefore, migration likely creates random noise acting to bias BBD estimates toward zero. Nonetheless, to avoid some measurement error, I restrict the sample to individuals under 30 in most models. These individuals have less time to move to other states.

There may be differences in the effects of $\mathrm{BBD}$ on education given individuals' age at BBD. Caucutt and Lochner (2012) demonstrated increased effects of relaxing credit constraints on younger children Caucutt and Lochner (2012). To check this effect, I generate the variable: Age at BBD 12 and under $_{i s t}$ to identify individuals 12 and under at the time of BBD. Because the education of individuals aged 13 through 17 at time of BBD are plausibly affected by BBD I also include an indicator variable for individuals aged 13 to 17 at the time of BBD.

\subsubsection{CPS Data}

This study uses data from the CPS March Supplement 1977 to 1999. The March supplement contains a rich store of individual level data. I omit survey observations from years prior to 1977 as the state of residence is not identified. Even so, this data provides a time frame where most of the variation in state $\mathrm{BBD}$ occurred; 36 states deregulated in those years. Additionally, because of the retroactive nature of my identification, I include observations from individuals residing in those three states where BBD occurred prior to 1977.

The last intrastate BBD occurred in 1999 (Iowa). All other states deregulated by 1994 . By ending in year 1999, I represent 38 states (all but Iowa) in the treated group. Limiting the dates from 1977 to 1999 narrows the set to 3.5 million observations. I exclude states deregulating before 1970 as no analogous BBD dates exist. ${ }^{12}$ This decreases the number of

ulated states, especially by more educated individuals who have greater means to migrate. Estimations excluding individuals moving in the past year are included in the robustness section to investigate the effect of measurement error.

${ }^{12}$ Rhode Island, South Dakota, Delaware, Maryland, D.C., North Carolina, South Carolina, Idaho, Nevada, Arizona, California, and Alaska deregulated bank branching before 1970. Levine and Rubinstein (2013) suggest that these states all deregulated in 1960, but the source they cite, Kroszner and Strahan (1999), only indicates that these states deregulated prior to 1970. For most studies of BBD this does not matter greatly because they are interested in how BBD effects the macroeconomy. In this chapter, however, the setup of the treatment group relies heavily on the year that these states deregulated. Therefore, I omit those states and D.C. deregulating at an unknown date unless otherwise indicated. 
Patrick A. Reilly Chapter 2. Bank Branching Deregulation and High School Graduation 16

observations to about 2.7 million.

I omit individuals surveyed before age 20 as there are many reasons why they might not have completed high school. I omit individuals aged 30 and above when surveyed to limit the measurement error caused by state-to-state migration. Also to avoid measurement error, I excluded individuals aged 18 or 19 at the time the state they live in deregulated. This leaves about 387,000 observations in the base model.

There are several educational outcome variables of interest. High School Graduate $i t$ takes the value of 1 if individual $i$ has received a high school degree or equivalent in or before year $t, 0$ otherwise. ${ }^{13}$ College $_{i t}$ takes the value of 1 if individual $i$ has attended college in or before year $t, 0$ otherwise. For data gathered in years 1977 to 1991, Bachelor $s_{i t}$ takes the value of 1 if individual $i$ finished at least four years of college in or before year $t, 0$ otherwise. For 1992 to 1999, Bachelor $s_{i t}$ takes the value of 1 if individual $i$ earned a Bachelor's Degree or higher in or before year $t, 0$ otherwise.

It is important to control for other factors affecting educational attainment to limit omitted variable bias. Murnane (2013) describes many indicators lowering the opportunity cost of learning or moving up a grade level. Herein lies one limitation of this study. The CPS contains no data on individuals during adolescence. It does not indicate family wealth, enrollment in prekindergarten, parent education levels, etc.

Rather, the CPS includes data on demographic variables, state of residence, age, and survey year. I include an indicator variable for nonwhite individuals, Nonwhite ist $_{\text {. There are }}$ also gender differences in high school graduation rates. These are captured by the indicator


Central Cityist indicates that the individual lives in a central city. $M S A_{\text {ist }}$ indicates that individual $i$ lives in a metropolitan area but outside of the central city. Individuals living in

\footnotetext{
${ }^{13}$ The CPS includes GED recipients which may distort economic impact of increased high school graduation in this study, see Cameron and Heckman (1993).

${ }^{14}$ Being in the Central City or MSA seem less important than Nonwhite and Female in determining education because these only indicate whether the individual is living in a city or MSA at the time of the survey, whereas individuals who are nonwhite or female at the time of the survey were that way their whole lives. If there is some persistence to type of area on individual lives (city, MSA, or rural) then they may have some explanatory power. However, individuals with low skills (high school dropouts) likely flock to cities as a place with greater opportunity and also greater public good production such as transportation (Glaeser et al., 2008). Additionally, cities have lower high school graduation rates. Not graduating high school makes it harder to find a job and harder to move, so there may be lower levels of graduates in cities for that reason.
} 
Patrick A. Reilly Chapter 2. Bank Branching Deregulation and High School Graduation 17

rural areas or individuals not answering which type of area they live in take the value of 0 for both of these indicators.

Table 2.2 presents summary statistics of the described variables. Each mean represents the proportion of the sample population with that attribute.

\subsection{Results}

These results focus on the effect of BBD on high school graduation and heterogeneous effects due to differences in race, gender, and age at deregulation. Table 2.3 splits the data into four subsamples: white males, white females, nonwhite males, and nonwhite females. White males are 1.3 percentage points more likely to graduate high school after the BBD. White females are 1.0 percentage points more likely. There are no significant effects for nonwhite males or nonwhite females. Cameron and Heckman (2001) suggest a marginal change in credit access at commercial banks will not help minority groups on average. It would take a much larger change in credit circumstances to influence this group.

To establish the validity of estimates using the identification strategy, methods, and data in this study, Table 2.4 presents the effects of BBD on higher education outcomes. Teng Sun and Yannelis (2016) estimate BBD increases college attendance by 2.6 percentage points. Using my data, I estimate around a 2 percentage point increase in college attendance for both males and females. The parameter estimate for Males is significant at the 10 percent alpha level, female at the 5 percent alpha level. This similar result suggests validity of my empirical method and data.

The last two specifications in Table 2.4 analyze bachelor degree achievement of white males and white females respectively. White males see a 2.1 percentage point increase in bachelor's degree attainment. White females enjoy a similar increase in likelihood of earning a bachelor's degree. BBD has greater impacts on college attendance and attainment than high school graduation because credit more directly affects college students through student loans.

Table 2.5 presents results splitting observations into two subsets: states with a history of unit banking and states with all other types of geographic restrictions leading up to merger 
Patrick A. Reilly Chapter 2. Bank Branching Deregulation and High School Graduation 18 and acquisition BBD. Deregulating directly from unit banking rather than from some less restrictive policy is a more radical change to intrastate branching and may generate a greater overall effect on educational outcomes. The first two specifications represent models of high school graduation for unit banking states and non-unit banking states respectively. Neither of these models identify BBD as a significant factor in explaining high school graduation.

The last two specifications in Table 2.5 analyze bachelor's degree attainment in unit banking and non-unit banking states respectively. Individuals living in non-unit banking states increase their likelihood of bachelor's degree attainment by 2.6 percentage points. Bachelor degree attainment by residents of unit banking states were unaffected by BBD policy.

This is a puzzling result. The timing of BBD in unit banking states is generally later than the timing in non-unit banking states. Unit banking states are also clustered toward the middle of the country and in more rural states. These systematic differences may affect the estimates. Additionally, before 1992, Bachelor $s_{i s t}=1$ indicates that individual $i$ completed at least 4 years of college. Whereas, for 1992 onward, Bachelor $s_{i s t}=1$ signifies that individual $i$ earned a bachelor's degree. In the unit-banking model, this difference in the dependent variable puts emphasis on BBD's effect on degree attainment due to the later timing of BBD in unit-banking states.

Studies by Carneiro and Heckman (2002) and Caucutt and Lochner (2012) show greater impact of policy on younger individuals. Table 2.6 presents a test of this claim. Models with only younger individuals (those aged 12 and under) at the time of BBD included in the treatment group estimate greater effects on these individuals than models with individuals 17 and under (1.4 as opposed to 1.0). However, the coefficient estimates are not significantly different from one another, so this does not provide strong evidence for or against the idea that BBD has a greater effect on younger individuals.

Individuals aged 12 and under during the policy change react differently to BBD than individuals aged 13 to 17 . Table 2.6 reports evidence of this heterogeneous effect with estimates suggestive of relatively higher increases to high school graduation and Bachelor's degree achievement for individuals aged 12 and under, whereas, older individuals at the time of BBD see relatively larger increases in college attendance. Interestingly, BBD has no 
Patrick A. Reilly Chapter 2. Bank Branching Deregulation and High School Graduation 19 significant effect on the college attendance of individuals aged 12 and under at the time of BBD.

This may suggest that increases to college attendance are short lived. Older individuals at the time of $\mathrm{BBD}$ benefit from increased credit supply, boosting their ability to afford college and their college attendance. In response, the price of postsecondary education would increase overtime, reducing the initial increase in college attendance. Additionally, an increase in postsecondary education prices changes the average college attendee. Applicants facing higher costs must be either more certain of earning a degree or earning more from their degree. This leads to increases in degree attainment.

Another explanation for increases in the likelihood of earning both high school and bachelor's degrees could come from increased business competition. Black and Strahan (2002) and Kerr and Nanda (2009) find BBD leading to easier credit increasing entrepreneurship and creative destruction. This increases competition in many industries. Employers may become more wary on the hiring side, stipulating stricter degree requirements to qualify employees for jobs. So, even though college attendance is not increasing, individuals entering college have incentives to seek higher degrees, Bachelor's instead of Associate's for instance.

More comprehensive than Table 2.6, Figure 2.3 depicts the dynamic impact of BBD on high school graduation. The figure presents coefficient estimates and $95 \%$ confidence bands corrected for state clustering. Coefficients estimate the effect of being a certain age at the time of BBD. Specifically, I estimate the following model.

$$
Y_{i s t}=\alpha+\sum_{j=0}^{12} \beta_{j} D_{i s t}^{24-j}+\beta_{13} D_{i s t}^{<12}+B X_{i s t}+\gamma \theta_{s} t+\theta_{s}+\tau_{t}+\epsilon_{i s t}
$$

$D_{i s t}^{24-j}=1$ if individual $i$ was age $24-j$ when state s deregulated, 0 otherwise. The parameter estimates are relative to the graduation likelihood of those individuals 25 years and older at the time of BBD. If properly specified, BBD should only affect the likelihood of high school graduation for individuals aged 17 and under. In this analysis, individuals turning 18 or 19 at the time of $\mathrm{BBD}$ as well as state specific linear time trends $\left(\theta_{s} t\right)$ are included in the estimation.

The figure demonstrates two main points. First, BBD's impact on high school graduation 
Patrick A. Reilly Chapter 2. Bank Branching Deregulation and High School Graduation 20

was fast acting and seems to be long lasting. With the exception of age 15 (slightly smaller positive estimate), all ages 17 and below at the time of BBD find similar impacts. Second, there is minimal evidence of BBD affecting those who should have already graduate high school. With the exception of 20-year-olds, those turning 17 prior to the date of BBD see no significant changes in likelihood of graduating high school. The positive estimate at 20 years old could result from imprecise measurement of high school graduates. CPS data groups together high school graduates and GED earners. Additionally, there is a possible trend forming from ages just above the 17 year old threshold. This is likely caused by BBD's impact on a significant number of 18 and 19 year olds yet to graduate from high school or earn GEDs.

\subsection{Robustness}

Table 3.11 summarizes robustness checks where high school graduation is the dependent variable. In Table 3.11, specification 1 is the baseline results for comparison. Specification 2 uses a Probit model rather than a linear probability model, as the LPM estimation technique assumes normal and homoskedastic errors, which may not hold here. The point estimates are nearly identical and the errors are actually larger for the LPM specification than the Probit, which suggests the LPM method with errors cluster-corrected by state provides satisfactory results.

Specification 3 changes the treatment group by restricting the treatment age at the year of $\mathrm{BBD}$ to be 16 and under rather than 17 and under, eliminating some possibly systematic measurement error. Some individuals, for example, may have graduated high school at age 16, which, if BBD occurred in their state when they were 17, would improperly mark them as treated. To protect against this sort of error, this specification omits 17 year olds from the sample. The results are no different from the baseline specification.

Specification 4 checks robustness by varying the sample years. In this case, I still begin the sample in the 1977 survey year, but I end in sample year 1989. The point estimates are no different when sample years are changed. This indicates that the selection of sample years of 1977 to 1999 is not biasing the results. 
Patrick A. Reilly Chapter 2. Bank Branching Deregulation and High School Graduation 21

One of the assumptions made when identifying the treatment was that migration from state to state is independent of $\mathrm{BBD}$, and, therefore, estimates of BBD's effect on education are lower bounds. To test this claim, specification 5 amends the original model by restricting the sample to exclude individuals who indicated they moved to their current state of residence in the past year. A decrease in parameter estimate suggests this assumption generates systematic bias inflating our results. The point estimates and significance levels are unchanged so there is no evidence of systematic measurement error due to recent interstate migration.

Specification 6 includes observations from all states, including the 11 states and D.C. that deregulated prior to 1970. The BBD dates used for those states and D.C. are from Levine and Rubinstein (2013). This does not change sign or significance. This will mainly add observations to the treatment group because, according to Levine and Rubinstein, the 11 states and D.C. deregulated in 1960.

If the likelihood of high school graduation increases over time and the number of treated individuals increase overtime as well one might expect a stationarity problem. Although year effects are included in all models, individual states may have their own trend in high school graduation rates. To account for this possibility, Specification 8 depicts estimates including state-specific linear time trends. Including these trends has little effect on the overall model.

Table 2.8 presents results of estimations using false BBD dates. Each state's false BBD date is randomized so the distribution of false dates matches the distribution of true dates. The randomization strategy is as follows. Each state is given a random number from a uniform distribution from 0 to 1 . The smallest random number is matched with the earliest BBD date. The second smallest random number is matched with the next earliest BBD date, etc.

Holding constant the distribution of $\mathrm{BBD}$ timing but randomizing the order in which states go pass BBD legislation helps assess if the results are spurious. If the effect of BBD is the same when the dates are randomized, then the results may be spurious. After randomization of BBD timing, BBD has no significant effect on the likelihood of high school graduation. Therefore, there is no evidence of a spurious relationship. 
Patrick A. Reilly Chapter 2. Bank Branching Deregulation and High School Graduation 22

\subsection{Conclusion}

I find that BBD increased high school graduation likelihood. I find no differences in BBD affecting educational achievement by gender. Race, however, proved to be an important factor. White individuals as a group were significantly affected while non-white individuals, on average, saw no change to their educational attainment after BBD. This result is consistent with Cameron and Heckman (2001) who suggest that non-white individuals react less to policies regarding labor or credit markets because the underlying detriment to education developed by these groups in early childhood. Changes to affordability or benefits of education during middle/high school cannot have a strong effects on these individuals because a lack of investment in early childhood reduced their academic potential and/or contributed to the development of personalities conflicting with traditional academics.

This research extends recent literature by looking at the effects of BBD not only on college enrollment, but on high school graduation as well. It is difficult to identify the channels responsible for these effects. But I can point out channels not at work. Most high schools do not charge tuition and therefore direct credit channels are not likely to affect high school graduation. This means some indirect credit channel exists, plausibly through the labor market or though increased family stability resulting from an increases in credit availability. Additionally, parameter estimates suggesting BBD increases college attendance and bachelor's degree achievement strengthens evidence found in the previous literature.

There are data limitations in this study. Future research should focus on identifying the specific channels responsible for the results, as well as using longitudinal data. The ability to follow an individual's state of residence over their lifetime would more precisely identify those affected by BBD. Additionally, knowing more about an individual's past will reduce the influence of omitted variables such as family income and parental educational background. 
Patrick A. Reilly Chapter 2. Bank Branching Deregulation and High School Graduation 23

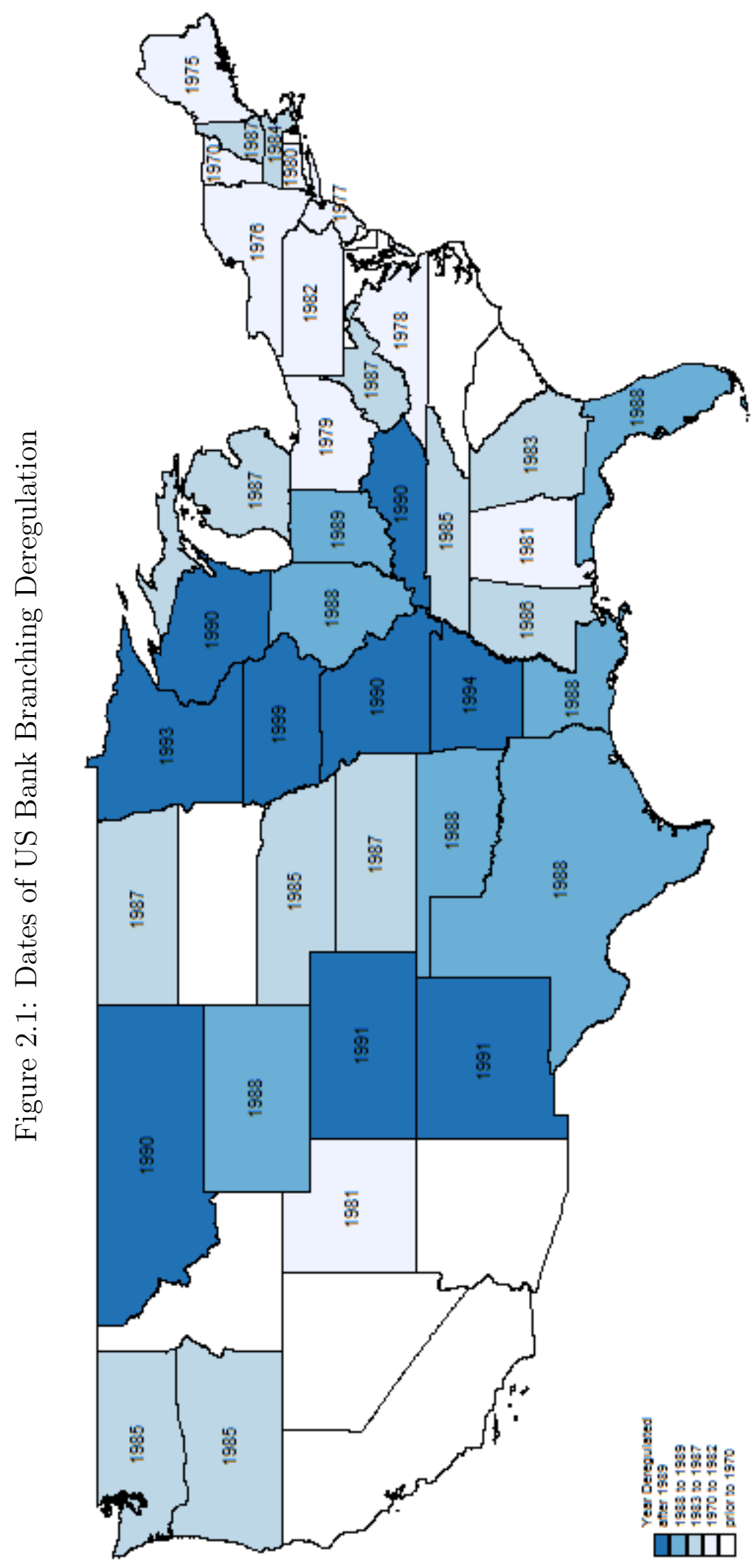


Patrick A. Reilly Chapter 2. Bank Branching Deregulation and High School Graduation 24

Figure 2.2: Intent to Treat Strategy, Two States

New York, Year of Deregulation: 1976

\begin{tabular}{|c|l|l|l|l|l|l|l|l|l|l|l|}
\hline CPS & Age & 20 & 21 & 22 & 23 & 24 & 25 & 26 & 27 & 28 & 29 \\
\hline Year & & & & & & & & & & & \\
\hline 1980 & & & & & & & & & & & \\
\hline 1981 & & & & & & & & & & & \\
\hline 1982 & & & & & & & & & & & \\
\hline 1983 & & & & & & & & & & & \\
\hline 1984 & & & & & & & & & & \\
\hline 1985 & & & & & & & & & & \\
\hline 1986 & & & & & & & & & \\
\hline 1987 & & & & & & & & & \\
\hline
\end{tabular}
$\begin{aligned} & \text { Not treated Treated } \\
& \text { | }\end{aligned}$

Mississippi, Year of Deregulation: 1986

\begin{tabular}{l}
\begin{tabular}{|c|l|l|l|l|l|l|l|l|l|l|l|}
\hline CPS & Age & 20 & 21 & 22 & 23 & 24 & 25 & 26 & 27 & 28 & 29 \\
\hline Year & & & & & & & & & & & \\
\hline 1985 & & & & & & & & & & & \\
\hline 1986 & & & & & & & & & & & \\
\hline 1987 & & & & & & & & & & & \\
\hline 1988 & & & & & & & & & & & \\
\hline 1989 & & & & & & & & & & & \\
\hline 1990 & & & & & & & & & & \\
\hline 1991 & & & & & & & & & & \\
\hline 1992 & & & & & & & & & & \\
\hline
\end{tabular} \\
Not treated \\
\hline
\end{tabular}


Patrick A. Reilly Chapter 2. Bank Branching Deregulation and High School Graduation 25

Figure 2.3: Bank Branching Deregulation's Effect on HSG by Age at BBD

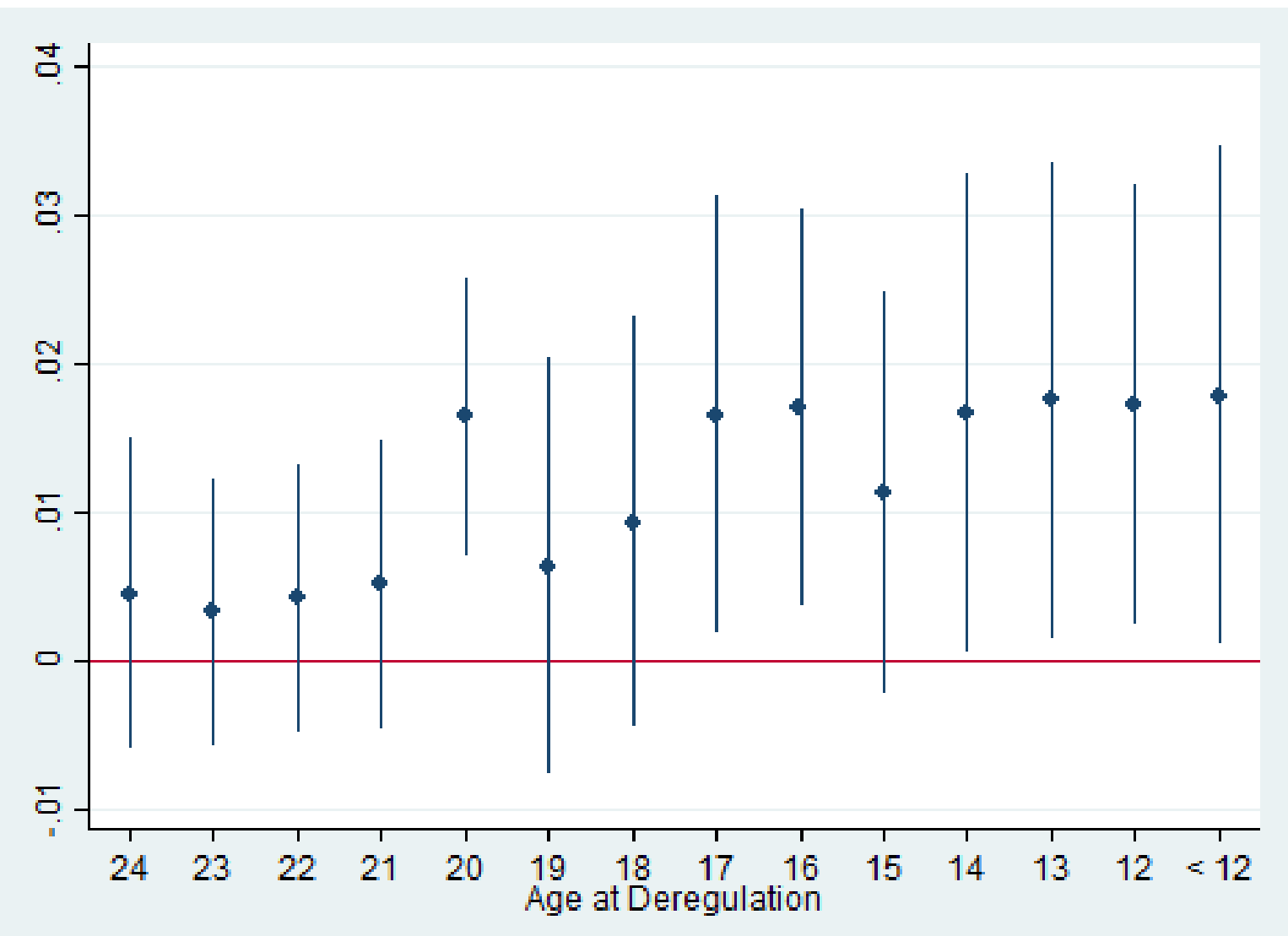


Patrick A. Reilly Chapter 2. Bank Branching Deregulation and High School Graduation 26

Table 2.1: Bank Branching Deregulation Dates, by Year

\begin{tabular}{|c|c|c|c|}
\hline State & Year & State & Year \\
\hline Alaska & $<1970$ & Tennessee & 1985 \\
\hline Arizona & $<1970$ & Washington & 1985 \\
\hline California & $<1970$ & Hawaii & 1986 \\
\hline Delaware & $<1970$ & Mississippi & 1986 \\
\hline Washington D.C. & $<1970$ & Kansas* & 1987 \\
\hline Idaho & $<1970$ & Michigan & 1987 \\
\hline Maryland & $<1970$ & New Hampshire & 1987 \\
\hline Nevada & $<1970$ & North Dakota* & 1987 \\
\hline North Carolina & $<1970$ & West Virginia* & 1987 \\
\hline Rhode Island & $<1970$ & Florida* & 1988 \\
\hline South Carolina & $<1970$ & Illinois $*$ & 1988 \\
\hline South Dakota & $<1970$ & Louisiana & 1988 \\
\hline Vermont & 1970 & Oklahoma* & 1988 \\
\hline Maine & 1975 & Texas* & 1988 \\
\hline New York & 1976 & Wyoming & 1988 \\
\hline New Jersey & 1977 & Indiana & 1989 \\
\hline Virginia & 1978 & Kentucky & 1990 \\
\hline Ohio & 1979 & Missouri* & 1990 \\
\hline Connecticut & 1980 & Montana* & 1990 \\
\hline Alabama & 1981 & Wisconsin* & 1990 \\
\hline Utah & 1981 & Colorado* & 1991 \\
\hline Pennsylvania & 1982 & New Mexico & 1991 \\
\hline Georgia & 1983 & Minnesota* & 1993 \\
\hline Massachusetts & 1984 & Arkansas* & 1994 \\
\hline Nebraska* & 1985 & Iowa* & 1999 \\
\hline Oregon & 1985 & & \\
\hline
\end{tabular}

Notes: Dates from Amel (1993). * indicates unit banking state. Year indicates when the corresponding state allowed bank branching throughout the state via mergers or acquisitions. $<1970$ indicates BBD prior to 1970. 
Patrick A. Reilly Chapter 2. Bank Branching Deregulation and High School Graduation 27

Table 2.2: Summary Statistics

\begin{tabular}{lrrrr}
\hline & mean & sd & $\min$ & $\max$ \\
\hline BBD & 0.315 & 0.464 & 0 & 1 \\
HS Grad & 0.859 & 0.348 & 0 & 1 \\
Some College & 0.484 & 0.500 & 0 & 1 \\
Bachelor's & 0.167 & 0.373 & 0 & 1 \\
Central City & 0.257 & 0.437 & 0 & 1 \\
MSA & 0.316 & 0.465 & 0 & 1 \\
Male & 0.482 & 0.500 & 0 & 1 \\
Nonwhite & 0.134 & 0.341 & 0 & 1 \\
\hline Observations & 386841 & & & \\
\hline
\end{tabular}

Notes: Data from the CPS March supplement: years 1977 to 1999 , ages 20 to 29 , states deregulating after 1969. Mean is the proportion of the sample with that attribute. 
Patrick A. Reilly Chapter 2. Bank Branching Deregulation and High School Graduation 28

Table 2.3: Effect of BBD on High School Graduation by Race and Gender

\begin{tabular}{lrrrrr}
\hline & HS Grad & HS Grad & HS Grad & HS Grad & HS Grad \\
\hline Deregulation & $0.010^{*}$ & $0.013^{* *}$ & -0.002 & $0.010^{*}$ & -0.006 \\
Male & $(0.004)$ & $(0.005)$ & $(0.015)$ & $(0.004)$ & $(0.013)$ \\
Nonwhite & $-0.009^{* * *}$ & & & & \\
& $(0.002)$ & & & & \\
& $-0.045^{* * *}$ & & & & \\
White or Non-white & $(0.011)$ & & & & Both \\
Male or Female & Both & Male & Non-white & White & Non-white \\
R-squared & 0.025 & 0.024 & 0.028 & Female & Female \\
Observations & 386841 & 163458 & 22883 & 171538 & 2826 \\
\hline
\end{tabular}

Note: ${ }^{*} p<0.05,{ }^{* *} p<0.01,{ }^{* * *} p<0.001$. Standard errors clustered by state in parentheses.

High school graduate is the dependent variable for all specifications. Each specification uses CPS March supplement data including years 1977 to 1999 and 39 states with mergers and acquisitions BBD after 1969. 
Patrick A. Reilly Chapter 2. Bank Branching Deregulation and High School Graduation 29

Table 2.4: Identification Validity: College Attendance and Attainment

\begin{tabular}{lrrrr}
\hline & Some College & Some College & Bachelor's & Bachelor's \\
\hline Deregulation & 0.020 & $0.022^{*}$ & $0.021^{*}$ & $0.020^{*}$ \\
& $(0.010)$ & $(0.009)$ & $(0.009)$ & $(0.010)$ \\
\hline Female or Male & Male & Female & Male & Female \\
Nonwhite or White & White & White & White & White \\
Ages Observed & 20 to 29 & 20 to 29 & 24 to 29 & 24 to 29 \\
R-squared & 0.022 & 0.030 & 0.022 & 0.022 \\
Observations & 163458 & 171538 & 101177 & 105705 \\
\hline
\end{tabular}

Note: ${ }^{*} p<0.05,{ }^{* *} p<0.01,{ }^{* * *} p<0.001$. Standard errors clustered by state in parentheses. The dependent variable labels each specification. The dependent variable takes the value of 1 if the individual attained that education level, 0 otherwise. Each specification uses CPS March supplement data including years 1977 to 1999 and 39 states with mergers and acquisitions BBD after 1969. 
Patrick A. Reilly Chapter 2. Bank Branching Deregulation and High School Graduation 30

Table 2.5: Comparison of Unit Banking vs Limited Branching Groups

\begin{tabular}{lrrrr}
\hline & HS Grad & HS Grad & Bachelor's & Bachelor's \\
\hline Deregulation & 0.015 & 0.004 & -0.003 & $0.026^{* *}$ \\
Male & $(0.007)$ & $(0.004)$ & $(0.023)$ & $(0.008)$ \\
& -0.007 & $-0.011^{* * *}$ & $0.010^{*}$ & $0.012^{* *}$ \\
Nonwhite & $(0.004)$ & $(0.003)$ & $(0.004)$ & $(0.003)$ \\
& -0.034 & $-0.051^{* * *}$ & $-0.073^{* * *}$ & $-0.077^{* * *}$ \\
MSA & $(0.028)$ & $(0.009)$ & $(0.014)$ & $(0.010)$ \\
& $0.041^{* * *}$ & $0.059^{* * *}$ & $0.073^{* * *}$ & $0.089^{* * *}$ \\
Central City & $(0.005)$ & $(0.010)$ & $(0.010)$ & $(0.012)$ \\
& -0.015 & -0.007 & $0.093^{* * *}$ & $0.079^{* * *}$ \\
Constant & $(0.023)$ & $(0.020)$ & $(0.013)$ & $(0.017)$ \\
& $0.804 * * *$ & $0.855^{* * *}$ & $0.171^{* * *}$ & $0.133^{* * *}$ \\
& $(0.013)$ & $(0.007)$ & $(0.012)$ & $(0.008)$ \\
\hline Unit Banking State & Yes & No & Yes & No \\
Ages Observed & 20 to 29 & 20 to 29 & 24 to 29 & 24 to 29 \\
R-squared & 0.031 & 0.022 & 0.018 & 0.025 \\
Observations & 153407 & 233434 & 95085 & 143052 \\
\hline
\end{tabular}

Note: ${ }^{*} p<0.05,{ }^{* *} p<0.01,{ }^{* * *} p<0.001$. Standard errors clustered by state in parentheses. The dependent variable labels each specification. The dependent variable labels each specification. Each specification uses CPS March supplement data including years 1977 to 1999 and 39 states with mergers and acquisitions BBD after 1969. 
Patrick A. Reilly Chapter 2. Bank Branching Deregulation and High School Graduation 31

Table 2.6: Comparison of Treatment Group by Age at BBD

\begin{tabular}{lrrrr}
\hline & HS Grad & Some College & Associate's & \multicolumn{1}{c}{ Bachelor's } \\
\hline Age at BBD: & $0.013^{*}$ & 0.014 & 0.003 & $0.028^{*}$ \\
12 and Under & $(0.005)$ & $(0.015)$ & $(0.021)$ & $(0.012)$ \\
Age at BBD: & $0.010^{*}$ & $0.020^{*}$ & 0.006 & $0.019^{*}$ \\
13 to 17 & $(0.004)$ & $(0.008)$ & $(0.014)$ & $(0.008)$ \\
Male & $-0.009^{* * *}$ & -0.001 & 0.003 & $0.011^{* * *}$ \\
& $(0.002)$ & $(0.003)$ & $(0.003)$ & $(0.003)$ \\
Nonwhite & $-0.045^{* * *}$ & $-0.073^{* * *}$ & $-0.078^{* * *}$ & $-0.077^{* * *}$ \\
& $(0.011)$ & $(0.011)$ & $(0.011)$ & $(0.008)$ \\
MSA & $0.052^{* * *}$ & $0.109^{* * *}$ & $0.101^{* * *}$ & $0.083^{* * *}$ \\
& $(0.006)$ & $(0.011)$ & $(0.010)$ & $(0.008)$ \\
Central City & -0.010 & $0.079^{* * *}$ & $0.087^{* * *}$ & $0.085^{* * *}$ \\
& $(0.015)$ & $(0.016)$ & $(0.014)$ & $(0.011)$ \\
Constant & $0.854^{* * *}$ & $0.389^{* * *}$ & $0.337^{* * *}$ & $0.136^{* * *}$ \\
& $(0.005)$ & $(0.008)$ & $(0.013)$ & $(0.008)$ \\
\hline Ages Observed & 20 to 29 & 20 to 29 & 22 to 29 & 24 to 29 \\
R-squared & 0.025 & 0.025 & 0.034 & 0.022 \\
Observations & 386841 & 386841 & 313025 & 238137 \\
\hline
\end{tabular}

Note: ${ }^{*} p<0.05,{ }^{* *} p<0.01,{ }^{* * *} p<0.001$. Standard errors clustered by state in parentheses. The dependent variable labels each specification. The dependent variable labels each specification. Each specification uses CPS March supplement data including years 1977 to 1999 and 39 states with mergers and acquisitions BBD after 1969. 
Patrick A. Reilly Chapter 2. Bank Branching Deregulation and High School Graduation 32

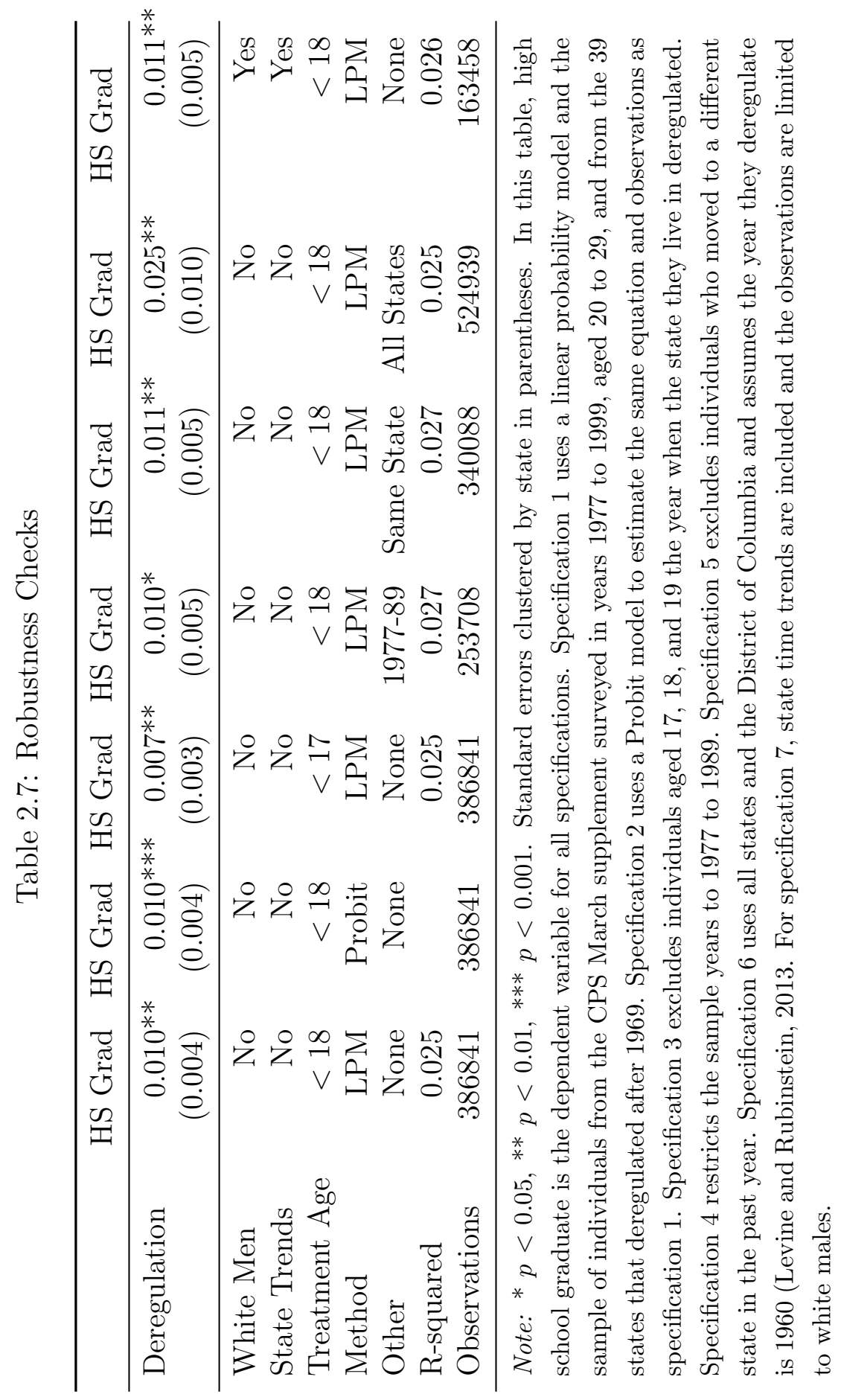


Patrick A. Reilly Chapter 2. Bank Branching Deregulation and High School Graduation 33

Table 2.8: Placebo Test, False BBD Dates

\begin{tabular}{lrrrrr}
\hline & HS Grad & HS Grad & HS Grad & HS Grad & HS Grad \\
\hline BBD False Date & 0.008 & 0.014 & -0.015 & 0.010 & -0.019 \\
& $(0.006)$ & $(0.008)$ & $(0.012)$ & $(0.006)$ & $(0.014)$ \\
Male & $-0.010^{* * *}$ & & & & \\
Nonwhite & $(0.002)$ & & & & \\
& -0.020 & & & & \\
\hline White or Non-white & $(0.027)$ & & & & \\
Male or Female & Both & White & Non-white & White & Non-white \\
R-squared & 0.026 & 0.032 & 0.033 & 0.033 & 0.028 \\
Observations & 392990 & 165900 & 24310 & 172693 & 30087 \\
\hline
\end{tabular}

Note: ${ }^{*} p<0.05,{ }^{* *} p<0.01,{ }^{* * *} p<0.001$. Standard errors clustered by state in parentheses. Models in this table feature false BBD dates. These dates use the same distribution of timing for BBD, but randomize where each state falls in that distribution. Each specification uses CPS March supplement data including years 1977 to 1999 and 39 states with false timing of mergers and acquisitions BBD after 1969. 
Patrick A. Reilly Chapter 2. Bank Branching Deregulation and High School Graduation 34

Table 2.9: False BBD Dates, by Year

\begin{tabular}{lrlr}
\hline State & Year & State & Year \\
\hline New York & $<1970$ & Nebraska & 1985 \\
North Carolina & $<1970$ & Washington & 1985 \\
Indiana & $<1970$ & West Virginia & 1986 \\
Alaska & $<1970$ & Florida & 1986 \\
Tennessee & $<1970$ & North Dakota & 1987 \\
Oklahoma & $<1970$ & South Carolina & 1987 \\
Missouri & $<1970$ & Texas & 1987 \\
Massachusetts & $<1970$ & Idaho & 1987 \\
Maryland & $<1970$ & Utah & 1987 \\
Oregon & $<1970$ & Rhode Island & 1988 \\
Vermont & $<1970$ & Minnesota & 1988 \\
Louisiana & $<1970$ & Kentucky & 1988 \\
Colorado & 1970 & Arkansas & 1988 \\
New Hampshire & 1975 & California & 1988 \\
New Jersey & 1976 & Hawaii & 1988 \\
Washington D.C. & 1977 & Mississippi & 1989 \\
Maine & 1978 & Ohio & 1990 \\
Connecticut & 1979 & Illinois & 1990 \\
Wisconsin & 1980 & New Mexico & 1990 \\
Iowa & 1981 & Arizona & 1990 \\
Delaware & 1981 & Wyoming & 1991 \\
Alabama & 1982 & Nevada & 1991 \\
Georgia & 1983 & Kansas & 1993 \\
Pennsylvania & 1984 & Virginia & 1994 \\
Michigan & 1985 & Montana & 1999 \\
South Dakota & 1985 & & \\
\hline
\end{tabular}

Note: The randomization strategy is as follows. Each state is given a random number from a uniform distribution from 0 to 1 . The smallest random number is matched with the earliest BBD date. The second smallest random number is matched with the next earliest BBD date, etc. 


\section{Chapter 3}

\section{Bank Branching Deregulation and High School Graduation: A Regression Discontinuity Approach}

Previous empirical work associates failure to graduate high school with a number of unfavorable outcomes. ${ }^{1}$ High school graduates are more likely to be employed, less likely to rely on government transfer payments, and earn more income than high school dropouts (Bridgeland et al., 2006; Oreopoulos, 2007). Non-pecuniary benefits of earning a high school diploma include better health (Lleras-Muney, 2002; Powdthavee, 2010), reduced likelihood of committing crime (Lochner and Moretti, 2004; Oreopoulos and Salvanes, 2011), and more active civic participation (Dee, 2004; Milligan et al., 2004; Siedler, 2010).

In addition to these internal benefits, earning a high school degree generates positive externalities. Greater employment and income decreases the need for transfer payments and increases tax revenue, providing the government additional resources to spend on other publicly provided goods and services or to reduce taxes. Better health outcomes impede the spread of disease and reduce overall health care costs. Crime represents a negative externality, so reducing crime through education generates external benefits. Finally, greater civic engagement leads to improved political outcomes.

Given the only substantial individual cost of graduating high school is the opportunity cost of time spent in the classroom (leisure, low skilled pay, starting a family a year or two early), putting forth enough effort to graduate seems likely. However, as recently as

\footnotetext{
${ }^{1}$ This research was conducted with restricted access to Bureau of Labor Statistics (BLS) data. The views expressed here do not necessarily reflect the views of the BLS.
} 
2009, over 3 million individuals from the U.S. aged 16 to 24 (8.1\% of this population) were identified as high school dropouts (Chapman et al., 2011).

Persistence of drop outs, particularly in an economy with diminishing availability of low-skilled work and increasing incense at welfare reliance, highlights the importance of understanding the intended and unintended effects of government policies on educational outcomes. Bank branching deregulation, the lifting of geographic restrictions on intrastate bank branching, is one such policy. During the 1970s, 1980s, and 1990s, 39 states switched from regulated branching to allowing banks to operate branches anywhere in the state via mergers or acquisitions. In this chapter, I analyze the impact of bank branching deregulation (hereafter BBD) on the likelihood of high school graduation.

To analyze this impact, I combine data from public sources with restricted use geocoded data from the National Longitudinal Survey of Youth 1979 (hereafter NLSY79). The NLSY79 public use data file contains pertinent information on respondents' education, cognitive ability, parents' education, and other important determinants of high school graduation. Geocoded data permit identification of individuals plausibly affected by BBD as it provides individuals' state residency histories. Geocoded data are also needed to employ regression-discontinuity design (hereafter RD) approaches to causal analysis in this setting.

RDs exploit a discontinuity of interest determined by a continuous variable (Hahn et al., 2001). In this study, the discontinuity is whether or not a state deregulated banking. The underlying continuous variable is distance to the state border. However, the NLSY geocoded data does not reach that level of granularity: county is the smallest observed geographic unit. Thus, samples are created based on counties on or near state borders. The preferred RD model uses a subsample of residents of border counties. Linear Probability Models (hereafter LPM) of individual high school graduation in the RD setup suggest BBD increased the likelihood of high school graduation at the border.

This chapter extends a large literature that uses variation in the timing of state level $\mathrm{BBD}$ as an exogenous increase in credit availability. Most research using BBD focuses on macroeconomic outcomes including economic growth (Jayaratne and Strahan, 1996; Clarke, 2004; Huang, 2008), banking industry composition and lending patterns (Cetorelli, 2006; Black and Strahan, 2002), and entrepreneurship (Black and Strahan, 2002; Kerr and Nanda, 
2009). More specifically, this chapter contributes to the growing area of research exploring the relationship between BBD and educational outcomes. Levine and Rubinstein (2013) and Teng Sun and Yannelis (2016) each find evidence of increased college attendance and post-secondary degree earning attributed to increases in credit availability post-BBD.

Previous research focused on post-secondary educational outcomes and credit market effects generated by BBD. This chapter focuses on secondary school educational outcomes, which, since high school is publicly provided, are not directly affected by credit constraints. Rather, improved credit likely impacts economic stability of families, labor market opportunities for dropouts or graduates, and opportunities for continuing education.

This research makes three main contributions. First, the chapter links credit availability with educational outcomes. Although it is not the first study to make this connection, this analysis reinforces the idea that credit availability has real and unintended effects on economic outcomes like educational attainment. Second, the use of NLSY79 data: ensures the high school graduation outcome variable is separated from GED earners, mitigates omitted variable bias as NLSY79 contains variables known to affect high school graduation such as Armed Forces Qualifying Test $(A F Q T)$ percentile, and limits measurement error because NLSY79 geocoded data identifies state residency on a yearly basis. Third, use of an RD approach generates results at the local treatment level, establishing an alternative argument for causation than the typical difference-in-differences approach used in previous BBD research.

\subsection{Background: Bank Branching Deregulation}

Prior to the 1970s, a majority of states restricted the geographic scope of bank operations both within state (intrastate) and between states (interstate). In part, these restrictions were relics of state revenue strategies used in the 19th and 20th centuries, before implementation of alternative taxes (Kroszner and Strahan, 1999). Prior to 1970, 11 states and D.C. allowed intrastate bank branching without restrictions, and 24 states allowed limited branching. For example, Pennsylvania allowed branching in all bordering counties of bank headquarters; Mississippi allowed 15 branches within 100 miles of headquarters (Amel, 1993). 15 states 
did not allow any intrastate branching; these were known as unit banking states. ${ }^{2}$ Unit banks had no branches. ${ }^{3}$

Beginning in the 1970s states began removing restrictions on bank branching. Kroszner and Strahan (1999) discussed the political economy of BBD. Increased competition in commercial banking and improvements in banking technology changed the status quo resulting in deregulation of the banking industry. Competition drastically lowered small banks' profitability, even for those banks protected by restricted bank branching. Larger banks found BBD beneficial, as it allowed them to spread risk and save on costs with new found economies of scale due to technological improvements. Kroszner and Strahan (1999) suggested these changes increased incentive for the large firms to lobby for BBD while reducing rent seeking in smaller firms culminating in BBD.

Across state variations in the timing of BBD identifies shocks to credit markets. For larger firms, this should not change borrowing behavior as they typically do not deal with commercial banks. However, lower commercial banking costs should be passed on to smaller firms and individuals seeking business loans, student loans, or home loans. Ceteris paribus, BBD increased the supply of credit by allowing consolidation of banks which created economies of scale and spread risk geographically, lowering operating costs. Prior research identifies many real economic impacts of improved access to credit via BBD including increased economic growth (Jayaratne and Strahan, 1996), decreased income inequality (Beck et al., 2010), and increases in entrepreneurship and firm turnover (Black and Strahan, 2002; Kerr and Nanda, 2009).

\subsection{Theoretical Foundations}

Most economists use models following Becker (1957) and Mincer (1958) to analyze individual economic decisions about education. These models suggest rational individuals forgo earnings and invest in education (training) if the increase in expected discounted fu-

\footnotetext{
${ }^{2}$ See Table 2.1 for the distribution of branch banking, limited branch banking, and unit banking states.

${ }^{3}$ Although banks in unit banking states where not allowed to have additional branches, some had additional "facilities" near the bank headquarters. For instance in Illinois in 1982 a bank could have a second "facility" within 3500 yards of headquarters and a third "facility" within the same county as the headquarters (Illinois Department of Financial \& Professional Regulation, 2015).
} 
ture earnings from educational investment outweigh current forgone earnings. Extensions to these models account for: likelihood of completing an additional year of schooling (Lang and Ruud, 1986), importance of an individual's cognitive and socioemotional skills for academic success (Cameron and Heckman, 2001), and human capital signaling (Betts, 1998; Bedard, 2001).

None of these extensions are an obvious choice for a model of BBD and education. However, the current banking deregulation literature provides insights into possible channels where BBD may affect (positively or negatively) educational attainment.

The most general economic theory through which policies affect education involve opportunity cost of education, wages forgone. Jayaratne and Strahan (1996) found evidence of increases in state GDP growth post-BBD. Beck et al. (2010) found evidence of relative increases in income and working hours for low skilled workers post-BBD. If this is true and if high school students realize the improvements to low skilled labor markets, then more students will seek employment. If a student accepts a full-time job then he/she will drop out immediately. If a student accepts a part-time position, he or she will devote less time to his or her studies and, on the margin, will take longer to graduate. This process increases the likelihood of dropping out of school all together (Rees and Mocan, 1997). So, BBD may result in more dropouts through improved low skill labor markets.

Contrary to Beck et al. (2010), Jerzmanowski and Nabar (2013) reported increased relative wages for high skilled laborers. If this is the case, skilled workers benefit more from BBD and so students react to changes in their potential labor market (Long et al., 2015) and stay in school longer. Thus, marginal individuals influenced by BBD tend to continue their educations.

Bedard's (2001) theory on ability signaling proposes another possible channel culminating in negative high school graduation outcomes via BBD. Prior to BBD, financial constraints forced poorer high ability individuals to end their educations at high school graduation, inflating the average level of ability signaled when earning a high school degree. post-BBD, with these high ability, previously financially constrained individuals now able to afford college, the average ability level signaled by a high school degree declines. Thus, high school degree earners are offered a lower wage premium relative to dropouts. Those individuals on 
the margin of staying in school have less incentive to graduate, so they drop out of school. Therefore, in this case, BBD should decrease high school graduation rates.

In another possible channel, economic growth brought on by BBD should raise local tax revenues, increasing funding for public schools. Jayaratne and Strahan (1996) found BBD generated higher state growth rates and Tewari (2014) reported greater homeownership as a result of $\mathrm{BBD}$. These each imply greater tax revenues and hence greater funding for public education post-BBD. Higher growth rates and homeownership also imply more stable families, as does increased credit availability. For instance, with better access to credit, a recently unemployed parent, on the margin, can be more judicious when finding employment without affecting life at home.

\subsection{Data and Methods}

This analysis focuses on BBD and educational outcomes at state border counties. I use linear probability models (LPMs) and differences-in-discontinuities (diff-in-disc) model, an RD type model, with the educational outcome of interest as my binary dependent variable. For RD models, I need a relatively small granularity for geographic location, therefore, I use the National Longitudinal Survey of Youth 1979 ( NLSY79) geocoded data, a data set which identifies county of residence, educational attainment, and many control variables capable of predicting educational attainment.

\subsubsection{Data}

The NLSY79 data set surveyed 12,686 individuals beginning in 1979 when the participant ages ranged from 14 to 22 . NLSY79 participants were interviewed annually until 1994 and then every two years from 1996 on. The data set includes many educational attributes. Education-related variables include: Highest Grade Completed, Highest Grade Completed by Mother $(H G C-M)$, High School Diploma or GED received, and Armed Forces Qualifying Test Percentile $(A F Q T)$. Demographic variables include: Race (White, Black, Hispanic, and Nonwhite), Sex of Participant, Number of Siblings, Family Income, and Age. The geocoded data provides information on county and state of residence in each 
survey year.

High School Graduate $(H S G)$ is the main variable of interest. $H S G$ takes the value of 1 if an individual received a high school diploma and takes the value of 0 if the individual did not graduate from high school or received a General Equivalency Degree (GED). According to Cameron and Heckman (1993), GED earners have outcomes closer to drop outs than to high school graduates. Therefore, separating HSG from GED earners strengthens the implications of my results. Highest Grade Completed $(H G C)$ takes the numeric value of the highest grade completed by a participant for each survey year with $H G C=8$ indicates the survey individual completed 8th grade but not 9th grade. $H G C=13$ indicates the survey individual completed one year of college, $H G C=14$ represents completing two years of college, etc.

Including demographic control variables reduces omitted variable bias. Age provides a participant's age in a given year. Female takes the value of 1 if an individual is female, 0 if male. Nonwhite takes the value of 1 if the individual is not white, 0 if the individual is white. Number of Siblings takes the value of the number of siblings the individual had in 1979.

Key to this data set are a number of individual level variables known to influence educational outcomes. AFQT is the percentile earned in the Armed Forces Qualifying Test administered in 1981 to each NLSY79 participant. The AFQT questions address arithmetic reasoning, vocabulary, and mathematical knowledge. $H G C-M$ is the highest grade completed by the surveyed individual's mother where the values act the same as $H G C$. Family Income provides the income of the participant's family in 1979. These three measures are important proxies for determinants of education level: educational ability $(A F Q T)$ and socio-economic well-being ( $H G C-M$ and Family Income).

AFQT percentiles depend on the learning of individuals, which reflect academic ability and effort. In economic models of educational attainment, the opportunity cost of an individual continuing education decreases as ability increases because high ability individuals need to put less time into their studies to succeed (Murnane, 2013). AFQT - Squared is also included to allow for diminishing returns. Diminishing returns are likely pronounced. 70 percent of individuals graduate in the sample. Those scoring a 100 rather than an 80 on 
the $A F Q T$ will not make much of a difference in high school graduation; whereas, scoring a 40 instead of a 20 likely has some impact. $A F Q T$ should be positively related to high school graduation. AFQT - Squared should be negatively related.

$H G C-M$, captures multiple determinants of educational achievement. First, $H G C-M$ may indicate the family's value of the importance of education, which in turn reflects parents' investment (not only money but time) in their children's education. Greater investment in education should increase educational attainment. Additionally, higher maternal grade level indicates a higher level of family income. Families with more income can afford better teachers, better tutors, and more educational resources. Greater educational investment increases educational attainment, ceteris paribus; therefore, $H G C-M$ should be positively related to high school graduation

Family/Income reflects socio-economic status. If education is a normal good, then welloff families will invest more in their children's education than poor families all else equal. A greater investment in education should increase the likelihood of graduating high school and the overall highest grade completed. Therefore, family income should be positively related to educational outcomes. I generally use Log Family Income to control for diminishing returns of income on educational attainment.

The remaining variables likely have less influence on high school graduation. Female controls for differences in high school graduation based on gender, Nonwhite differences based on race. Nonwhite individuals in aggregate have lower graduation rates (Murnane, 2013); however, this difference is likely attributed to HGC - M, Family Income 1979, and $A F Q T$ of non-white individuals.

Having more children means less time to spend with each individual child when he or she is developing. It also reduces family resources per child. Both of these decrease investment in education per child; hence, Number of Siblings should have a negative relationship with educational outcomes.

\subsubsection{Identifying Treated Individuals}

The NLSY79 Geocoded data contain information on respondents' states and counties

of residence for each survey year. The longitudinal aspect of $N L S Y 79$ promotes a fairly 
precise identification strategy. However, errors in treatment selection remain as there is no backward looking residency history.

Treated individuals are those plausibly affected by BBD prior to dropping out of or graduating from high school. For consistency, treated individuals lived in a branching state prior to their 18th birthday. However, some individuals are 18 years and older when first surveyed, and residency data does not exist for years prior to 1979. For individuals 18 and older in 1979, I impute their state of residence while in high school by assuming their resident state in 1979 (the nearest available data point) is the same as their state of residence when under 18. Therefore, the treatment identification variable, $B B D$, takes the value of 1 for both individuals who lived in a branching state when under 18 and individuals 18 or older in 1979 whose state of residence deregulated branching when they were 17 or younger.

Take four hypothetical survey participants: Anne, Bob, Cathy, and Dan. I first observe Anne when she is 19 years old and living in New York State (BBD in 1976) in 1979. As she is 18 or older in 1979, I assume that her state of residence in 1979, NY, was her state of residence when she was under the age of 18 . Thus, Anne is marked as treated since NY deregulated in 1976 when Anne was 16. .

I first observe Bob as a 22 year-old living in Ohio (BBd in 1979) in 1979. Bob is part of the 18 or older group in 1979 when Ohio deregulated bank branching. Thus, Bob is marked as non-treated.

I first observe Cathy at 14 years old living in New York (BBD in 1976) in 1979. I also observe her moving to Florida (BBD in 1987) in 1982. Cathy was under 18 when she lived in New York and NY, at that point, had bank branching so Cathy is marked as treated. ${ }^{4}$

I first observe Dan as a 17 year-old living in Massachusetts (BBD in 1984) in 1979. He moves to New Jersey (BBD in 1977) in 1981. Since he did not move to New Jersey until he was 19 years-old, New Jersey's BBD has no influence on Dan's high school completion. Instead, I mark Dan as non-treated because he lived in Massachusetts and MA did not deregulate branching until 1984.

Using this identification strategy, treated individuals under the age of 18 when first surveyed are properly identified. There is no guarantee of proper identification for other

\footnotetext{
${ }^{4}$ Cathy is always treated, even if she moves to a regulated state like Florida
} 
individuals. NLSY79 does not indicate where individuals lived before 1979, so some individuals marked as non-treated are, in fact, treated. For instance, what if Bob (from the above example) moved to Ohio from Vermont in 1973. Vermont deregulated branching in 1970, so if this was the case, I incorrectly identified Bob as non-treated.

Limitations identifying the treatment group create measurement error. Families move from state to state. Young adults move away from home to attend college or to secure work. Some moved from regulated states to branching states. Others moved from branching states to limited branching or unit banking states. If BBD does not contribute to relocation decisions, then any measurement error should be randomly assigned and parameter estimates are biased towards zero. In this case any significant effects would only strengthen with perfect identification. Measurement error becomes a problem if BBD is (or contributes to) a factor in the relocation decisions of families or young adults.

If $\mathrm{BBD}$ affects labor markets enough to change educational attainment, one might expect changes to individuals' choices for state of residence. However, moving is costly. It takes time to end a lease or to sell your house. Poorer families have very little time to look for a new place to stay in another state, let alone time to find work and physically move. Additionally, these families have adolescent children who make moving even more costly when the parent accounts for the child's ties to their social groups. Furthermore, the use of border counties, and the RD analysis mitigate possible endogeneity. If $\mathrm{BBD}$ increases job opportunity across the border then individuals living close to the border in the regulated state could simply commute to a new job across the border.

\subsubsection{State Selection}

The use of NLSY79 data limits variation in state BBD dates. 14-year-olds in 1979 turned 18 in 1983, so state BBDs occurring after 1982 have no effect on secondary education outcomes of NLSY participants. At the other end of the age range, 22-year-olds in 1979 were 17 in 1974, so there are no pre-treatment/control observations for any state deregulating branching before 1975. Given these constraints, the viable deregulating states are ME, NY, NJ, VA, OH, CT, AL, UT, and PA.

This analysis focuses on border counties because people from similar areas should have 
similar unobservable characteristics. Individuals living in border counties of these states overwhelmingly live in New York City, Philadelphia, and their suburbs in NY, NJ, and PA. This fact likely restricts the external validity to the Atlantic metropolis from Washington D.C. to Boston if I use all sample participants in the border counties of the above states. Additionally, NY and NJ deregulated only one year apart, so there is minimal cross state variation in policy timing. Because of this, Huang (2008) drops observations on the NY-NJ border in a related paper. Additionally, many younger individuals move to these areas, so measurement error becomes stronger when including New York City. Therefore, I omit the NY-NJ border and the NJ-PA border from my analysis.

Furthermore, the data used need to focus on deregulating states with enough observations in state border counties and whose neighboring states had unit banking or limited branching. Thus I omit the borders of Maine (too few observations), Virginia (only viable border is with West Virginia and has too few observations), Tennessee (too few observations), Utah (too few observations), and Pennsylvania (only one year of data and only the PA-WV border so not enough observations). Therefore, the main results use data for individuals residing along the borders of Ohio, Alabama, and the Connecticut border with Massachusetts (see Table $3.1)$.

Although not ideal, limiting my analysis to $\mathrm{OH}, \mathrm{CT}$, and $\mathrm{AL}$ as transition states has one distinct advantage, these states represent different US regions. OH is a Midwestern, Rust Belt state. CT represents the Northeast. And AL represents the South and even Appalachia in northern parts of the state. Therefore, results from this set of observations broadly reflect the impact of $\mathrm{BBD}$ in the US.

\subsubsection{Regression Model}

The following model explains variation in education outcomes.

$$
Y_{i}=\alpha+\beta_{1} B B D_{i}+\mathbf{X} \mathbf{1}_{\mathbf{i}} \beta_{\mathbf{2}}+\mathbf{X} \mathbf{2}_{\mathbf{i}} \beta_{\mathbf{3}}+\epsilon_{i s t}
$$

Where $Y_{i}$ is an educational attainment variable. $B B D_{i}$ takes the value of 1 if individual $i^{\prime} s$ likelihood of graduation was plausibly affected by BBD. More specifically, $B B D_{i}$ takes the 
value of 1 for both individuals who lived in a branching state when under 18 and individuals 18 or older whose state of residence in 1979 deregulated branching when they were 17 or younger.

$\mathbf{X} 1_{\mathbf{i}}$ is a vector of demographic control variables: Female $_{i}$ takes the value of 1 if individual $i$ is female; Nonwhite $e_{i}$, takes the value of 1 if individual $i$ is nonwhite, and Number of Siblings ${ }_{i}$ is the Number of Siblings that individual $i$ had in 1979.

$\mathbf{X} 2_{\mathbf{i}}$ is a vector of education related variables: $A F Q T_{i}$ is the percentile score that individual $i$ received in the Armed Forces Qualifying Test administered to all NLSY79 participants in 1981; $H G C-M_{i}$ is the highest grade completed by $i^{\prime} s$ mother in 1979; Log Family Income $_{i}$ is the natural log of family income in 1979 for $i$. And $\epsilon_{i}$ is the individual specific error term clustered by state of residence in 1979 .

\subsubsection{Regression Discontinuity Validity Checks}

Estimating RD models can improve empirical performance by producing a randomized experiment-like treatment assignment as individual close to the threshold of assignment should be similar in unobservable characteristics. To demonstrate plausible improvements to the counterfactual, panels A and B in Tables 3.2 and 3.3 present means and standard errors for both the entire state (Table 3.2) and the border county subsamples (Table 3.3). Table 3.4 compares differences in means between treated and non-treated individuals for the border county subsample (Panel A) and the entire state (Panel B). A reduction in the differences between treated and non-treated individuals for the border county subsample in observable charactersitcs indicates RD may also reduce differences in unobservables. If the full state subsample is more homogenous, then limiting estimation to border counties may not be appropriate.

The border county subsample improves the homogeneity of the covariate Nonwhite ${ }_{i}$. At the 95 percent confidence level, the Nonwhite population makes up a significantly larger proportion for the non-treated group relative to treated individuals in the full state sample. There is no difference at that confidence level for the border county subsample. This difference likely exists because of the inclusion of southern Florida and its large Latino population in the unrestricted sample along with the inclusion of more urban areas in the unrestricted 
sample, which includes cities like Atlanta and Philadelphia. Individuals from Florida, Atlanta, and Philadelphia would be non-treated for the most part.

\subsubsection{Differences-in-Discontinuity Design}

A pure geographic RD is not appropriate in this setting because systematic differences that may exist between control and treated states prior to BBD. Instead, I adopt the difference-in-discontinuities (diff-in-disc) as outlined by Grembi et al. (2016) to mitigate such problems. Grembi et al. (2016) estimate the diff-in-disc coefficient using the difference in intersections on either side of the running variable cutoff (here the distance to border) and on either side of the post treatment cutoff (here the year of BBD for corresponding treated state, 1979 for $\mathrm{OH}$ and bordering state, 1980 for CT and bordering states, and 1981 for Alabama and bordering states).

In this case, I estimate educational attainment impacts on four margins: as distance to the $\mathrm{BBD}$ border approaches 0 from treated states before $\mathrm{BBD}$, as the distance to $\mathrm{BBD}$ border approaches 0 from treated states after $\mathrm{BBD}$, as the distance to $\mathrm{BBD}$ border approaches 0 from control states before $\mathrm{BBD}$, and as the distance to $\mathrm{BBD}$ border approaches 0 from control states after BBD. Grembi et al. (2016) apply the OLS estimator to observations within a specified bandwidth, $\mathrm{h}$, of their running variable, both before and after their policy change. Likewise, I restrict the sample to individuals in border counties and estimate the model:

$$
Y_{i t}=\alpha+\beta_{1} D_{i t}+B_{i}\left(\beta_{2}+\beta_{3} D_{i t}\right)+T_{t}\left[\beta_{3}+\beta_{5} D_{i t}+B_{i}\left(\beta_{6}+\beta_{7} D_{i t}\right)\right]+\epsilon_{i t}
$$

Where $B_{i}=1$ indicates individual $i$ plausibly attended high school in a state that deregulated bank branching prior to 1982. $T_{t}$ is a dummy variable for post-BBD. $D_{i t}$ is the running variable, distance to $\mathrm{BBD}$ border, where negative values indicate residency in $\mathrm{OH}, \mathrm{CT}$, or AL. The coefficient of interest, $\beta_{6}$, identifies the local average treatment effect (LATE) of $\mathrm{BBD}$ on the education outcome variable, $Y_{i t}$. 
Patrick A. Reilly Chapter 3. BBD and HSG: A Regression Discontinuity Approach

\subsection{Results}

The results focus on BBD's impact on high school graduation and highest grade completed with a secondary analysis of BBD's effect on postsecondary achievement outcomes, namely college attendance and completing four or more years of college. Both LPM and RD models indicate increased probability of high school graduation for treated individuals as well as increases in postsecondary attendance and achievement.

Figure 3.1 illustrates the difference-in-discontinuities results. In each graph, distance to border is on the x-axis. Negative distance to border signifies survey participants from the deregulating states: Alabama, Connecticut, and Ohio. The y-axis variable is High School Graduate. The lines fit a quadratic of distance to border onto sub-samples of high school graduation grouped by distance to border. The plotted data points depict the ordered pairs of the average distance to border and the sample proportion/mean of the educational outcome for each bin/group.

The left column represents the pre-treatment group, using only the set of individuals turning 18 prior to $\mathrm{BBD}$ of their state or neighboring state. The pre-treatment border effect identifies differences between treated and control states prior to BBD. The right column observes only post-treatment, participants turning 18 after BBD of their state or neighbor state. The difference between the discontinuities before and after BBD illustrate the LATE. Notice that for High School Graduates at the border, treated states seem to increase high school graduation relative to regulated states post-BBD. These graphs resemble the results presented in Table 3.7.

Analysis begins with simple OLS with border county residents as a baseline and finish with diff-in-disc results. Table 3.5: contains results from Equation (3.1). Estimated standard errors reported on all tables are clustered-corrected at the state level unless specified differently. The results estimate a 12.5 percentage point increase in graduation likelihood relative to the control group post-BBD. The estimate for BBD's effect on high school graduation is relatively large as it is specific to border counties in for the three BBDs studied. Additionally, data include the NLSY79 oversample of socio-economically poor individuals. One must be judicious when making inferences of policy effects on other populations based 
on the results using these samples.

BBD had a slightly stronger effect on high school graduation of white male participants at 17.3 percentage points. Parameter estimates for white females and non-white individuals were all positive but not statistically different from zero. Nonetheless, these estimates suggest BBD brought about a Pareto improvement (at least in terms of the gender-race aggregate groups tested). Interestingly, in this model, $A F Q T$ score is not significantly related to high school graduation of white males; whereas, higher scoring females and nonwhites are significantly more likely to graduate high school. Factors keeping white males from graduating high school seem unrelated to academic ability; while minorities' and women's high school graduation outcomes were greatly affected by factors related to ability and family educational background.

All education related covariates ( $A F Q T, H G C-M$, and Log Income) have their expected sign. Interestingly, $H G C-M$ has no significant relationship with High School Graduate when Log Income is included in the model, but $H G C-M$ has a strong correlation with Highest Grade Completed. It follows that education level of family is persistent over generations for educational attainment above high school graduate.

Due to the binary nature of high school graduation and the high frequency of high school graduation in the US during the period of study, BBD will affect a small proportion of the population. Most likely affected are those individuals with characteristics that increase the likelihood of being a dropout, for instance low $A F Q T$ scores. Conversely, BBD is more likely to affect post-secondary educational outcomes for more intelligent individuals who would have graduated high school regardless of BBD, but who were struggling to afford tuition. Many of the results separate the data into groups to test whether or not these theories are true.

Table 3.6 divides the data with the 50th percentile AFQT score. The results show BBD has stronger effects on marginal individuals: high school students with relatively low $A F Q T$ scores and college aged individuals with relatively high AFQT scores. More interestingly, when restricted to individuals scoring less than 50 on the $A F Q T$ and who fail to earn a high school diploma BBD had a negative and significant effect on Highest Grade Completed. For those who do drop out of high school, another year of education has little benefit as it 
does not lead to a degree. Therefore, dropping out at an earlier age is not necessarily a bad outcome.

The rest of the models use diff-in-disc models. Table 3.7 presents results from Equation (3.2), the difference-in-discontinuity model from Grembi et al. (2016). These results are qualitatively the same as the LPM results; however, the magnitude of the parameter estimate for the LATE of BBD is 2 to 3 times higher than the LPM average treatment effect. These parameters are not estimating the same effect, but it does raise the question as to why the LATE estimate is larger than the ATE estimate.

A larger LATE could result from increased economic activity in deregulated areas improving schools through greater tax revenues along with improved parental employment opportunities. Better schools and more economically stable families decrease likelihood of dropping out for students on the deregulated side of the border. However, students on the still regulated side of the border find no improvements in school or family job security. But, if they live close enough to the border, teenagers might find more low skilled jobs available on the deregulated side. This would decrease high school graduation for non-treated individuals, especially close to the border.

Similar to the LPM model, diff-in-disc models of Highest Grade Completed $(H G C)$ provide no significant evidence that BBD significantly increased educational attainment overall. Nonwhite has a strong positive relationship with $H S G$ and $H G C$. Reducing the sample to only white participants does not significantly change treatment effect. For the diff-in-disc model, the nonwhite sample demonstrates positive and significant relationship between BBD and $H G C$. However, this is for a very small sample and the LPM model for the same observations provides no evidence of a relationship. The lack of an effect of BBD on $H G C$ may be evidence of the post-BBD separation seen in Table 3.6: academically poor individuals are leaving school earlier, while others are staying in school longer.

To further investigate $H G C$, Table 3.8 models different age splits: first all ages, then High school age (14 -- 18), undergraduate age (19 -- 22), and older individuals (23 -- 26). Again, BBD has no effect on $H G C$ for any of these age splits.

Additionally, Table 3.9 shows estimates of a negative parameter estimate of Number of Siblings for high school ages. This is not likely a story of spreading monetary resources 
among too many children. If it was, family income and mother's education would have been significant. Rather, this likely demonstrates that having more children causes parents to spend less time with each child, reducing social-emotional skills necessary to succeed in elementary, middle, and secondary school (Cameron and Heckman, 2001). So, students with more siblings are more likely to be held back a grade, resulting in less completed grade levels than members of their cohort with fewer siblings.

BBD may have different effects on education depending on income level. Table 3.9 provides results investigating this claim. Individuals with higher family incomes seem less likely to benefit from the BBD. Advantages for students from wealthy families make high school graduation almost certain regardless of BBD. The Highest Grade Completed specification found no evidence of effects from a income-treatment interaction.

A previous study by Levine and Rubinstein (2013) found that BBD helped higher achieving, low-income individuals attend college by making loans more affordable. Table 3.10 provides similar results to Levine and Rubinstein, adding to the validity of this data set and identification strategy. All specifications used an LPM model limiting observations to individuals scoring above the 33rd percentile in the AFQT. The samples differ by limiting the Family Income 1979 range. Specification (1) includes all income levels; (2) incomes below the 25th percentile; (3) incomes above the 25 th percentile; (4) incomes above the 50th percentile; (5) incomes above the 75th percentile; (6) incomes above the 90th percentile. BBD has positive and significant effects for the 2nd, 3rd, and 4th specifications. The top 25 percent of individuals in terms of family income are not significantly influenced by BBD. Thus, more credit may help higher ability individuals from lower class and middle class families afford college with no change to college attendance of lower income families.

\subsection{Robustness Checks and Falsification Tests}

The empirical designs utilized in this chapter lend themselves to certain vulnerabilities. This section refers to Table 3.11 which contains tests of validity for the results discussed in Section 3.4. Table 3.11 shows robustness tests for both the LPM estimator, the upper coefficient estimate, and the diff-in-disc approach, the lower coefficient estimate. The first 
test focuses on the binary dependent variable. Despite non-normality and heteroskedasticity of the error terms, the LPM typically performs well when the probability of the outcome is not close to zero or unity. Although the probability of graduating high school is relatively distant from 1 (about 0.8), I check performance of the LPM by estimating a Probit model and comparing its parameter estimates with the LPM. Using the Probit model does not significantly change estimates for BBD's effect on high school graduation. This is true for both LPM and diff-in-disc estimations.

The next test of robustness eliminates county indicator variables from the empirical model. There are over 60 counties in the sample and some counties have very few survey participants. According to Blankmeyer (2006), this could affect coefficient estimates for not only the indicator variables but also other variables in the model. However, the alternative specification does not show any significant changes to coefficient estimates reflecting BBD's effect on high school graduation.

The next pair of robustness exercises address possible measurement error generated by the assumption that individuals over the age of 17 in 1979 remained in the same state where they attended high school. This assumption allowed the use of the diff-in-disc design but introduced measurement error. The third column omits individuals who were over 17 years old in 1979 and college students before age 23. Individuals with some college experience have more opportunities and are more likely to have moved out of state (Bui and Miller, 2015). Omitting these individuals likely reduces measurement error without substantially reducing the size of the control group. The fourth column takes a more extreme approach by additionally omitting individuals above age 20 in 1979. This reduction of the control group reduces measurement error but also reduces the size of the pre-treatment group, causing a loss in significance in the LPM. However, the diff-in-disc results are robust to this test.

The final column simply removes outlying survey participants, those who never attended high school. This makes no difference in sign or significance of the parameter estimates. Interestingly, omitting these outliers, comprising 3.4 percent of the sample, narrows the gap in coefficient estimates between OLS and diff-in-disc designs.

To assess the diff-in-disc specification, Figure 3.2 uses survey participants from deregulating states only and makes the cutoff at the median distance (20 miles) to the border. 
There should be no discontinuity at 20 miles from the border, and more importantly, there should not be a difference in the before and after treatment graphs. This placebo test runs as expected. There is little difference at the cutoff while the before and after panels are nearly identical.

\subsection{Conclusion}

Graduates of high school are relatively better off than dropouts in terms of income, health outcomes, and standard of living (Bridgeland et al., 2006; Rumberger, 1987). This chapter finds removal of credit constraints in the form of BBD caused increases in high school graduation. Moreover, parameter estimates suggest positive effects of BBD for each group studied (white males, white females, and nonwhite males and females.). Estimates indicate BBD increased the likelihood of high school graduation by 13 percentage points for the sample studied. This effect is most noticeable in white males and in individuals with low $A F Q T$ scores. I also find high school dropouts left school earlier after BBD. This is not necessarily a negative outcome. These individuals face reduced benefits of an additional year of education as it will not lead to a high school degree. Therefore, dropouts ending education earlier may improve their lives especially if they find employment when they leave school.

One of the more important contributions of this chapter is the evidence of a causal relationship between BBD and high school graduation. Estimating an RD model, specifically a diff-in-disc model, provides evidence of relatively large increases to probability of high school graduation for treated individuals. Although the estimate for LATE is higher than plausible, the estimate approaches a more acceptable range of 15 percentage point increase when omitting individuals who did not enter high school.

More complete data could improve this study in precision and in scope. Although this study improved treatment identification, measurement error could still be problematic. Robustness models used to limit measurement errors in LPM actually reduced parameter estimates of average treatment effect for BBD on high school graduation. This indicates measurement error may have biased results away from zero. However, diff-in-disc estimates are 
unchanged for these robustness specifications. Additionally, scope of this chapter is limited to short term effects. It would be interesting to see how BBD affected individuals below age 10 at the time of BBD, as future educational attainment is greatly affected by educational investment at an early age (Cameron and Heckman, 2001). Future research might benefit by using data from the children of the NLSY and focusing on states with later BBD. This would improve identification and help to focus on earlier investments in education. 


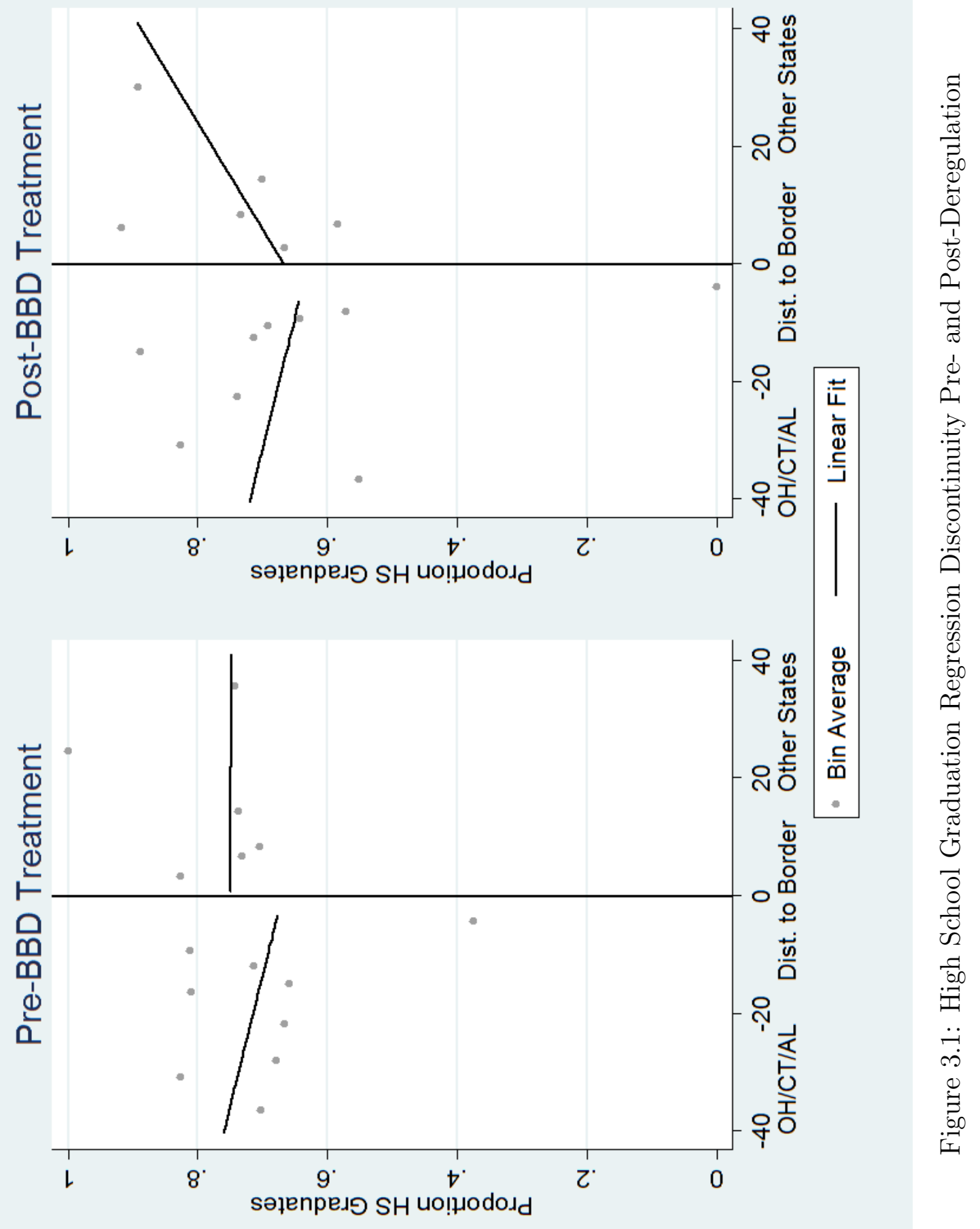




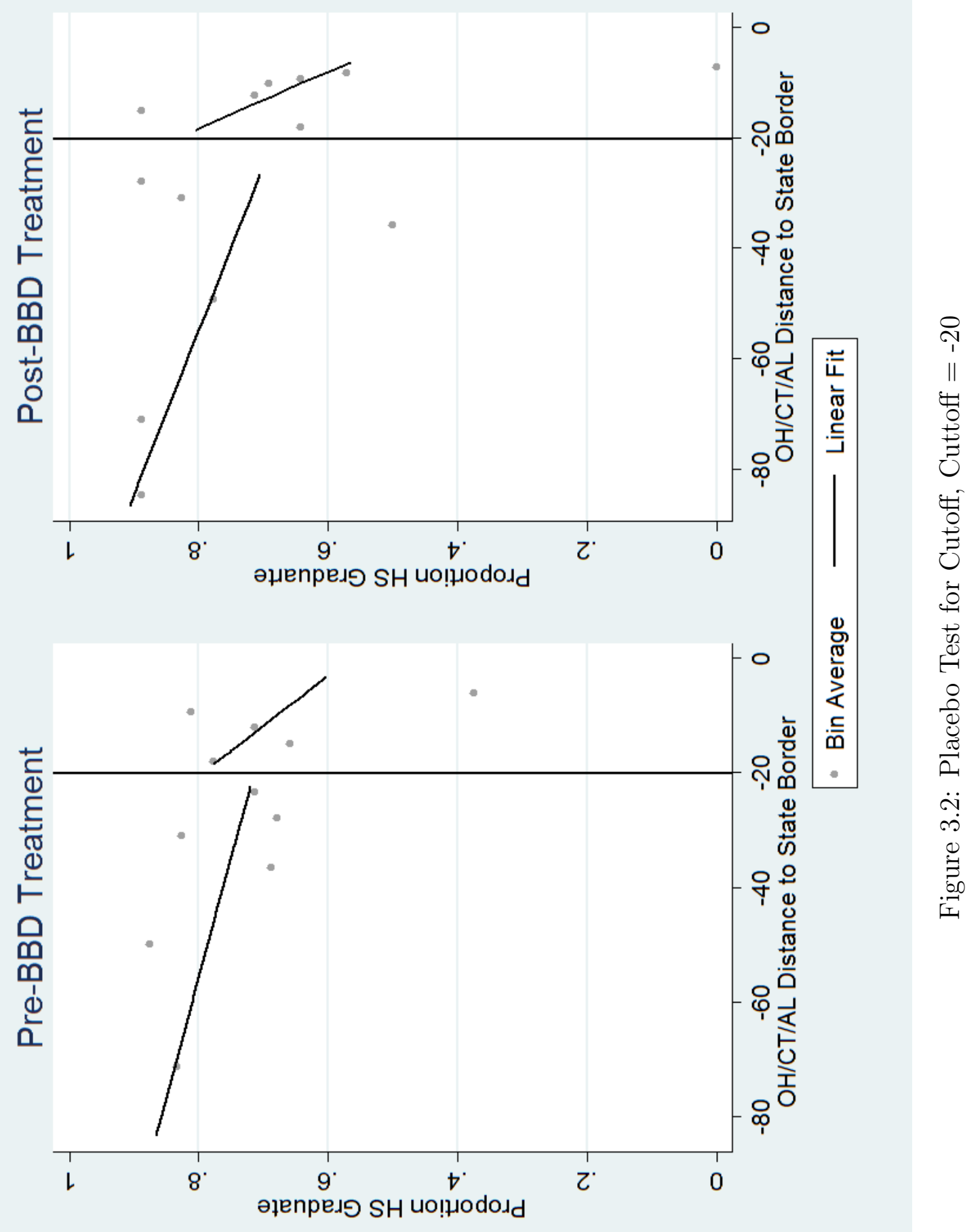


Table 3.1: Borders of Interest

\begin{tabular}{lclll}
\hline Early Deregulating State & Year & & Late Deregulating State & Year \\
\cline { 1 - 2 } Ohio & 1979 & & Pennsylvania & 1982 \\
Ohio & 1979 & & Michigan & 1987 \\
Ohio & 1979 & & West Virginia* & 1987 \\
Ohio & 1979 & & Indiana & 1989 \\
Ohio & 1979 & & Kentucky & 1990 \\
Connecticut & 1980 & & Massachusetts & 1984 \\
Alabama & 1981 & & Georgia & 1983 \\
Alabama & 1981 & & Tennessee & 1985 \\
Alabama & 1981 & & Mississippi & 1986 \\
Alabama & 1981 & & Florida* & 1988 \\
\hline
\end{tabular}

Notes: Dates from Amel (1993) and Kroszner and Strahan (1999). * indicates unit banking state. 
Patrick A. Reilly Chapter 3. BBD and HSG: A Regression Discontinuity Approach

Table 3.2: Summary Statistics, All Counties Sample, Age 22

\begin{tabular}{lrrrrr}
\hline Panel A: Regulated States & Obs. & Mean & SE & Min & Max \\
\hline High School Graduate & 2566 & 0.805 & 0.014 & 0 & 1 \\
Female & 2566 & 0.497 & 0.013 & 0 & 1 \\
Nonwhite & 2566 & 0.165 & 0.027 & 0 & 1 \\
Number of Siblings & 2566 & 3.316 & 0.081 & 0 & 19 \\
AFQT Percentile & 2566 & 49.07 & 1.35 & 1 & 99 \\
HGC-Mother & 2566 & 11.54 & 0.10 & 0 & 20 \\
Family Income 1979 & 2566 & 20168 & 681 & 5 & 75001 \\
\hline Panel B: Deregulated States & Obs. & Mean & SE & Min & Max \\
\hline High School Graduate & 408 & 0.805 & 0.022 & 0 & 1 \\
Female & 408 & 0.518 & 0.031 & 0 & 1 \\
Nonwhite & 408 & 0.126 & 0.031 & 0 & 1 \\
Number of Siblings & 408 & 3.398 & 0.136 & 0 & 16 \\
AFQT Percentile & 408 & 43.74 & 1.96 & 1 & 99 \\
HGC-Mother & 408 & 11.98 & 0.22 & 0 & 20 \\
Family Income 1979 & 408 & 21437 & 1333 & 603 & 75001 \\
\hline
\end{tabular}

Notes: Data in this statistical summary are from NLSY79: years 1979 to 1987, age 22. Summarized individuals either (1) resided in the following states in 1979 or (2) resided in one of the following states after 1979 but before the age of 18: AL, CT, FL, GA, IN, KY, MA, MI, MS, OH, PA, TN, or WV. Standard Errors clustered by state of residence. 
Patrick A. Reilly Chapter 3. BBD and HSG: A Regression Discontinuity Approach

Table 3.3: Summary Statistics, Border County Sample, Age 22

\begin{tabular}{lrrrrr}
\hline Panel A: Regulated States & Obs. & Mean & SE & Min & Max \\
High School Graduate & 405 & 0.806 & 0.020 & 0 & 1 \\
Female & 405 & 0.480 & 0.026 & 0 & 1 \\
Nonwhite & 405 & 0.114 & 0.030 & 0 & 1 \\
Number of Siblings & 405 & 3.375 & 0.152 & 0 & 16 \\
AFQT Percentile & 405 & 54.15 & 2.11 & 1 & 99 \\
HGC-Mother & 405 & 11.36 & 0.20 & 0 & 18 \\
Family Income & 405 & 20468 & 1384 & 5 & 75001 \\
\hline Panel B: Deregulated states & Obs. & Mean & SE & Min & Max \\
\hline High School Graduate & 183 & 0.855 & 0.030 & 0 & 1 \\
Female & 183 & 0.535 & 0.058 & 0 & 1 \\
Nonwhite & 183 & 0.115 & 0.045 & 0 & 1 \\
Number of Siblings & 183 & 3.501 & 0.217 & 0 & 16 \\
AFQT Percentile & 183 & 44.67 & 3.32 & 1 & 99 \\
HGC-Mother & 183 & 12.24 & 0.41 & 2 & 20 \\
Family Income 1979 & 183 & 22554 & 2831 & 603 & 75001 \\
\hline
\end{tabular}

Notes: Data in this statistical summary are from NLSY79: years 1979 to 1987, age 22. Summarized individuals either (1) resided in the border counties of $\mathrm{AL}, \mathrm{CT}$, or $\mathrm{OH}$ in 1979 or after 1979 if under age 18, (2) resided in a county bordering AL in 1979 or after 1979 if under age 18, (3) resided in a county bordering $\mathrm{OH}$ in 1979 or after 1979 if under age 18, or (4) resided in a MA county bordering CT in 1979 or after 1979 if age under 18. 
Patrick A. Reilly Chapter 3. BBD and HSG: A Regression Discontinuity Approach

Table 3.4: Mean Comparison Test: Are Border Counties more Homogenous?

\begin{tabular}{lrrrrrrr}
\hline \multirow{2}{*}{ Panel A: Border Counties } & \multicolumn{2}{c}{ Deregulated } & \multicolumn{2}{c}{ Regulated } & p-value \\
\cline { 2 - 7 } & Mean & SE & N & Mean & SE & N & (2-tailed) \\
\hline High School Graduate & 0.855 & & 183 & 0.806 & & 405 & 0.151 \\
Female & 0.535 & & 183 & 0.480 & & 405 & 0.217 \\
Nonwhite & 0.115 & & 183 & 0.114 & & 405 & 0.972 \\
Percent Urban (County) & 62.69 & 7.51 & 183 & 67.57 & 6.72 & 405 & 0.663 \\
Number of Siblings & 3.501 & 0.217 & 183 & 3.375 & 0.152 & 405 & 0.640 \\
AFQT-Percentile & 44.67 & 3.279 & 183 & 54.15 & 2.479 & 405 & $0.015^{* *}$ \\
HGC-Mother & 12.24 & 0.328 & 183 & 11.36 & 0.208 & 405 & $0.021^{* *}$ \\
Family Income 1979 & 22,554 & 2831 & 183 & 20,468 & 1384 & 405 & 0.457 \\
\hline \multirow{2}{*}{ Panel B: All Counties } & $\mathrm{Deregulated}$ & & $\mathrm{Regulated}$ & & p-value \\
\cline { 2 - 7 } & Mean & SE & $\mathrm{N}$ & Mean & SE & $\mathrm{N}$ & $(2$-tailed) \\
\hline High School Graduate & 0.805 & & 408 & 0.805 & & 2566 & \\
Female & 0.518 & & 408 & 0.497 & & 2566 & 0.431 \\
Nonwhite & 0.126 & & 408 & 0.165 & & 2566 & $0.046^{* *}$ \\
Percent Urban (County) & 68.32 & 5.87 & 408 & 69.26 & 2.98 & 2566 & 0.887 \\
Number of Siblings & 3.398 & 0.138 & 408 & 3.316 & 0.081 & 2566 & 0.608 \\
AFQT-Percentile & 43.74 & 1.94 & 408 & 49.07 & 1.35 & 2566 & $0.024^{* *}$ \\
HGC-Mother & 11.98 & 0.23 & 408 & 11.54 & 0.10 & 2566 & $0.080^{*}$ \\
Family Income 1979 & 21,437 & 1326 & 408 & 20,168 & 681 & 2566 & 0.395 \\
\hline
\end{tabular}

Notes: Data in this statistical summary are from NLSY79: years 1979 to 1987, age 22. Summarized individuals in Panel A either (1) resided in the border counties of AL, CT, or OH in 1979 or after 1979 if under age 18, (2) resided in a county bordering AL in 1979 or after 1979 if under age 18, (3) resided in a county bordering $\mathrm{OH}$ in 1979 or after 1979 if under age 18, or (4) resided in a MA county bordering CT in 1979 or after 1979 if age under 18. Summarized individuals in Panel B either (1) resided in the following states in 1979 or (2) resided in one of the following states after 1979 but before the age of 18: AL, CT, FL, GA, IN, KY, MA, MI, MS, OH, PA, TN, or WV. 
Patrick A. Reilly Chapter 3. BBD and HSG: A Regression Discontinuity Approach

Table 3.5: Effect of BBD on High School Graduation by Race and Gender

\begin{tabular}{|c|c|c|c|c|c|}
\hline & HSG & HGC & HSG & HSG & HSG \\
\hline$B B D$ & $\begin{array}{r}0.125^{* * *} \\
(0.009)\end{array}$ & $\begin{array}{r}0.302 \\
(0.348)\end{array}$ & $\begin{array}{c}0.173^{*} \\
(0.068)\end{array}$ & $\begin{array}{r}0.034 \\
(0.056)\end{array}$ & $\begin{array}{r}0.068 \\
(0.113)\end{array}$ \\
\hline Female & $\begin{array}{r}0.068 \\
(0.046)\end{array}$ & $\begin{array}{r}0.200 \\
(0.188)\end{array}$ & & & $\begin{array}{r}0.062 \\
(0.082)\end{array}$ \\
\hline Nonwhite & $\begin{array}{r}0.169^{* *} \\
(0.045)\end{array}$ & $\begin{array}{c}0.795^{*} \\
(0.279)\end{array}$ & & & \\
\hline$A F Q T$ & $\begin{array}{c}0.012^{* *} \\
(0.003)\end{array}$ & $\begin{array}{r}0.035^{* * *} \\
(0.005)\end{array}$ & $\begin{array}{r}0.002 \\
(0.010)\end{array}$ & $\begin{array}{c}0.019 * * \\
(0.004)\end{array}$ & $\begin{array}{r}0.023^{* * *} \\
(0.003)\end{array}$ \\
\hline AFQT Squared & $\begin{array}{c}-0.000^{*} \\
(0.000)\end{array}$ & $\begin{array}{r}0.000 \\
(0.000)\end{array}$ & $\begin{array}{r}0.000 \\
(0.000)\end{array}$ & $\begin{array}{r}-0.000^{* *} \\
(0.000)\end{array}$ & $\begin{array}{r}-0.000^{* * *} \\
(0.000)\end{array}$ \\
\hline$H G C(M)$ & $\begin{array}{r}0.013 \\
(0.011)\end{array}$ & $\begin{array}{c}0.125^{* *} \\
(0.029)\end{array}$ & $\begin{array}{r}0.029 \\
(0.023)\end{array}$ & $\begin{array}{r}-0.002 \\
(0.011)\end{array}$ & $\begin{array}{c}0.034^{*} \\
(0.011)\end{array}$ \\
\hline Siblings & $\begin{array}{r}-0.012 \\
(0.009)\end{array}$ & $\begin{array}{r}-0.046 \\
(0.022)\end{array}$ & $\begin{array}{r}-0.010 \\
(0.016)\end{array}$ & $\begin{array}{r}-0.026 \\
(0.014)\end{array}$ & $\begin{array}{r}-0.003 \\
(0.006)\end{array}$ \\
\hline Log(Family Income) & $\begin{array}{r}0.090^{* * *} \\
(0.019)\end{array}$ & $\begin{array}{r}0.149 \\
(0.086)\end{array}$ & $\begin{array}{c}0.085^{*} \\
(0.036)\end{array}$ & $\begin{array}{c}0.119 * * \\
(0.031)\end{array}$ & $\begin{array}{c}0.059^{*} \\
(0.024)\end{array}$ \\
\hline State Dummies & Yes & Yes & Yes & Yes & Yes \\
\hline Year Dummies & Yes & Yes & Yes & Yes & Yes \\
\hline County Dummies & Yes & Yes & No & No & No \\
\hline Nonwhite & Yes & Yes & No & No & Yes \\
\hline White & Yes & Yes & Yes & Yes & No \\
\hline Male & Yes & Yes & Yes & No & Yes \\
\hline Female & Yes & Yes & No & Yes & Yes \\
\hline Age Observed & 22 & 22 & 22 & 22 & 22 \\
\hline R-squared & 0.196 & 0.578 & 0.178 & 0.290 & 0.352 \\
\hline Observations & 588 & 588 & 213 & 206 & 169 \\
\hline
\end{tabular}

Note: ${ }^{*} p<0.05,{ }^{* *} p<0.01,{ }^{* * *} p<0.001$. Standard errors clustered by state of residence in 1979/before age of 18 in parentheses. 
Patrick A. Reilly Chapter 3. BBD and HSG: A Regression Discontinuity Approach 62 Table 3.6: Effect of BBD on High School Graduation, Split at AFQT $=50$

\begin{tabular}{|c|c|c|c|c|c|}
\hline & HSG & HSG & $\mathrm{HGC}$ & $\mathrm{HGC}$ & $\mathrm{HGC}$ \\
\hline \multirow[t]{2}{*}{$B B D$} & 0.008 & $0.215^{* * *}$ & $0.435^{*}$ & 0.043 & $-1.678^{*}$ \\
\hline & $(0.031)$ & $(0.029)$ & $(0.147)$ & $(0.300)$ & $(0.697)$ \\
\hline \multirow[t]{2}{*}{ Female } & 0.091 & 0.034 & $0.218^{*}$ & 0.200 & -0.054 \\
\hline & $(0.058)$ & $(0.075)$ & $(0.098)$ & $(0.191)$ & $(0.398)$ \\
\hline \multirow[t]{2}{*}{ Nonwhite } & -0.018 & 0.190 & 0.145 & $0.910^{*}$ & $1.295^{*}$ \\
\hline & $(0.129)$ & $(0.088)$ & $(0.306)$ & $(0.317)$ & $(0.442)$ \\
\hline \multirow[t]{2}{*}{$A F Q T$} & 0.035 & $0.039 * *$ & 0.062 & $0.098^{* * *}$ & $0.172^{*}$ \\
\hline & $(0.023)$ & $(0.010)$ & $(0.063)$ & $(0.020)$ & $(0.036)$ \\
\hline \multirow[t]{2}{*}{ AFQTSquared } & -0.000 & $-0.001^{*}$ & -0.000 & $-0.001^{*}$ & $-0.003^{*}$ \\
\hline & $(0.000)$ & $(0.000)$ & $(0.000)$ & $(0.000)$ & $(0.001)$ \\
\hline \multirow[t]{2}{*}{$H G C-M$} & $0.024^{*}$ & -0.002 & $0.099^{*}$ & $0.042^{*}$ & $-0.035^{*}$ \\
\hline & $(0.009)$ & $(0.013)$ & $(0.042)$ & $(0.017)$ & $(0.013)$ \\
\hline \multirow[t]{2}{*}{ Siblings } & -0.015 & -0.007 & -0.057 & -0.046 & $-0.084^{* * *}$ \\
\hline & $(0.013)$ & $(0.014)$ & $(0.031)$ & $(0.026)$ & $(0.015)$ \\
\hline \multirow[t]{2}{*}{ Log(Family Income) } & $0.097 * *$ & $0.102^{* *}$ & $0.066^{*}$ & $0.141^{*}$ & -0.168 \\
\hline & $(0.027)$ & $(0.023)$ & $(0.028)$ & $(0.049)$ & $(0.277)$ \\
\hline AFQT & $>49$ & $<50$ & $>49$ & $<50$ & $<50$ \\
\hline State Dummies & Yes & Yes & Yes & Yes & Yes \\
\hline Year Dummies & Yes & Yes & Yes & Yes & Yes \\
\hline County Dummies & Yes & Yes & Yes & Yes & Yes \\
\hline Age Dummies & No & No & Yes & Yes & Yes \\
\hline Dropouts Only & Yes & Yes & No & No & Yes \\
\hline Ages Observed & 22 & 22 & $18-23$ & $18-23$ & $20-23$ \\
\hline R-squared & 0.031 & 0.317 & 0.550 & 0.422 & 0.465 \\
\hline Observations & 219 & 369 & 1120 & 2017 & 480 \\
\hline
\end{tabular}

Note: ${ }^{*} p<0.05,{ }^{* *} p<0.01,{ }^{* * *} p<0.001$. Standard errors clustered by state of residence in 1979 /before age of 18 in parentheses. 
Table 3.7: $\quad$ Difference-in-Discontinuities Method, Local Average Treatment Effect of BBD on Educational Outcomes

\begin{tabular}{|c|c|c|}
\hline & HSG & HGC \\
\hline \multirow[t]{2}{*}{$B B D$} & $0.323^{* * *}$ & 0.551 \\
\hline & $(0.045)$ & $(0.939)$ \\
\hline \multirow[t]{2}{*}{ Female } & 0.071 & 0.206 \\
\hline & $(0.050)$ & $(0.200)$ \\
\hline \multirow[t]{2}{*}{ Nonwhite } & $0.163^{* *}$ & $0.809^{*}$ \\
\hline & $(0.047)$ & $(0.276)$ \\
\hline \multirow[t]{2}{*}{$A F Q T$} & $0.011^{* *}$ & $0.038 * * *$ \\
\hline & $(0.004)$ & $(0.005)$ \\
\hline \multirow[t]{2}{*}{ AFQTSquared } & $-0.000^{*}$ & -0.000 \\
\hline & $(0.000)$ & $(0.000)$ \\
\hline \multirow[t]{2}{*}{$H G C-M$} & 0.013 & $0.128 * *$ \\
\hline & $(0.012)$ & $(0.031)$ \\
\hline \multirow[t]{2}{*}{ Siblings } & -0.012 & $-0.048^{*}$ \\
\hline & $(0.009)$ & $(0.020)$ \\
\hline \multirow[t]{2}{*}{ Log(Family Income $)$} & $0.095 * * *$ & 0.137 \\
\hline & $(0.019)$ & $(0.083)$ \\
\hline State Dummies & Yes & Yes \\
\hline Year Dummies & Yes & Yes \\
\hline County Dummies & Yes & Yes \\
\hline Diff-in-Disc & Yes & Yes \\
\hline Age Observed & 22 & 22 \\
\hline R-squared & 0.196 & 0.579 \\
\hline Observations & 588 & 588 \\
\hline
\end{tabular}

Note: ${ }^{*} p<0.05,{ }^{* *} p<0.01,{ }^{* * *} p<0.001$. Standard errors clustered by state of residence in 1979/before age of 18 in parentheses. 
Patrick A. Reilly Chapter 3. BBD and HSG: A Regression Discontinuity Approach

Table 3.8: Difference-in-Discontinuities Method, Local Average Treatment Effect of BBD on Grade Completion by Age

\begin{tabular}{|c|c|c|c|c|}
\hline & $\mathrm{HGC}$ & $\mathrm{HGC}$ & $\mathrm{HGC}$ & $\mathrm{HGC}$ \\
\hline \multirow[t]{2}{*}{$B B D(L A T E)$} & -0.028 & 0.147 & 0.313 & 0.454 \\
\hline & $(0.396)$ & $(0.314)$ & $(0.642)$ & $(0.741)$ \\
\hline \multirow[t]{2}{*}{ Female } & $0.215^{* *}$ & $0.231^{*}$ & 0.277 & 0.215 \\
\hline & $(0.095)$ & $(0.083)$ & $(0.142)$ & $(0.137)$ \\
\hline \multirow[t]{2}{*}{ Nonwhite } & $0.737^{* * *}$ & 0.432 & $0.688^{*}$ & $0.994^{* * *}$ \\
\hline & $(0.146)$ & $(0.219)$ & $(0.237)$ & $(0.209)$ \\
\hline \multirow[t]{2}{*}{$A F Q T$} & $0.031^{* * *}$ & $0.031^{* *}$ & $0.039^{* * *}$ & $0.034^{* * *}$ \\
\hline & $(0.009)$ & $(0.009)$ & $(0.005)$ & $(0.005)$ \\
\hline \multirow[t]{2}{*}{ AFQT Squared } & -0.000 & -0.000 & $-0.000^{*}$ & 0.000 \\
\hline & $(0.000)$ & $(0.000)$ & $(0.000)$ & $(0.000)$ \\
\hline \multirow[t]{2}{*}{$H G C-M$} & $0.090 * * *$ & 0.002 & $0.095^{* * *}$ & $0.133^{* *}$ \\
\hline & $(0.025)$ & $(0.021)$ & $(0.019)$ & $(0.035)$ \\
\hline \multirow[t]{2}{*}{ Siblings } & $-0.058^{* *}$ & $-0.043^{*}$ & $-0.052^{*}$ & -0.057 \\
\hline & $(0.021)$ & $(0.016)$ & $(0.018)$ & $(0.032)$ \\
\hline \multirow[t]{2}{*}{ Log(Family Income $)$} & 0.101 & -0.006 & $0.130^{*}$ & 0.145 \\
\hline & $(0.070)$ & $(0.029)$ & $(0.052)$ & $(0.067)$ \\
\hline State Dummies & Yes & Yes & Yes & Yes \\
\hline Year Dummies & Yes & Yes & Yes & Yes \\
\hline County Dummies & Yes & Yes & Yes & Yes \\
\hline Age Dummies & Yes & Yes & Yes & Yes \\
\hline Diff-in-Disc & Yes & Yes & Yes & Yes \\
\hline Age Observed & $14-26$ & $14-18$ & $19-22$ & $23-26$ \\
\hline R-squared & 0.642 & 0.720 & 0.548 & 0.572 \\
\hline Observations & 7136 & 1183 & 2151 & 2089 \\
\hline
\end{tabular}

Note: ${ }^{*} p<0.05,{ }^{* *} p<0.01,{ }^{* * *} p<0.001$. Standard errors clustered by state of residence in 1979/before age of 18 in parentheses. 
Table 3.9: Effect of BBD on Educational Attainment, Income-BBD Interaction

\begin{tabular}{|c|c|c|}
\hline & HSG & $\mathrm{HGC}$ \\
\hline \multirow[t]{2}{*}{$B B D$} & $3.205^{*}$ & -7.100 \\
\hline & $(1.132)$ & $(4.535)$ \\
\hline \multirow{2}{*}{ Log(Family Income $)$} & $0.094^{* * *}$ & -0.037 \\
\hline & $(0.013)$ & $(0.149)$ \\
\hline \multirow[t]{2}{*}{ IncomexDeregulation } & $-0.299^{*}$ & 0.784 \\
\hline & $(0.120)$ & $(0.402)$ \\
\hline \multirow[t]{2}{*}{ Female } & 0.080 & 0.184 \\
\hline & $(0.051)$ & $(0.186)$ \\
\hline \multirow[t]{2}{*}{ Nonwhite } & $0.174^{* *}$ & $0.784^{*}$ \\
\hline & $(0.050)$ & $(0.264)$ \\
\hline \multirow[t]{2}{*}{$A F Q T$} & $0.012^{* *}$ & $0.036^{* * *}$ \\
\hline & $(0.004)$ & $(0.006)$ \\
\hline \multirow{2}{*}{ AFQT Squared } & $-0.000^{*}$ & 0.000 \\
\hline & $(0.000)$ & $(0.000)$ \\
\hline \multirow[t]{2}{*}{$H G C-M$} & 0.013 & $0.130^{* *}$ \\
\hline & $(0.011)$ & $(0.032)$ \\
\hline \multirow[t]{2}{*}{ Siblings } & -0.011 & $-0.050^{*}$ \\
\hline & $(0.009)$ & $(0.020)$ \\
\hline State Dummies & Yes & Yes \\
\hline Year Dummies & Yes & Yes \\
\hline County Dummies & Yes & Yes \\
\hline Diff-in-Disc & Yes & Yes \\
\hline Age Observed & 22 & 22 \\
\hline R-squared & 0.208 & 0.582 \\
\hline Observations & 588 & 588 \\
\hline \multicolumn{3}{|c|}{$\begin{array}{l}\text { Note: } * p<0.05, * * p<0.01,{ }^{* * *} p<0.001 \text {. Stan- } \\
\text { dard errors clustered by state of residence in } 1979 / \text { be- } \\
\text { fore age of } 18 \text { in parentheses. }\end{array}$} \\
\hline
\end{tabular}


Patrick A. Reilly Chapter 3. BBD and HSG: A Regression Discontinuity Approach 66

Table 3.10: Effect of BBD on College Attendance Grouped by Income Level

\begin{tabular}{|c|c|c|c|c|c|c|}
\hline & College & College & College & College & College & College \\
\hline$B B D$ & $\begin{array}{r}0.194^{* *} \\
(0.048)\end{array}$ & $\begin{array}{c}0.531 * \\
(0.163)\end{array}$ & $\begin{array}{c}0.158^{*} \\
(0.050)\end{array}$ & $\begin{array}{c}0.205^{*} \\
(0.087)\end{array}$ & $\begin{array}{r}0.152 \\
(0.123)\end{array}$ & $\begin{array}{r}-0.027 \\
(0.127)\end{array}$ \\
\hline Female & $\begin{array}{c}0.078^{*} \\
(0.028)\end{array}$ & $\begin{array}{r}-0.083 \\
(0.092)\end{array}$ & $\begin{array}{c}0.083^{*} \\
(0.031)\end{array}$ & $\begin{array}{r}0.031 \\
(0.044)\end{array}$ & $\begin{array}{c}0.143^{*} \\
(0.051)\end{array}$ & $\begin{array}{r}0.300 \\
(0.139)\end{array}$ \\
\hline Nonwhite & $\begin{array}{r}0.346^{* *} \\
(0.081)\end{array}$ & $\begin{array}{r}0.249 \\
(0.154)\end{array}$ & $\begin{array}{r}0.391^{* * *} \\
(0.079)\end{array}$ & $\begin{array}{r}0.368 \\
(0.223)\end{array}$ & $\begin{array}{c}0.558^{*} \\
(0.227)\end{array}$ & $\begin{array}{r}0.144 \\
(0.078)\end{array}$ \\
\hline$A F Q T$ & $\begin{array}{r}0.011 \\
(0.007)\end{array}$ & $\begin{array}{r}-0.006 \\
(0.019)\end{array}$ & $\begin{array}{r}0.014 \\
(0.008)\end{array}$ & $\begin{array}{c}0.022^{*} \\
(0.008)\end{array}$ & $\begin{array}{c}0.023^{*} \\
(0.008)\end{array}$ & $\begin{array}{c}-0.018^{*} \\
(0.006)\end{array}$ \\
\hline AFQT Squared & $\begin{array}{r}0.000 \\
(0.000)\end{array}$ & $\begin{array}{r}0.000 \\
(0.000)\end{array}$ & $\begin{array}{r}-0.000 \\
(0.000)\end{array}$ & $\begin{array}{r}-0.000 \\
(0.000)\end{array}$ & $\begin{array}{r}-0.000 \\
(0.000)\end{array}$ & $\begin{array}{c}0.000^{*} \\
(0.000)\end{array}$ \\
\hline$H G C-M$ & $\begin{array}{r}0.054^{* * *} \\
(0.009)\end{array}$ & $\begin{array}{r}0.044 \\
(0.035)\end{array}$ & $\begin{array}{r}0.047^{* *} \\
(0.012)\end{array}$ & $\begin{array}{r}0.043 \\
(0.024)\end{array}$ & $\begin{array}{c}0.073^{*} \\
(0.021)\end{array}$ & $\begin{array}{c}0.056^{*} \\
(0.020)\end{array}$ \\
\hline Siblings & $\begin{array}{r}-0.006 \\
(0.007)\end{array}$ & $\begin{array}{c}-0.044 \\
(0.020)\end{array}$ & $\begin{array}{r}-0.006 \\
(0.008)\end{array}$ & $\begin{array}{r}0.002 \\
(0.009)\end{array}$ & $\begin{array}{r}0.010 \\
(0.031)\end{array}$ & $\begin{array}{r}0.025 \\
(0.054)\end{array}$ \\
\hline $\log ($ Family Income $)$ & $\begin{array}{r}-0.010 \\
(0.023)\end{array}$ & $\begin{array}{r}-0.082 \\
(0.101)\end{array}$ & $\begin{array}{r}0.029 \\
(0.047)\end{array}$ & $\begin{array}{r}0.034 \\
(0.112)\end{array}$ & $\begin{array}{r}-0.086 \\
(0.132)\end{array}$ & $\begin{array}{c}-0.388^{*} \\
(0.119)\end{array}$ \\
\hline State I & $\mathrm{Y}$ & $\mathrm{Y}$ & Yes & $\mathrm{Y}$ & Ye & Yes \\
\hline Year Dummies & Yes & $\mathrm{Ye}$ & Yes & Yes & Yes & Yes \\
\hline County Dummies & Yes & Yes & Yes & Yes & Yes & Yes \\
\hline$A F Q T>33$ & Yes & Yes & Yes & Yes & Yes & Yes \\
\hline Family Income Percentile & All & $<25$ & $>25$ & $>50$ & $>75$ & $>90$ \\
\hline Diff-in-Disc & Yes & Yes & Yes & Yes & Yes & Yes \\
\hline Age Observed & $21-26$ & $21-26$ & $21-26$ & $21-26$ & $21-26$ & $21-26$ \\
\hline R-squared & 0.477 & 0.681 & 0.480 & 0.468 & 0.548 & 0.468 \\
\hline Observations & 1741 & 421 & 1320 & 924 & 466 & 175 \\
\hline
\end{tabular}

Note: ${ }^{*} p<0.05,{ }^{* *} p<0.01,{ }^{* * *} p<0.001$. Standard errors clustered by state of residence in 1979/before age of 18 in parentheses. 
Table 3.11: Robustness Estimations

\begin{tabular}{|c|c|c|c|c|c|}
\hline LPM & HSG & HSG & HSG & HSG & HSG \\
\hline BBD & $\begin{array}{r}0.121^{* * *} \\
(0.014)\end{array}$ & $\begin{array}{r}0.123^{* * *} \\
(0.014)\end{array}$ & $\begin{array}{r}0.097^{* * *} \\
(0.013)\end{array}$ & $\begin{array}{r}0.047 \\
(0.041)\end{array}$ & $\begin{array}{r}0.132^{* * *} \\
(0.034)\end{array}$ \\
\hline Probit & $\mathrm{X}$ & & & & \\
\hline Restriction & & & $\begin{array}{r}\text { Not a } \\
\text { student }\end{array}$ & $\begin{array}{l}\text { Not a } \\
\text { student }\end{array}$ & $H G C>8$ \\
\hline County & & & X & $\mathrm{X}$ & $\mathrm{X}$ \\
\hline Age & 22 & 22 & 22 & 20 & 22 \\
\hline Observations & 579 & 588 & 477 & 445 & 568 \\
\hline R-squared & & 0.254 & 0.314 & 0.273 & 0.260 \\
\hline Pseudo R2 & 0.268 & & & & \\
\hline diff-in-disc & HSG & HSG & HSG & HSG & HSG \\
\hline $\mathrm{BBD}$ & $\begin{array}{r}0.419 * * * \\
(0.088)\end{array}$ & $\begin{array}{r}0.299^{* * * *} \\
(0.052)\end{array}$ & $\begin{array}{r}0.394^{* * *} \\
(0.066)\end{array}$ & $\begin{array}{r}0.320^{* * *} \\
(0.051)\end{array}$ & $\begin{array}{r}0.156^{* * *} \\
(0.047)\end{array}$ \\
\hline Probit & $\mathrm{X}$ & & & & \\
\hline Restriction & & & $\begin{array}{r}\text { Not a } \\
\text { student }\end{array}$ & $\begin{array}{l}\text { Not a } \\
\text { student }\end{array}$ & $H G C>8$ \\
\hline County & & & $\mathrm{X}$ & X & $\mathrm{X}$ \\
\hline Age & 22 & 22 & 22 & 20 & 22 \\
\hline Observations & 579 & 588 & 477 & 445 & 568 \\
\hline R-squared & & 0.259 & 0.329 & 0.290 & 0.260 \\
\hline Pseudo R2 & 0.277 & & & & \\
\hline
\end{tabular}

Notes: Standard errors clustered by state of residence in 1979/before age of 18 . ** and ${ }^{* * *}$ represent 5 and 1 percent significance levels, respectively. The first two specifications in each panel use Probit instead of linear regressions; however, the diff-in-disc panel does not have county dummies. The 3rd and 4th specifications use linear models, but do not have county dummies. In both panels, the 5 th and 6th specifications omit participants that are currently students; however, the 5th specification observes individuals at age 22 , whereas the 6 th specification observes individuals at age 20 . In bother panels the 7 th, 8 th, and 9 th specifications restrict the sample by omitting nonwhites, females, and individuals with less than a 9th grade education, respectively. 


\section{Chapter 4}

\section{The Impact of Big-Time Sports on University Outcomes: Evidence from NCAA Conference Realignment}

Intercollegiate athletic programs at American colleges and universities experienced unprecedented growth over the last few decades. Sanderson and Siegfried (2015) report that median athletic program revenue increased from $\$ 28.5$ million in 2004 to $\$ 68.9$ million in 2013 for the 126 colleges and universities playing in National Collegiate Athletic Association's (NCAA) Football Bowl Subdivision (FBS). These represent the largest intercollegiate athletic programs in the country. Fulks (1998) reports that the average revenues for NCAA Division 1-A colleges and universities (the precursor to FBS) was about \$6.8 million in 1985 .

Under the accounting standards used by NCAA institutions, funds transferred from the general university budget to the athletic department fall under the category of "revenues" even though economists would call these funds "subsidies." According to Sanderson and Siegfried (2015), about $20 \%$ of the revenues reported by FBS athletic departments take the form of subsidies, about $\$ 20$ million per year. The figures reported by Fulks (1998) suggest equally large or larger subsidies, in percentage terms, at Division 1-A athletic departments as far back as the 1980s. Then, and now, only a few athletic departments at this level report revenues greater than total expenditures. These large, persistent subsidies from universities to their intercollegiate athletic departments clearly raise important questions about the relationship between big-time college sports and academic outcomes.

A large body of empirical research addresses the relationship between big-time college 
sports and outcomes in other parts of the university, which we call academic outcomes. These academic outcomes include the number and quality of new undergraduate applicants to the university, student achievement in terms of grade point average, retention, and graduation of undergraduate students, and general fund revenues like donations, tuition revenues, and state government appropriations. This empirical literature posits that successful intercollegiate athletic programs, typically football and men's basketball, generate an advertising effect that enhances a university's ability to attract high-quality students, engage alumni, and lobby legislators. ${ }^{1}$ In terms of student performance, papers in this literature assume that following a successful athletic program either increases the opportunity cost of studying, thus reducing student academic performance, or acts as a complement to studying, perhaps by increasing student engagement or attachment to the university, increasing student academic performance.

Much of the empirical research uses athletic success measures like football and men's basketball winning percentage, bowl appearances, NCAA basketball tournament success, final ranking in football and basketball polls, and end-of-season position in the Sagarin and Massey computer rankings of college teams. Little attention has been paid to identification or causal inference in this literature; most studies implicitly assume intercollegiate athletic success to be uncorrelated with unobservable institution-specific factors that affect academic outcomes. Perhaps because of this lack of identification, no consensus has been reached in this literature. Papers conclude that successful football and men's basketball teams increase or decrease academic outcomes, depending on the athletic success measure, time period, and sample of schools analyzed.

Several recent papers use causal inference methods to assess the relationship between intercollegiate athletics and academic outcomes. Pope and Pope (2014) use a regression discontinuity design (RDD) to investigate the causal impact of success in the NCAA men's basketball tournament on the number and quality of new freshman applicants at 332 schools that played Division 1 basketball or Division 1A football over the period 1994-2001 using

\footnotetext{
${ }^{1}$ Some papers call this the "Flutie Effect" because of increases in applications and the quality of incoming freshman classes at Boston College while Doug Flutie was the quarterback on the successful BC football teams in the early 1980s (which lost to West Virginia University all four years Flutie played for BC).
} 
a unique data set containing information on where individual applicants send SAT scores. Pope and Pope (2014) found that qualifying for the NCAA tournament increased the number of applicants sending their SAT scores to a university by 2\%, making the Sweet 16 increased it by about $4 \%$, making the Final Four increased it by $6 \%$, and winning the national championship increased it by $9 \%$ in the following year. Football success also increased the number of applicants sending their SAT scores to a university.

Anderson (2017) uses the propensity score method to investigate the causal impact of football success on a number of academic outcomes at all FBS/Division 1A schools (about 120 schools) over the period 1990-2009. Academic outcomes included donations, undergraduate applicants, acceptance rates, SAT scores, first-time undergraduate enrollment, and a measure of academic reputation. Anderson (2017) creates a football success measure exogenous to any unobservable school-specific factors by exploiting unexpected week-to-week outcomes (upset wins or losses) over the course of each football season. Football success increased donations to the athletic department, applicants, acceptance rates, first-time in-state freshmen enrollment, SAT scores at the 25th percentile, and academic reputation of the school. Taken together, the evidence in these two papers suggest that successful intercollegiate athletic programs generate significant positive spillover benefits in terms of improvements in academic outcomes.

However, these papers, like prior research, focus on measures of athletic success. In sports leagues, athletic success is zero sum; for each successful team in an athletic conference, there must be an unsuccessful team. This muddies the overall impact of intercollegiate athletics on academic outcomes. If a successful football or men's basketball season causes applications to increase, does an unsuccessful season cause applications to decrease? While a handful of teams have continuous success in football or men's basketball, most FBS teams go through periods of success and periods of failure. If periods of success and failure roughly even out over the long run, what is the overall effect of intercollegiate athletics on academic outcomes at these universities? Focusing solely on athletic success cannot provide an answer to this question.

We extend the line of research using causal inference methods to assess the relationship between intercollegiate athletics and academic outcomes. Instead of focusing on athletic 
success, we exploit a different intercollegiate athletic outcome: changes in athletic conference affiliation. A substantial number of FBS schools changed conference membership over the last 20 years. A university cannot unilaterally decide to move to a new athletic conference. An invitation to join a new athletic conference can only be extended when a majority of existing conference members vote to extend an invitation to a new member. The reason for much of the athletic conference realignment over the past 20 years comes from conferences attempting to increase revenues generated by selling the broadcast rights to athletic events, not from attempts to improve academic outcomes at member universities. Moving from one conference to another should be plausibly exogenous to unobservable institution-specific factors affecting academic outcomes. Conference changes also reflect variation in the intercollegiate athletic environment at a school without the limitations associated with success-based measures.

We empirically analyze the causal effect of intercollegiate athletics on academic outcomes using conference membership changes as a treatment in a difference-in-differences approach, along with propensity score matching approach to generate appropriate samples of untreated institutions. We use data from 90 FBS colleges and universities over the period 2000-2015, a period with a large number of changes in conference membership. Difference-in-differences results from the full sample contain weak evidence that changing conferences reduces the number applicants and entering class ACT scores, and increases state appropriations to public institutions. Difference-in-differences estimates using propensity score matched control groups provide no evidence that switching to a power 5 conference improves academic outcomes. Finally, use of select realignment clusters indicate inconsistent outcomes when athletic programs switch to better conferences.

\subsection{Context}

\subsubsection{Previous Literature on Athletics and Academic Outcomes}

In the unique higher education system in the US, the academic units of colleges and universities often subsidize intercollegiate athletic programs. This outcome generated a substantial body of research assessing the relationship between intercollegiate athletics and academic outcomes to determine why these subsidies are provided, and what the larger 
university community gets in return for these subsidies. This research focused on two broad categories of academic outcomes: student outcomes and financial outcomes.

\section{Intercollegiate Athletics and Student Outcomes}

Most of the empirical literature on the relationship between post-secondary athletics and academics analyzes the impact of athletic success on student-related outcomes. The existing literature contains mixed results on the relationship between big-time college athletics and student outcomes. Possible student-related outcome variables influenced by sports programs include: applications and admissions, quality of new admits, retention, graduation, and student academic performance.

The primary mechanism through which athletic success affects the quantity and quality of undergraduate applicants to a university is an advertising effect. Successful college athletic programs generate name recognition and popularity for a university, increasing the applicant pool size and potentially the academic ability of incoming students (McCormick and Tinsley, 1987). Much of this literature focuses on the SAT scores of the incoming freshman class, a measure of the quality of incoming undergraduate students.

In this literature McCormick and Tinsley (1987), Tucker and Amato (1993), Mixon Jr (1995), Mixon et al. (2004), Tucker and Amato (2006), Pope and Pope (2009), and Segura and Willner (2016) find evidence that successful football and basketball programs were associated with higher SAT scores in incoming freshman classes. Bremmer and Kesselring (1993) and Smith (2008) find no evidence that football or basketball success were associated with higher SAT scores of incoming freshmen classes. Tucker (2005) finds mixed evidence, including no statistical relationship in the 1990s and a weak positive relationship between football success and SAT scores in 2002.

Many early studies used SAT score data from a single incoming class and did not adequately control for unobservable school-specific factors. Early studies generally found only football success related to higher SAT scores while later studies found only basketball success related to higher scores. Only Tucker and Amato (2006), Pope and Pope (2009), Smith (2008), and Segura and Willner (2016) use panel data that allow for fixed effects to control for unobservable institution-level heterogeneity. 
None of these studies used causal inference methods to investigate the relationship between athletic success and incoming freshman class SAT scores. Most used lags in athletic success, but this does not adequately control for long-run changes in school-specific unobservables, for example a sustained effort by university administrators to increase resources devoted to intercollegiate athletics, that might bias the estimated relationship between athletic success and incoming student quality. In addition, the use of athletic success variables ignores any possible relationship between athletic failure and incoming student SAT scores. Only Anderson (2017) addresses these issues, but this study focuses only on football success and finds a negative effect of unexpected football losses on student outcomes.

While SAT scores received most of the attention, research also examined other studentrelated academic outcomes and athletic success. Tucker (1992) and Segura and Willner (2016) find evidence that graduation rates decreased with athletic success or were unrelated to athletic success. Rishe (2003), Tucker (2004), Mixon Jr and Trevino (2005), and Hickman and Meyer (2017) find a positive relationship between athletic success and graduation rates. Again, these studies suffer from a lack of attention to the impact of athletic failure on graduation rates and a lack of causal inference methods. Mixon Jr and Trevino (2005) find a positive relationship between football success and freshman retention rates; Hickman and Meyer (2017) find a positive relationship between both football and basketball success and freshman retention rates. However, both ignore the effect of athletic failure on freshman retention rates, an important omission since decisions made by freshman have a long-lasting impact on enrollment.

Another line of research examines the relationship between the number of undergraduate applicants to a school and athletic success. Murphy and Trandel (1994), Pope and Pope (2009), Pope and Pope (2014) and Anderson (2017) report evidence that freshman applications increase with football and basketball success. Pope and Pope (2014) and Anderson (2017) use causal inference methods, and the detailed data used by Pope and Pope (2014) indicate substantial heterogeneity in the characteristics of applicants that respond to athletic success. Again, only Anderson (2017) examines the impact of athletic failure, and finds that applications decline with unexpected football losses. Also, an increase in applicant pool size, though likely improving the ability of incoming classes, may not generate significant 
improvements in the quality of admitted students.

The results in Pope and Pope (2009) and Pope and Pope (2014) using detailed, individuallevel data on SAT scores indicate that applicants with a strong interest in consuming or participating in intercollegiate sports may base their application decisions on recent athletic success. These applicants tend to be male, so a successful athletic campaign may increase applications from only a homogenous group of potential students. Therefore, it is important to measure a number of characteristics of applicants and admits when analyzing the impact of athletic success on academic outcomes.

Finally, a recent set of papers casts substantial doubt on the idea that successful intercollegiate athletic programs generate positive academic benefits for students. Lindo et al. (2012) and Hernández-Julián and Rotthoff (2014) undertake detailed studies of the relationship between football success and individual student grades at the University of Oregon and Clemson University, respectively. Both universities enjoyed very successful football seasons during the period of analysis.

Both studies contain convincing evidence that successful football programs reduced student GPAs in the fall semester, during football season. Hernández-Julián and Rotthoff (2014) find that this negative effect carries over to the following spring semester. Both found that grades of students at the lower end of the socio-economic spectrum, (those with higher levels of financial aid and student loans) suffered the most during these periods. Both studies make the case that football success was exogenous to unobservable university-specific factors that might affect student GPAs, and both use detailed individual-level controls for student ability, unlike all of the other studies reviewed above. Since GPA predicts future labor market success, these results suggest large and persistent negative individual effects of exposure to a successful football program during the undergraduate educational experience.

In general, the literature on intercollegiate athletic success and student-related academic outcomes contains mixed results. Research finds both negative and positive effects on incoming freshman class quality, retention, graduation rates, and applications. Nearly all of these studies ignore the effect of athletic failure on these outcomes. The limited evidence using causal inference methods finds negative effects of athletic failure, casting further doubt on the general findings in this literature. 
Only a few previous studies focused on the presence or absence of athletic programs, which appears to be a better outcome measure, as this would reflect the average effect of periods of athletic success and failure on academic outcomes. McCormick and Tinsley (1987) find that incoming freshman class SAT scores were higher at schools in six prominent "Power Conferences" (ACC, Big 8, Big 10, PAC 10, SEC, SWC). Goff (2000) finds that applications dropped when football teams were eliminated and increased when new football teams were added in a case study of four universities in the 1990s. Caudill et al. (2018) find that applications declined after football programs were dropped at a sample of 10 universities over the period 1997-2015. These results suggest that focusing on measures of athletic success overlooks key features of the relationship between big-time college sports and academic outcomes.

\section{Intercollegiate Athletics and Financial Outcomes}

Another line of research analyzes the effects of conference realignment on financial outcomes at universities, including athletic department revenues, state appropriations, tuition revenues, and donations. The mechanisms underlying this relationship generally differ from those in the literature on athletic success and student academic outcomes, since revenues come from fans and donors, legislators, and parents.

Hoffer and Pincin (2015) report substantial increases in athletic revenue and expenditures when teams moved to more competitive football conferences. Kearney (2014) find basketball success increased total athletic department revenues. These direct relationships are expected, since the athletic department benefits directly from higher ticket sales and television broadcast revenues during periods of athletic success.

Humphreys (2006) and Alexander and Kern (2010) both find athletic success positively associated with state appropriations to public universities. Humphreys (2006) analyzes a large sample of colleges and universities over a long period and found that the presence of a big-time football program increased state appropriations. Alexander and Kern (2010) find that successful big-time sports programs increased state appropriations; each FBS school in their sample received about a million additional dollars in state appropriations for each additional football or basketball win. Both papers posit that legislators respond favorably 
to athletic success by rewarding successful schools.

An extensive literature examines the effect of athletic success on donations to colleges and universities. A large number of data sources and success measures are used. The results are decidedly mixed. See Humphreys and Mondello (2007) and Anderson (2017) for reviews of this literature.

A few papers examine the relationship between intercollegiate athletic success and tuition revenues. This line of research assumes that successful football or basketball teams increase demand for enrollment among prospective students which reduces the price elasticity of demand. This reduction allows schools to charge higher tuition, increasing tuition revenues. Mixon Jr and Ressler (1995) reported that out-of-state student enrollment was higher at schools with successful men's basketball programs using data from the early 1990s, and inferred that this led to increases in tuition revenues, since out-of-state students pay higher tuition at public universities. Alexander and Kern (2009) find that schools in major power conferences with successful football and basketball programs charged higher tuition and fees, raising tuition revenues using panel data from 1987-2007. Smith (2012) finds no evidence of a relationship between athletic success and tuition revenues using a broader panel of universities than Alexander and Kern (2009). None of these papers use causal inference methods.

In general, the existing literature finds evidence that athletic success affects financerelated academic outcomes based on a number of common financial variables. However, this literature also generally ignores the effect of athletic failure and does not make use of causal inference methods.

\subsubsection{Conference Realignment in Big-Time College Sports}

Instead of focusing on athletic success, we exploit conference realignment as an exogenous source of variation in the costs and benefits of intercollegiate athletics. Beyond athletic success, athletic conference peers act as an academic benchmark potentially spurring academic competition (Kramer II, 2014; Sweitzer, 2009).

Athletic conference realignment directly reflects the growing importance of television broadcast rights revenues in big-time college sports. Until the early 1980s, the NCAA nego- 
tiated with television networks for the rights to broadcast college football and men's basketball games on behalf of institutions and tightly controlled the number of games that were televised and the number of television appearances any NCAA school could make in a season. There were also relatively few networks that were interested in televising NCAA sporting events. ESPN began operation on 7 September 1979, and broadcast a few college football games on tape delay starting in the 1979 regular season, but did not begin broadcasting live college football games until the 1984 season.

The NCAA sold the first football television broadcast rights deal to NBC in 1952 for $\$ 1.1$ million (\$10.5 million in 2018 dollars). ${ }^{2}$ The contract allowed NBC to broadcast one regular season game per week to a national audience on Saturday afternoon. In 1953 the NCAA allowed multiple regional broadcasts of different games on selected weeks. This contract was terminated after the 1953 season. In 1955 the contract was again sold, this time for the rights to broadcast one nationally-televised regular season Saturday afternoon game per week for eight Saturdays and a small number of regionally-televised games in a single time slot on Saturday afternoon for five weeks during the regular season. ${ }^{3}$ This system remained in place until 1981, when the Board of Regents of the University of Georgia and University of Oklahoma sued the NCAA on the grounds that the NCAA college football television broadcast regulation violated anti-trust law. This landmark case is commonly called the Board of Regents case.

In June 1984 the US Supreme Court ruled that the NCAA was in violation of anti-trust law and could no longer regulate college football broadcasts. The right to negotiate football broadcast rights, and distribute the revenues, devolved to conferences, and in some cases, individual universities. Unshackled from NCAA control, conferences underwent substantial changes to increase broadcast rights revenues.

Conference membership in big-time college sports was stable in the pre Board of Regents era. ${ }^{4}$ The Big 10 Conference had the same members from its founding in the $1890 \mathrm{~s}$ until

\footnotetext{
${ }^{2}$ The first game broadcast under this contract was TCU versus Kansas on 20 September 1952.

${ }^{3}$ Bowl games were exempted from NCAA broadcast regulation and have been regularly televised since the 1950 s.

${ }^{4}$ The only notable exceptions were the University of Arizona and Arizona State University joining the Pacific 8 to form the Pacific 10 in 1978. Although this move was not based on broadcast rights, it was based on revenues. The University of Southern California (USC) was tired of losing money traveling to play in
} 
1990 with the exception of the (ex post wise) choice by the University of Chicago to eliminate all intercollegiate sports in 1940 and the addition of Ohio State (1912) and Michigan State (1950). Ten of the founding members of the Southeastern Conference (SEC) have been continuous members since 1932. Only a few membership changes occurred in SEC in the pre Board of Regents era, notably the (ex post wise) choice by the University of the South (Sewanee) to eliminate all intercollegiate sports in 1940.

Schools occasionally left major athletic conferences for independent status in the pre Board of Regents era. Georgia Tech and Tulane left the Southeastern Conference, and South Carolina left the Atlantic Coast Conference in the mid 1960s. In this era, television broadcast rights were controlled by the NCAA so leaving a conference resulted in no change in broadcast rights fees.

The Board of Regents decision clearly impacted conference incentives, spurring realignment and other outcomes in big-time college sports (Carroll and Humphreys, 2016). The Board of Regents decision put conferences in charge of negotiating television broadcast rights contracts. At the same time, the number of broadcasters televising college football exploded, driving up the value of these rights fees and revenues (Sanderson and Siegfried, 2018).

The growing importance of college football television broadcast rights increased the return to broadcasts of college football games, and conferences responded by adding new members that would increase the footprint of their TV audience. Traditional athletic conferences like the Big 10 added universities from Pennsylvania, Maryland, and New Jersey, well outside their original territory in the midwest. The PAC-10 Conference expanded eastward, adding teams in Utah and Colorado. Some long-lived conferences like the SWC were torn apart and new power conferences like the Big 12 emerged from the ashes.

Sanderson and Siegfried (2015) and Sanderson and Siegfried (2018) emphasize that these changes were driven by the desire of conferences to increase television broadcast revenues, and not by university-led attempts to improve academic outcomes. We exploit these changes to better understand the impact of intercollegiate athletic programs on broader academic outcomes at universities. Conference realignment represents an exogenous change to the Penn State and others unless a change was made to the Pac 8 Hansen (2016). 
intercollegiate athletic environment on campus that is plausibly exogenous to unobservable university-level factors affecting academic outcomes. Television-revenue generated conference realignments represent ideal natural experiments to be used with modern causal inference methods like difference-in-differences models and propensity score matching.

\subsection{Data}

We collected data from 90 NCAA Division 1 Football Bowl Subdivision (FBS) colleges and universities over the period 2000-2015 from a number of sources. We combine data on university characteristics from the Integrated Postsecondary Education Data System, state and local macroeconomic indicators from Bureau of Economic Analysis (BEA) Regional Economic Information System (REIS), and data on Division I athletic conference affiliation from publicly available news outlets. Table 4.1 provides summary statistics for our data.

We begin by describing athletic conference membership and realignment over the sample period. The first two rows of Table 4.1 motivate our empirical analysis. About $21 \%$ of the team-seasons in the sample involved a change in athletic conferences.

\subsubsection{Changes to Conference Membership}

We define conference changes or switches as the case where institutions switch from one athletic conference to another. As discussed above, a relatively large number of NCAA Division 1-A/FBS schools switched conferences since the 1984 Board of Regents decision. These changes in conference affiliation reflect the fact that the 1984 Board of Regents Supreme Court decision reduced the power of the NCAA to regulate television schedules and appearances in college football and increased the power of athletic conferences.

Figure 4.1 illustrates the number of universities switching conferences for the first time since the formation of the Big 12 Conference. ${ }^{5}$ Some teams change conferences more than once over the period, so the conference changes shown on Figure 4.1 do not represent the full extent of realignment over this time period. For simplicity, we only identify a change of conference if it is the first move since the Big 12 formed. Notice that conference changes are

\footnotetext{
${ }^{5}$ For a complete accounting of NCAA D1 Football Conference changes since 1965 see Bostock et al. (2013).
} 
not uniformly distributed over time. Rather, they tend to cluster during specific periods. For example, the demise of the Big West Conference in 2001 and the collapse of the Big East Conference in 2013.

Not all conference changes are equal, even at the same school; conference realignments are heterogeneous. Consider the experience of Texas Christian University (TCU). TCU left the Southwest Conference (SWC) in 1996 when the Big 12 formed from a merger of some members of the SWC and the Big 8 Conference. Lacking an invitation to join the newly formed Big 12, TCU moved to the Western Athletic Conference, which expanded to a megaconference from a smaller conference with 10 incumbents by adding six teams from the Big West Conference and SWC. This move was certainly not a step up for TCU, since they traded membership in a conference with powerhouse football schools like Texas and Texas A\&M for membership in a conference with Texas-El Paso and Tulsa. It was perhaps a lateral move, but more likely a step down in terms of prestige of their conference foes. This was a negative conference move for TCU.

TCU's most recent conference change saw the Horned Frogs join some of their old SWC rivals (Baylor, Texas, and Texas Tech) and most of the former Big 8 conference in the Big 12 conference when former SWC member Texas A\&M moved from the Big 12 to the Southeastern Conference in 2012 and former Big 8 member Colorado moved to the PAC 10 conference in 2011. In this case, TCU found itself joining more prestigious conference affiliates, which increased the profile of TCU's athletic programs. This was undoubtedly a positive move for TCU. We must account for the difference between negative conference changes and positive conference changes when assessing the relationship between conference changes and educational outcomes.

To account for this we create two different conference move indicator variables. One indicates any move from one FBS conference to another. The other indicates a move from an FBS conference to a Power 5 Conference (ACC, Big 10, Big 12, Pac 12, or SEC). In this project we only include FBS conference changes after 1996 (the year the Big 12 was formed). The variable Conference Change $_{i t}=1$ if university $i$ moved to a different athletic conference after 1996 and before year $t$. The variable Conference Change $5_{i t}=1$ if university $i$ moved to a Power 5 conference after 1996 but before year $t$. These variables act as treatment 
indicators for each model described in the Empirical Analysis section. Before discussing the empirical methods, we describe the institution specific academic outcome variables.

\subsubsection{IPEDS Data}

The Integrated Postsecondary Education Data System (IPEDS) is the richest publicly available data set on characteristics of US institutions of higher education. IPEDS data contain variables in several broad categories including institutional characteristics, revenues, expenditures, graduation rates, admissions, and incoming student test scores. It is cumbersome to format IPEDS in panel data form so we use Delta Cost Project (DCP) data. The DCP team formatted much of the IPEDS universe into an easily usable panel structure.

Some researchers caution against using the DCP data because it collapses data from multiple institutions in a university system into a single unified institution. Jaquette and Parra (2016) highlight concerns about the DCP aggregation of university systems into a single composite institution. DCP treats all institutions that are part of a larger university system (e. g. UMass Amherst, UMass Boston, and UMass Lowell) as one consolidated entity, aggregating or averaging each variable from individual campuses. A prime example of this issue is the University of Texas System. According to DCP, the University of Texas at Austin had an enrollment of 229,778 in 2015, a large value that reflects total enrollment across the entire University of Texas system, which contains 14 individual institutions.

In this analysis, the use of institution/group specific fixed effects mitigates the likelihood of any systemic bias in our main results because the DCP consistently aggregates data for the entire grouping each year. Additionally, we limit our scope to FBS schools, typically the main campuses of these groupings. Because of the relative sizes of the main campuses, any major change in variable $x$ for the group almost certainly results from a similar change in variable $x$ for the main campus. We would only be concerned in two situations. First, if conference realignment of the main campus of a university system/grouping systematically directed funds/applicants/enrollees from satellite campuses to the main campus or from main campuses to the satellite campuses. Or second, if the institutional system/grouping has two D1, FBS football schools. We eliminate this second concern by omitting the two systems/groups with more than one FBS football school (UT Austin and UT El Paso in the 
University of Texas system; UNM and NM State in the University of New Mexico system).

\section{Revenues and Expenditures}

As noted by Hoffer and Pincin (2015) some university administrators believe conference changes may reduce the need for the university to subsidize its athletics programs by generating more revenue. However, Hoffer and Pincin (2015) find increases in athletic revenues stick to athletics departments like a fly to flypaper. Nevertheless, we assess the extent to which conference changes affect academic spending or university-wide revenues. The following describes the revenue and expenditure data. We normalize all expenditure and revenue data to a per full time student basis and deflate dollar values to 1982-1984 dollars using the Consumer Price Index (CPI).

On Table 4.1, State Appropriation (The variable State $_{i t}$ below) is direct state appropriations to university $i$ in year $t$. This is funding from state governments to help universities in their state meet operating expenses. State and Local $i$ represents revenue generated by university $i$ in year $t$ in the form of state and local appropriations, grants, and contracts.

Private $_{i t}$ are revenue from private gifts, grants, and contracts. This includes only those gifts, grants, and contracts that are directly related to instruction, research, public service, or other institutional purposes. Federal ${ }_{i t}$ are revenues from federal grants or contracts for training programs, research, or public service activities for which expenditures are reimbursable under the terms of a government grant or contract, includes Pell Grants for institutions that do not treat it as a pass-through to tuition revenues.

Expenditure data focus on research and instruction. Research Total $i$ is the total spending on activities specifically organized to produce research outcomes and commissioned by an agency either external to the institution or separately budgeted by an organizational unit within the institution for university $i$ in year $t$. Research Salaries ${ }_{i t}$ are the salaries and wages paid to directly support research in institution $i$ in year $t$.

Total Instruction ${ }_{i t}$ includes expenses of the colleges, schools, departments, and other instructional divisions of the institution and expenses for departmental research and public service for university $i$ in year $t$ that are not separately budgeted. Instruction Salary $y_{i t}$ is the employee salary/wage/compensation component of Total Instruction for university $i$ in 
year $t$.

\section{Characteristics of Incoming and Existing Students}

Institutions in IPEDS began providing information on admissions beginning in fall 2002. We use Applicants $s_{i t}$, the number of applicants to institution $i$ in the fall semester of year $t$, and Admissions $s_{i t}$, the number of first time college students enrolled at institution $i$ in year $t$. Universities have reported Total Enrollment $i$ since the inception of postsecondary data collection. This is the number of students enrolled in a course at institution $i$ at the beginning of the fall semester of year $t$.

Institutions in IPEDS began submitting summary measures of standardized test scores for their incoming classes starting in 2002. They report components of two test types, the $\mathrm{ACT}$ and the SAT. We use each testing component as an outcome variable. They are as follows: ACT Composite, ACT Math, ACT Verbal, SAT Math, and SAT Critical Reading. In earlier years, universities had more leeway on reporting these scores. For instance, in 2004 , regulations only required schools to report scores for tests where $60 \%$ of their enrolled students provided those scores to the university. In more recent years, if any students submit test scores and test scores are required for admission the institution must report the first and third quartiles.

\section{Student Retention and Completion}

Our final variables from the IPEDS database reflect student success in terms of remaining enrolled in school and graduating with a degree. Graduation Rate $e_{i t}$ is the fraction of a cohort of students at university $i$ who graduated by year $t$ with their intended degree within $150 \%$ of the normal time to degree completion. For example, the graduation rate for 2008 is the fraction of the 2002 cohort of new Bachelor's Degree seekers and the 2005 cohort of new Associate's Degree seekers who earned their respective degrees by 2008. It is important to account for the lagged characteristic of this variable when interpreting results. Retention Rate Rit $_{\text {is }}$ the proportion of year $(t-1)$ 's first-time, full-time cohort of students who re-enrolled at institution $i$ as either full-time or part-time students in the fall of year $t$. 
Patrick A. Reilly Chapter 4. Big-Time Sports and University Outcomes

\subsubsection{REIS Data}

We collect BEA Regional Accounts data to control for variation in economic factors at the state and county level that may influence the outcome variables listed above. We

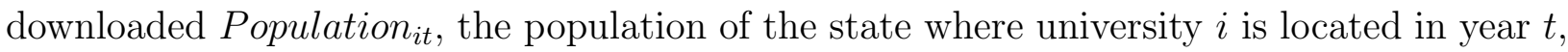
State $R G D P P C_{i t}$, the per capita GDP of the state where university $i$ is located in year $t$ in 2017 Dollars, County Income $i t$ the personal income in year of the county in which university $i$ is located, and State Unemployment ${ }_{i t}$, the unemployment rate of the state where university $i$ is located in year $t .^{6}$

\subsection{Empirical Analysis}

We estimate average treatment effects of moving from one athletic conference to another on university-level outcomes. To identify a causal effect of a conference switch we must account for the heterogenous nature of both universities and conferences, and any correlation between the treatment variable, switching athletic conference affiliation, and unobservable university-specific and state-specific factors that affect the decision to change athletic conference affiliation. We address these issues using a variety of causal inference methods including difference-in-differences methods, propensity score matching, and focusing empirical analysis on clusters of homogeneous conference moves. First, we discuss the identification of our treatment variable to establish our claim of quasi-random treatment selection.

\subsubsection{Identification}

This research uses athletic conference realignment as a quasi-random treatment that possibly generates negative or positive changes in academic outcomes at universities. Much of the previous research on intercollegiate athletics and academic outcomes typically used win percentage, bowl appearances, NCAA Men's Basketball Tournament appearances, or final poll rankings as proxy variables for intercollegiate athletic success. However, using athletic success measures may introduce endogeneity problems, as university administrators could

\footnotetext{
${ }^{6}$ Virginia separates its counties and independent cities. Therefore we use data from the independents cities of Blacksburg, VA and Charlottesville, VA instead of county income for Virginia Tech and University of Virginia respectively.
} 
direct funding to intercollegiate athletics as a means to increase these academic outcomes.

Using athletic conference realignment mitigates this problem. Athletic conferences aim to maximize revenues generated from sale of the television broadcast rights to games played by conference members. Decisions to add new members to an athletic conference are made by the conference commissioner in consultation with current members. Many of the conference realignment decisions in the sample reflect attempts by conferences to expand the conference television footprint, or the number of television viewing households that might watch conference games. Alternatively, realignment may reflect attempts by a conference to improve the quality of athletic competition in the conference.

Athletic conferences invite new schools to join based on the expected effect of new conference members on total conference television broadcast rights revenues. When conferences expand, they offer membership to universities with large fan bases or large potential fan bases. These factors are unlikely to be correlated with unobservable institution-specific factors that affect academic outcomes like the number of applicants, standardized test scores of applicants, student retention rates, graduation rates, or other variables under the control of university decision makers. This forms the basis of the identification approached used here; we assume that a change in athletic conference affiliation is uncorrelated with unobservable institution-specific factors affecting academic outcomes at universities.

Because conference membership invitations reflect the television broadcast rights revenue generating potential of new conference members, we need to control for state and local characteristics like state population and state per capita real GDP, which reflect the number and disposable income of the fans of schools invited to join a conference. The academic outcomes of new conference members should not be correlated with conference television broadcast rights revenue or state and local economic conditions. Because realignment decisions should be exogenous to academic conditions at universities that switch conferences, we can use conference changes as a quasi-randomly assigned treatment in this setting.

\subsubsection{Baseline Empirical Model}

Our baseline model, Equation (4.1), is a reduced form model of the determination of institution-specific outcome variables. This equation can be used to generate estimates of the 
average treatment effect of a school switching conferences using the standard difference-indifferences framework with institution and time fixed effects. This approach assumes that the decision to switch athletic conferences is uncorrelated with unobservable institution-specific factors that affect academic outcomes. Treated schools switch from one athletic conference to another and remain treated in all periods after switching athletic conferences. The panel nature of the data allows us to include institution fixed effects to control for unobservable, time invariant institutional factors, and year fixed effects to control for unobservable, time varying factors that affect all institutions in the sample. Finally, we use state-level, countylevel, and institution-level time varying explanatory variables to control for state-, countyand institution-level time varying factors that may impact academic outcome variables at institutions in the sample. $\beta$ is the estimated ATE of switching athletic conferences.

$$
Y_{i t}=\alpha+\beta S w i t c h_{i t}+\gamma X_{i t}+\delta_{i}+\theta_{t}+\epsilon_{i t}
$$

Where $Y_{i t}$ represents a university-specific outcome variable. Switch ${ }_{i t}$ is the treatment variable indicating a university switched conferences in some year $T<t$. $X_{i t}$ is a vector of control variables for university $i$ at time $t$, namely, state real GDP per capita, unemployment rate, and population for university $i$ 's state, county real GDP per capita for the county in which institution $i$ resides and, for most models, total enrollment in university $i . \delta_{i}$ is a university fixed effect. $\theta_{i}$ is a year fixed effect and $\epsilon_{i t}$ is a heteroscedasticity-robust equation error term randomly distributed around zero that captures all other factors that affect the university-specific outcome variables.

For Equation (4.1), the parameter $\beta$ reflects the ATE for a switch in athletic conference membership for any institution. However, as discussed in detail in the data section, we would need to investigate the circumstances surrounding each realignment to categorize it as a boon or a bust for the university. But we want to avoid arbitrarily deciding which realignments are "good" and which are "bad" for their universities. Rather, we claim realignment to a Power 5 Conference (ACC, Big 10, Big 12, Pac 12, or SEC) creates an undoubtedly improved situation for the realigning university. Therefore, Equation (4.2) uses the same specification with the exception of the treatment variable, Switch Power $5_{i t}$, which identifies only those 
university-years where university $i$ joins a power 5 conference prior to year $t .^{7}$

$$
Y_{i t}=\alpha+\beta\left(\text { Switch Power } 5_{i t}\right)+\gamma X_{i t}+\delta_{i}+\theta_{t}+\epsilon_{i t}
$$

Other than the treatment variable, Equation (4.2) is a replica of Equation (4.1).

\subsubsection{Propensity Score Matching}

The previous models use data on 90 institutions and their athletics programs. Not all of these universities are ideal comparisons. In our second model, we control the realignments of schools like West Virginia University and Texas A\&M with schools like Tulane and Kent State. Granted, we are simply using all available data, but not all universities could plausibly replace WVU or Texas A\&M as conference switchers and therefore closely represent a counterfactual. The real problem is, not all universities are equally likely to switch conferences, especially switch to a power 5 conference. Additionally, the likelihood of switching conference is not constant across time so university fixed effects cannot control for this discrepancy. Without question, the group of institutions that has changed to power 5 conferences shared characteristics that made them more likely to switch conferences than other institutions. If we can model the probability of changing conferences based on observable characteristics, then we can identify non-switching universities that shared similar probabilities to switch conferences as the actual conference changers. Therefore, to better resemble a randomized control trial, we assign a more appropriate comparison group via Propensity Score Matching (PSM). We then estimate difference-in-difference models, only including the matched observations as controls. ${ }^{8}$

First, we estimate the propensity scores: a measure of the likelihood of treatment assignment (in this case conference changes) based on observable characteristics. We believe conferences rely on expected revenue improvements when determining membership offers.

\footnotetext{
${ }^{7}$ We include universities realigning to non-power 5 conferences in the control group. This represents an implicit assumption that non-power 5 conference switches do not systematically affect academic outcomes. If non-power 5 realignments positively affect academic outcomes our estimated ATE's for power 5 conferences are biased downward and vice-versa

${ }^{8}$ Although some PSM methods use difference-in-means as the treatment effect, doing so in this case would ignore the time variation in our data. Therefore, we simply use PSM as a method of identifying a more appropriate control group.
} 
So, we estimate the propensity scores using a logit model, estimating the log odds of realignment based on observable characteristics that likely influence expected conference revenues. TV broadcast revenues depend on the number of viewers reached, so we posit that state population, the disposable revenue of those in the state, the size of the institution, and the success of the institution will likely influence the marginal increase in viewership postconference change. Therefore, we estimate the log-odds (logit) of conference switching based on averages of the previous five years for state population, state real GDP per capita, state unemployment, total enrollment, and bowl appearances.

In this model, we observe conference switchers up to their year of realignment. We observe control universities from 2000 to 2015. We also omit universities from the top conferences (Big 10 and SEC) and the lowest level conferences (MAC and Sun Belt) as it is extremely unlikely that these athletics programs would change affiliation to a Power 5 conference. We assume Switch Power $5_{i t}$ is a random variable selected from a one-draw binomial distribution with probability of switching to a power 5 conference equal to $\pi_{i t}$ for university $i$ in year $t$. Equation (4.3) estimates the logit of $\pi_{i t}$.

$$
\eta_{i t}=\log i t\left(\pi_{i t}\right)=\log \frac{\pi_{i t}}{1-\pi_{i t}}=x_{i t}^{\prime} \beta
$$

Where $x_{i t}^{\prime}$ is a vector of variables listed above and $\beta$ is a coefficient vector. Estimates for $\beta$ are available in the appendix tables. Specific to the year of each switch, we pair each treated university with control university that has the closest predicted logit value based on Equation (4.3). The relatively low propensity of switching makes using the predicted logit necessary. To avoid the control universities being matched with two treated universities, we start by matching the treated university with the highest logit first, the second highest second, ect and removing the matched university from the pool of untreated universities at each stage. To ensure that the pairs are near enough matches, we choose a caliper of $0.2 \sigma^{2}$, where $\sigma^{2}$ is the standard deviation of the predicted logit values. This analysis identifies 13 matches for the 15 universities changing to power 5 conferences. Table 4.2 identifies the matches. We estimate academic outcome variables using Equation (4.2) with the matched universities listed in Table 4.2. 


\subsubsection{Analyzing Realignment Clusters}

Problems may still exist using this PSM method to establish the control group. Eleven of the 13 matches are already members of Power 5 conferences; whereas only 6 of the 15 treated universities switched from one power 5 conference to another. Many of the switchers join conferences of the matched universities, so existence of any conference peer effect would cloud the meaning of parameter estimates. Additionally, many of the conference changes result in increased number of teams in a conference. This in itself could improve bargaining power of a conference when it comes to TV Broadcast Rights and increases conference-wide revenue by making possible conference championship games. So for this set of switchers and controls, expansion affects both groups, which could bias results.

Rather, we believe estimating the difference in the outcomes of a conference switcher from conference $j$ and the universities still in conference $j$ is a more appropriate test of the effect of conference changes. We address this in our final model specification where we look at two specific clusters of athletic conference realignment. The first occurred in 2004 and 2005 when the University of Miami, Virginia Tech, and Boston College left the Big East Conference for the Atlantic Coast Conference and Louisville and Cincinnati replaced them in the Big East. ${ }^{9}$

We categorize each of these conference changes as improvements for the realigning school. Miami, VaTech, Louisville, and Cincinnati were the powerhouses of their respective conferences. They were not forced to change conferences. They chose to switch when given the opportunity because they believed it was advantageous. If moving to the ACC was advantageous to Miami and VaTech then we can safely assume the same logic holds for BC.

We limit our data set to members of Conference USA and the Big East Conference in 2003 with the exception of USF, which joined D1 FBS Football in that same year. This smaller data set assures an excellent comparison group, the former conference members of the realigning universities. There is even direct evidence that if Miami or VaTech had refused to switch then the ACC would plausibly have asked other BE schools to join them

\footnotetext{
${ }^{9}$ The University of South Florida also moved from Conference USA to the Big East in 2005. However, South Florida had only been part of FBS football for two years prior to this move. The impact of a conference move may be affected by the amount of time spent in FBS before the move. This could bias our results. Therefore, we omit USF from this model specification.
} 
since Syracuse and Pittsburgh do so in 2013. Additionally, CUSA schools joined former $\mathrm{BE}$ schools when the AAC formed. Those conference changing universities mentioned above comprise our treatment group for the years they hold membership in their new conferences. Universities leave the data set if they change conferences at a later time (i.e. WVU in after 2011). We model this selective data set with Equation (4.1).

We use the same method with universities realigning in 2011 and 2012 moving to Power 5 conferences. We limit the data set to universities in the Mountain West Conference or the Big East Conference in 2005. Conference changers include those schools moving into power five conferences (TCU, Utah, WVU, Louisville, Pittsburgh, and Syracuse). With the exception of the formation of the American Athletic Conference, which kept the Big East Conference control schools together, there is no additional movement from these conferences. Since all the realignments in this case are to Power 5 conferences, we can use either Equation (4.1) or Equation (4.2) to estimate the average treatment effect of these realignments.

\subsection{Results}

We find two general patterns across methods and outcome variables. First, conference changes as a whole seems to have negative or no relationship with academic outcomes. Second, conference changes identified as expected improvements for the switching athletics program see no or perhaps positive effects on academic outcomes. We highlight the results following the order outlined in the last section. We begin by analyzing the general effects of conference changes on the entire set of schools in a difference-in-differences framework. Next, we discuss the estimated ATE of conference switching using a PSM framework. Finally, we focus on clusters of conference realignment where the conference changes all represent improvements in regional or national attention received by football programs while restricting control universities to those starting in the same conference as the switching universities.

\subsubsection{Full Sample Results}

Tables 2 through 12 present estimates of the ATE of conference changes using Equation (4.1), estimating the ATE of changing conferences in general, and Equation (4.2), estimating 
the ATE of changing to power 5 conferences in particular, for the entire sample of $90 \mathrm{NCAA}$ D-1 FBS schools. Because conference changes advertise universities in a new light or to a new audience, number of applicants is one of the main outcomes variables of interest in this study. Table (4.3) presents estimates indicating significant reductions of around 2700 applicants for universities switching to any FBS conference; whereas, the estimated ATE of a school switching to a power 5 conference is less precise and around -1400. If conference changes significantly reduce applications, universities might automatically counter to keep enrollment steady by increasing acceptance rates. We find imprecise positive estimates for conference changes on acceptance rates.

We cannot claim that conference switching makes universities less selective using acceptance rates. However, we can use test scores to measure if conference switching affects incoming student quality. Tables 4.5 through 4.9 present estimates of the ATE of switching and power 5 switching on first (Q1) and third (Q3) quartile scores of incoming students for the SAT and ACT standardized tests. We find negative estimates across test score specifications; however, few are significant. Interestingly, although we estimate significantly greater reductions in applicants for universities changing to any conference, we find only universities switching to power 5 conferences encountered significantly negative impacts on incoming students' test scores.

Changes in perception can plausibly explain why switching to big-time football conferences might reduce incoming student ability while losing fewer applicants than typical conference switchers. First, people are more aware or pay more attention to big-time conference changes than conference change in general. This advertising effect might limit any reductions in applications common to switching conferences. However, not every applicant will view conference changes in the same light. Imagine two types of applicants, an investing applicant, who values college because of expected improvements in labor market outcomes, and a consuming applicant, one who values college as an experience. The investing applicant views University X switching to a Power 5 conference as a negative because the university is associated more with football, taking away from its academic prestige. On the margin, the investing applicant would decide not to apply to University X. On the other hand, the consuming applicant views University X switching to a Power 5 conference as a benefit be- 
cause this improves the amenities an applicant can consume while at University X. On the margin, the consuming applicant would rather apply if University X switches to a power 5 conference. If a greater proportion of high (low) ability applicants are investing (consuming) applicants, then we would expect lower ability levels of incoming students after a university switches to a power 5 conference. Neither applicant type cares if University X switches to a non-power 5 conference; therefore, conference realignment in general would have no affect on incoming students' abilities.

The final set of outcomes focus on institution specific funding and expenditures. Table 4.10, Table 4.11, Table 4.12, and Table 4.13 present results on Instructional Expenditures, Research Expenditures, State and Local Funding, and Private and Federal Funding respectively. We find power 5 conference changes increase some funding and expenditure measures. Research salaries tend to increase post-power 5 realignment as do state appropriations and state and local grants and contracts. Realignment overall has little impact. We find decreases in instructional spending and increases in state appropriations at the 10 percent level.

It is important to note these results include university systems or groupings. To reduce any possible biases introduced when modeling aggregated outcome variables, we also estimate each model omitting universities that are or were part of institutional systems or groupings. Results from these models located in the appendix tables are consistent with the above results.

\subsubsection{Propensity Score Based Control Group Selection}

The remainder of our analysis focuses on selecting proper comparison universities for positive conference changes beginning with selecting comparison universities based on predicted treatment likelihood. We select those control universities with predicted log odds of switching to a power 5 conference closest to the predicted log odds of programs actually moving to power 5 conferences.

Table 4.14, using Equation (4.2) and limiting analysis to institutions selected, presents the parameter estimates and standard errors of the conference change treatment (Switch P5). We find consistently insignificant parameter estimates. One exception is the first quartile $\mathrm{ACT}$ verbal scores, which are negatively related to switching to a power 5 conference at the 
10 percent level. Generally speaking, using this selection method, conference improvements appear to have no affect on academic outcomes of universities. This null result begs the question to universities, why subsidize big-time college football?.

However, this result could derive from problems with our new control group. The perfect counterfactual for say WVU leaving the Big East for the Big 12 would be if we could observe a reality where WVU stayed in the Big East. Rather, we select a control group comprised of mostly Pac 12, ACC, and Big 12 schools (10/13), the conferences which many of the switchers $(10 / 15)$ are joining. This is not the ideal setup for difference-in-differences. Although the control schools may be more similar to the switchers, if conference peers have an effect on each other, then conference change affect both the treatment and the control groups possibly biasing any results. To mitigate these concerns, the next section focuses instead on the conference foes left behind by universities experiencing positive conference changes.

\subsubsection{Investigating Realignment Clusters}

College football realignments are often clustered at specific points in time. First movers generate conference membership positions for second movers who, in turn, open up conference switching opportunities for other programs or perhaps weaknesses in their former conferences. Figure 4.1 depicts three clusters from our sample years. One centered around 2001 when the Big West Conference ceased to exist and its small-time teams jostled for affiliations in second and third tier conferences. One in 2004 and 2005 when Miami and VaTech sought to improve their fortunes in the ACC. And finally, one centered around the demise of the Big East Football Conference, which took place between 2011 and 2014. We analyze the latter two realignment clusters as they involve movement in the top tier conferences.

\section{4/05 Realignment Cluster}

Propensity score matching should select an improved control group by matching on observable characteristics. However, we might improve on this method by using a control group of schools from the former conference of universities with undoubtedly positive realignments. We begin with the 2004/05 conference realignment comprised of three Big East Conference members (University of Miami, Virginia Tech, and Boston College) joining the 
Atlantic Coast Conference and two Conference USA members (Cincinnati and Louisville) joining the Big East Conference. Each of these moves were athletic conference improvements for the switchers. The true counterfactual would see the switchers staying in their respective conferences. This identifies a natural control group, the former conference members of the universities changing conferences. Thus, we use Equation (4.1) to model how these five conference changes affected university academic outcomes using former conference foes as the control group.

Table 4.15 presents evidence of positive academic effects for these conference changes for student retention and graduation. Those teams changing conferences saw a 5 percentage point improvement in graduation rates and a 4 percentage point improvement in first time student retention rate than their former conference peers. This suggests that students are more likely to stay at their university when the relative quality of football competition improves. It is important to note, however, that retention rates are first available in 2004, so when including fixed effects, this estimate only pertains to Boston College, Louisville, and Cincinnati, those schools realigning in 2005.

In Table 4.16 and Table 4.17, we present findings on how the 2004/05 realignment cluster affected incoming student test scores. Following conference changes, incoming students' ACT scores improved by 0.9 to 1.6 percentage points for both Q1 and Q3. SAT scores improved by over 20 points for both the first and third quartiles in Math and the first quartile of Critical Reading. The third quartile critical reading score improved by 12 points after conference changes.

Although these five universities saw improvements in student retention, graduation, and test scores, all estimates of the ATE of conference changes on university funding and spending found in Tables 4.18 and 4.19 are imprecise. It is likely that most funding and expenditures are stable from year-to-year. Additionally, athletic departments spend any increase in revenues from changing conferences, failing to relieve the university of any subsidization to the athletics department (Hoffer and Pincin, 2015). These improved academic outcomes may be specific to this conference switching cluster. To assess the external validity we check the 2011/12/13 realignment cluster using the same method. 
Patrick A. Reilly Chapter 4. Big-Time Sports and University Outcomes

\section{1/12/13 Realignment Cluster}

The 2011/12/13 conference changes we focus on are really just a part of a larger mass of conference changes. We select those conference switches that are most certainly improvements, namely, programs moving from non-power 5 to power 5 conferences. We include those universities changing football conferences from the Big East Conference to the Atlantic Coast Conference and to the Big 12 Conference and also universities changing from the Mountain West Conference to the Pac 12 Conference and to the Big 12 Conference. The universities changing conferences are: Utah, TCU, WVU, Syracuse, and Pittsburgh. We do not include movements of Big 12 universities to Power 5 conferences because these were lateral movements from one Power 5 conference to another.

For these conference changes we do not estimate positive impacts. Rather, we find imprecise positive estimates on Applicants, Acceptance Rate, Graduation Rate, and Retention Rate in Table 4.20. Mainly imprecise, mostly negative effects to test scores in Tables 4.21 and 4.22. Table 4.23 presents imprecise estimates for all but State Appropriations. Our estimates suggest conference change reduces State Appropriations. In specifications estimating expenditures on research and instruction (Table 4.24), we find conference changes positively affected research salaries and instructional spending at the $10 \%$ alpha level.

We expect imprecise estimates, especially for graduation rates of previous cohorts, because many of these variables will act with a slight lag and we only observe university characteristics for three or four years after the conference changes. However, these results suggest we should reject the external validity of our results from the 2004/05 cluster. The 2011/12/13 conference changes we focused on were certainly improvements for the switchers and we did not find positive results as we did in the 2004/05 conference changes above. It could be that some of these realignments, most notably Syracuse and Pittsburgh, were out of necessity rather than desire. Additionally, there could be saturation in the Power 5 Conferences. With all of the conference expansion, being part of a big-time football conference may not result in as much increase in prestige or popularity than it did during the 2004/05 conference changes. Whatever the case, we do not claim the results from 2004/05 realignment would hold for other conference changes. 
Patrick A. Reilly Chapter 4. Big-Time Sports and University Outcomes

\subsection{Conclusion}

To defend the subsidization of big-time sports programs in the United States, advocates refer to the revenue creation and advertising benefits of successful university athletics programs. But this cannot be a one-size-fits-all argument for subsidies because each team's success is built on other teams' failures. However, subsidization of athletics might prove useful to university academics in general if universities not only benefit through success, but also through simply vying against big-time sports programs on the field. We test this by modeling how conference changes in FBS football affect university academic outcomes. Not only does this empirical strategy test whether participation in big-time college sports affects academic outcomes, it also avoids identification issues met by previous research focusing on the impact of athletic success on university outcomes.

We find that conference changes have mostly insignificant or negative effects on academic outcomes. In our full model, conference changes, even switching to power 5 conferences, reduce the number applications and test scores of incoming students. We do provide evidence that universities switching to higher tiered conferences in the 2004/05 realignment cluster improved some academic outcomes. However, similar switches in a later time period had few precisely estimated effects. In sum, although there may be evidence of improved outcomes for changes to big-time conferences, the aftershocks caused by these first movers likely have negative academic impacts for NCAA D1-FBS football programs as a whole. 
Patrick A. Reilly

\section{Figures and Tables}

Figure 4.1: Conference Changes by Year, First Time Switchers

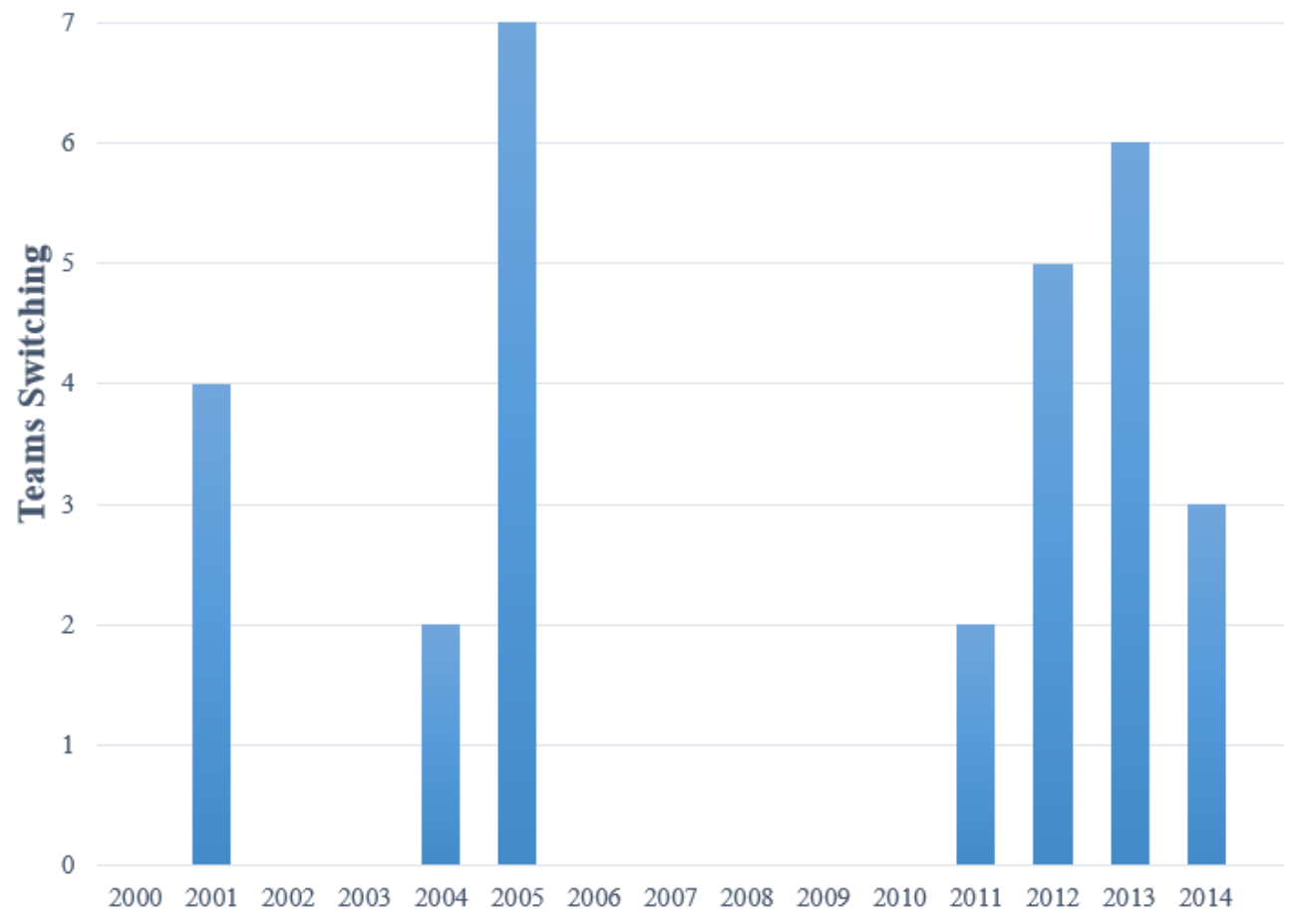


Patrick A. Reilly Chapter 4. Big-Time Sports and University Outcomes

Table 4.1: Summary Statistics, Full Sample

\begin{tabular}{|c|c|c|c|c|c|}
\hline & Mean & St. Dev. & Min & $\operatorname{Max}$ & Obs \\
\hline Conference Change & 0.21 & 0.41 & 0 & 1 & 1552 \\
\hline Conference Change Power 5 & 0.05 & 0.22 & 0 & 1 & 1552 \\
\hline State Appropriations & 8938 & 4314 & 28 & 24222 & 1064 \\
\hline State \& Local Grants \& Contracts & 10463 & 6972 & 30 & 33820 & 1250 \\
\hline Private Gifts Grants \& Contracts & 4410 & 8283 & 0 & 66357 & 1207 \\
\hline Federal Grants \& Contracts & 8599 & 9458 & 356 & 69382 & 1261 \\
\hline Total Research & 8739 & 9427 & 0.02 & 67233 & 1247 \\
\hline Research Salaries \& Wages & 4240 & 4369 & 0.18 & 30890 & 1242 \\
\hline Instructional Expenditures & 14428 & 11069 & 3567 & 89588 & 1261 \\
\hline Instructional Salaries \& Wages & 9033 & 6229 & 513 & 50456 & 1260 \\
\hline Enrollment (1000s) & 23.19 & 12.00 & 3.36 & 74.11 & 1551 \\
\hline Applicants & 16866 & 10262 & 2077 & 86537 & 1240 \\
\hline Acceptance Rate & 63.4 & 20.3 & 5.1 & 99.2 & 1240 \\
\hline Graduation Rate & 65.9 & 15.2 & 30.0 & 96.5 & 1358 \\
\hline Retention Rate & 84.9 & 7.9 & 62.0 & 99.0 & 1134 \\
\hline ACT Comp. 25 & 22.7 & 3.2 & 14 & 32 & 1192 \\
\hline ACT Comp. 75 & 27.8 & 2.8 & 22 & 34 & 1192 \\
\hline ACT English 25 & 21.9 & 3.4 & 14 & 33 & 1074 \\
\hline ACT English 75 & 28.2 & 3.1 & 21 & 35 & 1074 \\
\hline ACT Math 25 & 21.8 & 3.4 & 15 & 32 & 1075 \\
\hline ACT Math 75 & 27.8 & 3.0 & 22 & 35 & 1075 \\
\hline SAT Verbal 25 & 522 & 60.7 & 390 & 710 & 1200 \\
\hline SAT Verbal 75 & 632 & 54.8 & 480 & 780 & 1200 \\
\hline SAT Math 25 & 542 & 65.8 & 400 & 750 & 1200 \\
\hline SAT Math 75 & 653 & 57.8 & 520 & 800 & 1200 \\
\hline State Population (Mil) & 10.49 & 9.36 & 0.49 & 38.99 & 1552 \\
\hline State GDP/pop (1000) & 38.81 & 7.56 & 20.85 & 64.59 & 1552 \\
\hline County Income/pop (1000s) & 32.33 & 10.80 & 13.01 & 85.35 & 1552 \\
\hline State Unemployment Rate & 6.30 & 2.06 & 2.30 & 13.70 & 1552 \\
\hline
\end{tabular}

Notes:Data from 2000 to 2015. Omits Texas, UTEP, University of New Mexico and New Mexico State and service academies (US Air Force Academy, US Naval Academy, and US Military Academy). ACT scores, SAT scores, and Graduation Rate data not available until 2002. Applicants data not available until 2003, and Retention Rate data not available until 2004. Revenue and expenditure data used starting in 2003 because of differences in reporting from public and private institutions. 
Table 4.2: PSM Treated and Control Pairs

\begin{tabular}{lll}
\hline Year & Switcher & Match \\
\hline 2004 & University of Miami (FL) & Arizona State University \\
2004 & Virginia Tech & University of Washington \\
2005 & Boston College & Colorado State University \\
2011 & University of Colorado & University of Kansas \\
2011 & University of Utah & University of Wyoming \\
2011 & University of Nebraska & University of Oregon \\
2012 & West Virginia University & Texas Tech University \\
2012 & Texas A\&M University & Georgia Tech \\
2012 & University of Missouri & No Match \\
2012 & Texas Christian University & Wake Forest University \\
2013 & University of Pittsburgh & Brigham Young University \\
2013 & Syracuse University & Oklahoma State University \\
2014 & University of Louisville & University of Virginia \\
2014 & University of Maryland & University of Oklahoma \\
2014 & Rutgers University & No Match \\
\hline
\end{tabular}

Note: BYU's 2012 predicted logit was within the caliper of Missouri's, however, Pittsburgh matched with BYU at a higher predicted logit. Rutgers had no matches within the caliper of $0.2 \sigma^{2}$. 
Table 4.3: Admissions Outcomes and Conference Changes, Full Sample

\begin{tabular}{|c|c|c|c|c|}
\hline & $\begin{array}{c}(1) \\
\text { Applicants }\end{array}$ & $\begin{array}{c}(2) \\
\text { Applicants }\end{array}$ & $\begin{array}{c}(3) \\
\text { Acceptance Rate }\end{array}$ & $\begin{array}{c}(4) \\
\text { Acceptance Rate }\end{array}$ \\
\hline Conference Change & $\begin{array}{r}-2713.6^{* * *} \\
(691.9)\end{array}$ & & $\begin{array}{r}1.7 \\
(1.6)\end{array}$ & \\
\hline Conference Change Power 5 & & $\begin{array}{r}-1368.1^{*} \\
(713.9)\end{array}$ & & $\begin{array}{r}2.5 \\
(1.8)\end{array}$ \\
\hline State Population (Mil) & $\begin{array}{r}1587.3^{* * *} \\
(559.9)\end{array}$ & $\begin{array}{r}1527.0^{* *} \\
(584.6)\end{array}$ & $\begin{array}{r}-1.2 \\
(0.8)\end{array}$ & $\begin{array}{l}-1.1 \\
(0.8)\end{array}$ \\
\hline State RPCGDP (1000s) & $\begin{array}{r}109.6 \\
(112.1)\end{array}$ & $\begin{array}{r}95.5 \\
(111.7)\end{array}$ & $\begin{array}{r}0.4 \\
(0.2)\end{array}$ & $\begin{array}{r}0.4 \\
(0.2)\end{array}$ \\
\hline Cty RPC Inc (1000s) & $\begin{array}{r}199.3^{* *} \\
(86.3)\end{array}$ & $\begin{array}{l}172.6^{*} \\
(92.0)\end{array}$ & $\begin{array}{r}-0.3 \\
(0.2)\end{array}$ & $\begin{array}{r}-0.2 \\
(0.2)\end{array}$ \\
\hline State Unemployment Rate & $\begin{array}{r}83.1 \\
(251.5)\end{array}$ & $\begin{array}{r}54.5 \\
(257.9)\end{array}$ & $\begin{array}{l}1.0^{*} \\
(0.5)\end{array}$ & $\begin{array}{l}1.0^{*} \\
(0.5)\end{array}$ \\
\hline Year & $\begin{array}{r}297.3^{*} \\
(172.4) \\
\end{array}$ & $\begin{array}{r}325.2^{*} \\
(176.8) \\
\end{array}$ & $\begin{array}{r}-0.5 \\
(0.4) \\
\end{array}$ & $\begin{array}{l}-0.5 \\
(0.4) \\
\end{array}$ \\
\hline University FE & Yes & Yes & Yes & Yes \\
\hline Year FE & Yes & Yes & Yes & Yes \\
\hline Years & $2003-2015$ & $2003-2015$ & $2003-2015$ & $2003-2015$ \\
\hline Observations & 1240 & 1240 & 1240 & 1240 \\
\hline
\end{tabular}

Note: ${ }^{*} p<0.1,{ }^{* *} p<0.05,{ }^{* * *} p<0.01$. Robust standard errors in parentheses. Service academies omitted. The University of Texas and New Mexico University Systems omitted as they have multiple FBS teams. Coefficient estimates in the Conference Change row represent the ATE of a move to any conference. Estimates in the Conference Change Power 5 row represent the ATE of a move to a Power 5 conference (ACC, Big 10, Big 12, Pac 12, or SEC). 
Table 4.4: Graduation and Retention Rates and Conference Changes, Full Sample

\begin{tabular}{|c|c|c|c|c|}
\hline & $\begin{array}{c}(1) \\
\text { Graduation } \\
\text { Rate }\end{array}$ & $\begin{array}{c}(2) \\
\text { Graduation } \\
\text { Rate }\end{array}$ & $\begin{array}{c}(3) \\
\text { Retention } \\
\text { Rate }\end{array}$ & $\begin{array}{c}\quad(4) \\
\text { Retention } \\
\text { Rate }\end{array}$ \\
\hline Conference Change & $\begin{array}{r}1.2 \\
(0.8)\end{array}$ & & $\begin{array}{r}0.3 \\
(0.5)\end{array}$ & \\
\hline Conference Change Power 5 & & $\begin{array}{r}0.4 \\
(0.9)\end{array}$ & & $\begin{array}{r}0.3 \\
(0.8)\end{array}$ \\
\hline State Population (Mil) & $\begin{array}{r}0.6 \\
(0.4)\end{array}$ & $\begin{array}{r}0.6 \\
(0.4)\end{array}$ & $\begin{array}{r}0.2 \\
(0.3)\end{array}$ & $\begin{array}{r}0.2 \\
(0.3)\end{array}$ \\
\hline State RPCGDP (1000s) & $\begin{array}{l}-0.2^{*} \\
(0.1)\end{array}$ & $\begin{array}{c}-0.2^{*} \\
(0.1)\end{array}$ & $\begin{array}{r}-0.2^{* * *} \\
(0.1)\end{array}$ & $\begin{array}{r}-0.2^{* * *} \\
(0.1)\end{array}$ \\
\hline Cty RPC Inc (1000s) & $\begin{array}{l}0.2^{* *} \\
(0.1)\end{array}$ & $\begin{array}{l}0.2^{* *} \\
(0.1)\end{array}$ & $\begin{array}{r}0.1 \\
(0.1)\end{array}$ & $\begin{array}{r}0.1 \\
(0.1)\end{array}$ \\
\hline State Unemployment Rate & $\begin{array}{r}0.0 \\
(0.2)\end{array}$ & $\begin{array}{r}0.0 \\
(0.2)\end{array}$ & $\begin{array}{l}-0.3^{*} \\
(0.1)\end{array}$ & $\begin{array}{l}-0.3^{*} \\
(0.1)\end{array}$ \\
\hline Enrollment & $\begin{array}{r}0.3^{* * *} \\
(0.1)\end{array}$ & $\begin{array}{r}0.3^{* * *} \\
(0.1)\end{array}$ & $\begin{array}{r}0.2 \\
(0.1)\end{array}$ & $\begin{array}{r}0.2 \\
(0.1)\end{array}$ \\
\hline Year & $\begin{array}{c}0.4^{* *} \\
(02)\end{array}$ & $\begin{array}{r}03^{*} \\
(0.2)\end{array}$ & $\begin{array}{r}0.3^{* * *} \\
(0.1)\end{array}$ & $\begin{array}{r}0.3^{* * *} \\
(0.1)\end{array}$ \\
\hline University Fixed Effects & Yes & Yes & Yes & Yes \\
\hline Year Fixed Effects & Yes & Yes & Yes & Yes \\
\hline Years & $2002-2015$ & $2002-2015$ & $2002-2015$ & $2002-2015$ \\
\hline Observations & 1357 & 1357 & 1134 & 1134 \\
\hline
\end{tabular}

Note: ${ }^{*} p<0.1,{ }^{* *} p<0.05,{ }^{* * *} p<0.01$. Robust standard errors in parentheses. Service academies omitted. The University of Texas and New Mexico University Systems omitted as they have multiple FBS teams. Coefficient estimates in the Conference Change row represent the ATE of a move to any conference. Estimates in the Conference Change Power 5 row represent the ATE of a move to a Power 5 conference (ACC, Big 10, Big 12, Pac 12, or SEC). 
Table 4.5: ACT Composite Scores and Conference Changes, Full Sample

\begin{tabular}{lrrrr}
\hline & \multicolumn{1}{c}{$(1)$} & \multicolumn{1}{c}{$(2)$} & \multicolumn{1}{c}{$(3)$} & $(4)$ \\
& Q1 & \multicolumn{1}{c}{ Q1 } & \multicolumn{1}{c}{ Q3 } & \multicolumn{1}{c}{ Q3 } \\
\hline Conference Change & -0.143 & & -0.027 & \\
& $(0.200)$ & & $(0.179)$ & \\
Conference Change Power 5 & & -0.357 & & -0.283 \\
& & $(0.232)$ & & $(0.183)$ \\
State Population (Mil) & $0.211^{* *}$ & $0.215^{* * *}$ & $0.170^{* *}$ & $0.173^{* *}$ \\
& $(0.082)$ & $(0.081)$ & $(0.070)$ & $(0.070)$ \\
State RPCGDP (1000s) & $-0.074^{* *}$ & $-0.071^{* *}$ & $-0.042^{* *}$ & $-0.038^{*}$ \\
& $(0.031)$ & $(0.031)$ & $(0.021)$ & $(0.021)$ \\
Cty RPC Inc (1000s) & $0.080^{* * *}$ & $0.078^{* * *}$ & $0.032^{*}$ & $0.031^{*}$ \\
& $(0.019)$ & $(0.019)$ & $(0.018)$ & $(0.018)$ \\
State Unemployment Rate & -0.019 & -0.020 & $-0.059^{*}$ & $-0.058^{*}$ \\
& $(0.041)$ & $(0.040)$ & $(0.034)$ & $(0.034)$ \\
Enrollment & 0.021 & 0.023 & 0.049 & $0.051^{*}$ \\
Year & $(0.027)$ & $(0.027)$ & $(0.031)$ & $(0.031)$ \\
& $0.063^{*}$ & $0.063^{*}$ & $0.091^{* *}$ & $0.090^{* *}$ \\
& $(0.038)$ & $(0.038)$ & $(0.038)$ & $(0.038)$ \\
\hline University Fixed Effects & Yes & Yes & Yes & Yes \\
Year Fixed Effects & Yes & Yes & Yes & Yes \\
Year & $2002-2015$ & $2002-2015$ & $2002-2015$ & $2002-2015$ \\
Observations & 1191 & 1191 & 1191 & 1191 \\
\hline
\end{tabular}

Note: ${ }^{*} p<0.1,{ }^{* *} p<0.05,{ }^{* * *} p<0.01$. Robust standard errors in parentheses. Service academies omitted. The University of Texas and New Mexico University Systems omitted as they have multiple FBS teams. Coefficient estimates in the Conference Change row represent the ATE of a move to any conference. Estimates in the Conference Change Power 5 row represent the ATE of a move to a Power 5 conference (ACC, Big 10, Big 12, Pac 12, or SEC). 
Table 4.6: ACT Verbal Scores and Conference Changes, Full Sample

\begin{tabular}{lrrrr}
\hline & \multicolumn{1}{c}{$(1)$} & \multicolumn{1}{c}{$(2)$} & \multicolumn{1}{c}{$(3)$} & \multicolumn{1}{c}{$(4)$} \\
& \multicolumn{1}{c}{$\mathrm{Q} 1$} & \multicolumn{1}{c}{$\mathrm{Q} 1$} & \multicolumn{1}{c}{$\mathrm{Q} 3$} & \multicolumn{1}{c}{ Q3 } \\
\hline Conference Change & -0.303 & & -0.205 & \\
& $(0.222)$ & & $(0.260)$ & -0.360 \\
Conference Change Power 5 & & $-0.593^{* *}$ & & $(0.364)$ \\
& & $(0.241)$ & & $0.211^{*}$ \\
State Population (Mil) & $0.325^{* * *}$ & $0.316^{* * *}$ & $0.217^{*}$ & $(0.121)$ \\
& $(0.118)$ & $(0.116)$ & $(0.123)$ & $-0.065^{* *}$ \\
State RPCGDP (1000s) & $-0.095^{* * *}$ & $-0.092^{* * *}$ & $-0.067^{* *}$ & $(0.030)$ \\
& $(0.033)$ & $(0.033)$ & $(0.029)$ & 0.032 \\
Cty RPC Inc (1000s) & $0.094^{* * *}$ & $0.091^{* * *}$ & 0.034 & $(0.021)$ \\
& $(0.023)$ & $(0.023)$ & $(0.021)$ & -0.040 \\
State Unemployment Rate & -0.052 & -0.055 & -0.038 & $(0.044)$ \\
& $(0.046)$ & $(0.045)$ & $(0.044)$ & 0.023 \\
Enrollment & 0.015 & 0.020 & 0.021 & $(0.035)$ \\
Year & $(0.027)$ & $(0.027)$ & $(0.035)$ & $0.177^{* * *}$ \\
& $0.093^{*}$ & $0.094^{*}$ & $0.176^{* * *}$ & $(0.048)$ \\
\hline University Fixed Effects & $(0.049)$ & $(0.050)$ & $(0.048)$ & Yes \\
Year Fixed Effects & Yes & Yes & Yes & Yes \\
Years & Yes & Yes & Yes & 1073 \\
Observations & $2002-2015$ & $2002-2015$ & $2002-2015$ & $2002-2015$ \\
\hline
\end{tabular}

Note: ${ }^{*} p<0.1,{ }^{* *} p<0.05,{ }^{* * *} p<0.01$. Robust standard errors in parentheses. Service academies omitted. The University of Texas and New Mexico University Systems omitted as they have multiple FBS teams. Coefficient estimates in the Conference Change row represent the ATE of a move to any conference. Estimates in the Conference Change Power 5 row represent the ATE of a move to a Power 5 conference (ACC, Big 10, Big 12, Pac 12, or SEC). 
Table 4.7: ACT Math Scores and Conference Changes, Full Smaple

\begin{tabular}{lrrrr}
\hline & \multicolumn{1}{c}{$(1)$} & \multicolumn{1}{c}{$(2)$} & \multicolumn{1}{c}{$(3)$} & $(4)$ \\
& Q1 & \multicolumn{1}{c}{ Q1 } & \multicolumn{1}{c}{ Q3 } & \multicolumn{1}{c}{ Q3 } \\
\hline Conference Change & 0.049 & & -0.054 & \\
& $(0.209)$ & & $(0.174)$ & \\
Conference Change Power 5 & & $-0.316^{*}$ & & -0.184 \\
& & $(0.184)$ & & $(0.203)$ \\
State Population (Mil) & $0.223^{* *}$ & $0.222^{* *}$ & $0.245^{* * *}$ & $0.243^{* * *}$ \\
& $(0.096)$ & $(0.094)$ & $(0.082)$ & $(0.082)$ \\
State RPCGDP (1000s) & -0.019 & -0.016 & -0.038 & -0.037 \\
& $(0.029)$ & $(0.029)$ & $(0.025)$ & $(0.025)$ \\
Cty RPC Inc (1000s) & $0.055^{* * *}$ & $0.056^{* * *}$ & $0.039^{* *}$ & $0.038^{* *}$ \\
& $(0.019)$ & $(0.019)$ & $(0.018)$ & $(0.017)$ \\
State Unemployment Rate & -0.066 & -0.065 & -0.053 & -0.054 \\
& $(0.041)$ & $(0.040)$ & $(0.042)$ & $(0.042)$ \\
Enrollment & $0.070^{* *}$ & $0.074^{* *}$ & 0.008 & 0.009 \\
Year & $(0.030)$ & $(0.031)$ & $(0.029)$ & $(0.028)$ \\
& 0.022 & 0.020 & $0.067^{*}$ & $0.067^{*}$ \\
& $(0.044)$ & $(0.045)$ & $(0.039)$ & $(0.039)$ \\
\hline University Fixed Effects & Yes & Yes & Yes & Yes \\
Year Fixed Effects & Yes & Yes & Yes & Yes \\
Years & $2002-2015$ & $2002-2015$ & $2002-2015$ & $2002-2015$ \\
Observations & 1074 & 1074 & 1074 & 1074 \\
\hline
\end{tabular}

Note: ${ }^{*} p<0.1,{ }^{* *} p<0.05,{ }^{* * *} p<0.01$. Robust standard errors in parentheses. Service academies omitted. The University of Texas and New Mexico University Systems omitted as they have multiple FBS teams. Coefficient estimates in the Conference Change row represent the ATE of a move to any conference. Estimates in the Conference Change Power 5 row represent the ATE of a move to a Power 5 conference (ACC, Big 10, Big 12, Pac 12, or SEC). 
Table 4.8: SAT Critical Reading Scores and Conference Changes, Full Smaple

\begin{tabular}{lrrrr}
\hline & $(1)$ & $(2)$ & $(3)$ & $(4)$ \\
& Q1 & Q1 & Q3 & Q3 \\
\hline Conference Change & -1.5 & & -0.2 & \\
& $(3.1)$ & & $(2.7)$ & \\
Conference Change Power 5 & & -4.4 & & -2.7 \\
& & $(3.3)$ & & $(3.0)$ \\
State Population (Mil) & $4.7^{* * *}$ & $4.7^{* * *}$ & $3.0^{* *}$ & $3.0^{* *}$ \\
& $(1.5)$ & $(1.5)$ & $(1.4)$ & $(1.4)$ \\
State RPCGDP (1000s) & $-1.2^{* *}$ & $-1.1^{* *}$ & $-0.9^{*}$ & $-0.8^{*}$ \\
& $(0.5)$ & $(0.5)$ & $(0.5)$ & $(0.5)$ \\
Cty RPC Inc (1000s) & $0.9^{* * *}$ & $0.9^{* * *}$ & $0.8^{* * *}$ & $0.8^{* * *}$ \\
& $(0.3)$ & $(0.3)$ & $(0.3)$ & $(0.3)$ \\
State Unemployment Rate & 0.4 & 0.4 & -0.9 & -0.9 \\
& $(0.9)$ & $(0.9)$ & $(0.8)$ & $(0.8)$ \\
Enrollment & -0.5 & -0.5 & 0.0 & 0.0 \\
Year & $(0.435)$ & $(0.428)$ & $(0.4)$ & $(0.4)$ \\
& 0.6 & 0.6 & 0.3 & 0.3 \\
University Fixed Effects & $(0.7)$ & $(0.8)$ & $(0.7)$ & $(0.7)$ \\
Year Fixed Effects & Yes & Yes & Yes & Yes \\
Years & Yes & Yes & Yes & Yes \\
Observations & $2002-2015$ & $2002-2015$ & $2002-2015$ & $2002-2015$ \\
\hline
\end{tabular}

Note: $* p<0.1,{ }^{* *} p<0.05,{ }^{* * *} p<0.01$. Robust standard errors in parentheses. Service academies omitted. The University of Texas and New Mexico University Systems omitted as they have multiple FBS teams. Coefficient estimates in the Conference Change row represent the ATE of a move to any conference. Estimates in the Conference Change Power 5 row represent the ATE of a move to a Power 5 conference (ACC, Big 10, Big 12, Pac 12, or SEC). 
Table 4.9: SAT Math Scores and Conference Changes, Full Smaple

\begin{tabular}{lrrrr}
\hline & $(1)$ & $(2)$ & $(3)$ & $(4)$ \\
& Q1 & Q1 & Q3 & Q3 \\
\hline Conference Change & -3.0 & & -2.2 & \\
& $(3.8)$ & & $(3.2)$ & \\
Conference Change Power 5 & & -4.1 & & -2.7 \\
& & $(4.0)$ & & $(3.5)$ \\
State Population (Mil) & 2.3 & 2.2 & 1.1 & 1.0 \\
& $(1.7)$ & $(1.7)$ & $(1.5)$ & $(1.5)$ \\
State RPCGDP (1000s) & $-1.2^{* *}$ & $-1.2^{* *}$ & -0.6 & -0.6 \\
& $(0.6)$ & $(0.6)$ & $(0.5)$ & $(0.5)$ \\
Cty RPC Inc (1000s) & $0.8^{* *}$ & $0.8^{* *}$ & $0.8^{* *}$ & $0.8^{* *}$ \\
& $(0.3)$ & $(0.3)$ & $(0.3)$ & $(0.3)$ \\
State Unemployment Rate & $-1.8^{* *}$ & $-1.8^{* *}$ & $-1.7^{* *}$ & $-1.7^{* *}$ \\
& $(0.8)$ & $(0.8)$ & $(0.7)$ & $(0.7)$ \\
Enrollment & 0.1 & 0.1 & 0.5 & 0.5 \\
Year & $(0.5)$ & $(0.5)$ & $(0.5)$ & $(0.5)$ \\
& $1.3^{*}$ & $1.3^{*}$ & 0.6 & 0.7 \\
University Fixed Effects & $(0.7)$ & $(0.7)$ & $(0.8)$ & $(0.8)$ \\
Year Fixed Effects & Yes & Yes & Yes & Yes \\
Years & Yes & Yes & Yes & Yes \\
Observations & $2002-2015$ & $2002-2015$ & $2002-2015$ & $2002-2015$ \\
\hline
\end{tabular}

Note: ${ }^{*} p<0.1,{ }^{* *} p<0.05,{ }^{* * *} p<0.01$. Robust standard errors in parentheses. Service academies omitted. The University of Texas and New Mexico University Systems omitted as they have multiple FBS teams. Coefficient estimates in the Conference Change row represent the ATE of a move to any conference. Estimates in the Conference Change Power 5 row represent the ATE of a move to a Power 5 conference (ACC, Big 10, Big 12, Pac 12, or SEC). 
Table 4.10: Instructional Expenditures and Conference Changes, Full Smaple

\begin{tabular}{|c|c|c|c|c|}
\hline & $\begin{array}{c}(1) \\
\text { Total }\end{array}$ & $\begin{array}{c}(2) \\
\text { Total }\end{array}$ & $\begin{array}{c}(3) \\
\text { Salaries } \\
\text { and Wages }\end{array}$ & $\begin{array}{c}(4) \\
\text { Salaries } \\
\text { and Wages }\end{array}$ \\
\hline Conference Change & $\begin{array}{r}-1093^{*} \\
(623)\end{array}$ & & $\begin{array}{c}-404 \\
(291)\end{array}$ & \\
\hline Conference Change Power 5 & & $\begin{array}{r}-351 \\
(450)\end{array}$ & & $\begin{array}{r}32 \\
(229)\end{array}$ \\
\hline State Population (Mil) & $\begin{array}{r}390 \\
(312)\end{array}$ & $\begin{array}{r}367 \\
(311)\end{array}$ & $\begin{array}{r}199 \\
(162)\end{array}$ & $\begin{array}{r}192 \\
(161)\end{array}$ \\
\hline State RPCGDP (1000s) & $\begin{array}{r}-8 \\
(72)\end{array}$ & $\begin{array}{r}-17 \\
(73)\end{array}$ & $\begin{array}{r}-26 \\
(48)\end{array}$ & $\begin{array}{r}-32 \\
(49)\end{array}$ \\
\hline Cty RPC Inc(1000s) & $\begin{array}{r}225 \\
(144)\end{array}$ & $\begin{array}{r}214 \\
(144)\end{array}$ & $\begin{array}{r}87 \\
(52)\end{array}$ & $\begin{array}{r}83 \\
(52)\end{array}$ \\
\hline State Unemployment Rate & $\begin{array}{r}321^{* * *} \\
(121)\end{array}$ & $\begin{array}{l}308^{* *} \\
(119)\end{array}$ & $\begin{array}{r}94 \\
(71)\end{array}$ & $\begin{array}{r}87 \\
(70)\end{array}$ \\
\hline Enrollment & $\begin{array}{r}-66 \\
(58)\end{array}$ & $\begin{array}{r}-73 \\
(59)\end{array}$ & $\begin{array}{r}-93^{* *} \\
(39)\end{array}$ & $\begin{array}{r}-98^{* *} \\
(39)\end{array}$ \\
\hline Year & $\begin{array}{r}-135 \\
(218) \\
\end{array}$ & $\begin{array}{r}-119 \\
(219) \\
\end{array}$ & $\begin{array}{r}-5 \\
(83) \\
\end{array}$ & $\begin{array}{r}2 \\
(84) \\
\end{array}$ \\
\hline University Fixed Effects & Yes & Yes & Yes & Yes \\
\hline Year Fixed Effects & Yes & Yes & Yes & Yes \\
\hline Years & $2003-2015$ & $2003-2015$ & $2003-2015$ & $2003-2015$ \\
\hline Observations & 1260 & 1260 & 1259 & 1259 \\
\hline
\end{tabular}

Note: ${ }^{*} p<0.1,{ }^{* *} p<0.05,{ }^{* * *} p<0.01$. Robust standard errors in parentheses. Service academies omitted. The University of Texas and New Mexico University Systems omitted as they have multiple FBS teams. Coefficient estimates in the Conference Change row represent the ATE of a move to any conference. Estimates in the Conference Change Power 5 row represent the ATE of a move to a Power 5 conference (ACC, Big 10, Big 12, Pac 12, or SEC). 
Table 4.11: Research Expenditures and Conference Changes, Full Smaple

\begin{tabular}{|c|c|c|c|c|}
\hline & $\begin{array}{c}(1) \\
\text { Total }\end{array}$ & $\begin{array}{c}(2) \\
\text { Total }\end{array}$ & $\begin{array}{c}(3) \\
\text { Salaries }\end{array}$ & $\begin{array}{c}(4) \\
\text { Salaries }\end{array}$ \\
\hline Conference Change & $\begin{array}{r}30 \\
(289)\end{array}$ & & $\begin{array}{r}67 \\
(147)\end{array}$ & \\
\hline Conference Change Power 5 & & $\begin{array}{r}341 \\
(339)\end{array}$ & & $\begin{array}{l}295^{* *} \\
(138)\end{array}$ \\
\hline State Population (Mil) & $\begin{array}{c}237^{*} \\
(142)\end{array}$ & $\begin{array}{c}239^{*} \\
(140)\end{array}$ & $\begin{array}{r}85 \\
(71)\end{array}$ & $\begin{array}{r}87 \\
(71)\end{array}$ \\
\hline State RPCGDP (1000s) & $\begin{array}{r}-23 \\
(49)\end{array}$ & $\begin{array}{r}-29 \\
(49)\end{array}$ & $\begin{array}{r}-5 \\
(18)\end{array}$ & $\begin{array}{r}-9 \\
(18)\end{array}$ \\
\hline Cty RPC Inc (1000s) & $\begin{array}{l}82^{* *} \\
(40)\end{array}$ & $\begin{array}{l}82^{* *} \\
(39)\end{array}$ & $\begin{array}{r}36 \\
(31)\end{array}$ & $\begin{array}{r}37 \\
(31)\end{array}$ \\
\hline State Unemployment Rate & $\begin{array}{r}5 \\
(72)\end{array}$ & $\begin{array}{r}1 \\
(73)\end{array}$ & $\begin{array}{c}-11 \\
(25)\end{array}$ & $\begin{array}{c}-14 \\
(25)\end{array}$ \\
\hline Enrollment & $\begin{array}{r}-87^{* *} \\
(43)\end{array}$ & $\begin{array}{c}-91^{* *} \\
(43)\end{array}$ & $\begin{array}{r}-56^{* *} \\
(24)\end{array}$ & $\begin{array}{r}-59^{* *} \\
(24)\end{array}$ \\
\hline Year & $\begin{array}{r}-50 \\
(68)\end{array}$ & $\begin{array}{r}-46 \\
(68)\end{array}$ & $\begin{array}{r}-40 \\
(50)\end{array}$ & $\begin{array}{r}-37 \\
(49)\end{array}$ \\
\hline University Fixed Effects & Yes & Yes & Yes & Yes \\
\hline Year Fixed Effects & Yes & Yes & Yes & Yes \\
\hline Years & $2003-2015$ & $2003-2015$ & $2003-2015$ & $2003-2015$ \\
\hline Observations & 1246 & 1246 & 1241 & 1241 \\
\hline
\end{tabular}

Note: ${ }^{*} p<0.1,{ }^{* *} p<0.05,{ }^{* * *} p<0.01$. Robust standard errors in parentheses. Service academies omitted. Coefficient estimates in the Conference Change row represent the ATE of a move to any conference. Estimates in the Conference Change Power 5 row represent the ATE of a move to a Power 5 conference (ACC, Big 10, Big 12, Pac 12, or SEC). 
Table 4.12: State and Local Funding and Conference Changes, Full Smaple

\begin{tabular}{|c|c|c|c|c|}
\hline & $\begin{array}{c}(1) \\
\text { State }\end{array}$ & $\begin{array}{c}(2) \\
\text { State }\end{array}$ & $\begin{array}{c}(3) \\
\text { State \& Local }\end{array}$ & $\begin{array}{c}(4) \\
\text { State \& Local }\end{array}$ \\
\hline Conference Change & $\begin{array}{c}576^{*} \\
(343)\end{array}$ & & $\begin{array}{r}426 \\
(361)\end{array}$ & \\
\hline Conference Change Power 5 & & $\begin{array}{l}722^{* *} \\
(338)\end{array}$ & & $\begin{array}{r}819^{*} \\
(471)\end{array}$ \\
\hline State Population (Mil) & $\begin{array}{r}-314 \\
(299)\end{array}$ & $\begin{array}{r}-306 \\
(301)\end{array}$ & $\begin{array}{r}123 \\
(223)\end{array}$ & $\begin{array}{r}152 \\
(216)\end{array}$ \\
\hline State RPCGDP (1000s) & $\begin{array}{r}146^{* *} \\
(67)\end{array}$ & $\begin{array}{r}146^{* *} \\
(66)\end{array}$ & $\begin{array}{r}73 \\
(74)\end{array}$ & $\begin{array}{r}66 \\
(74)\end{array}$ \\
\hline Cty RPC Inc (1000s) & $\begin{array}{r}-121^{* * *} \\
(44)\end{array}$ & $\begin{array}{r}-116^{* * *} \\
(44)\end{array}$ & $\begin{array}{l}-13 \\
(35)\end{array}$ & $\begin{array}{r}-9 \\
(33)\end{array}$ \\
\hline State U- Rate & $\begin{array}{r}-147 \\
(108)\end{array}$ & $\begin{array}{r}-140 \\
(105)\end{array}$ & $\begin{array}{r}-127 \\
(90)\end{array}$ & $\begin{array}{r}-133 \\
(89)\end{array}$ \\
\hline Total Enrollment (1000s) & $\begin{array}{r}-179^{* * *} \\
(60)\end{array}$ & $\begin{array}{r}-181^{* * *} \\
(60)\end{array}$ & $\begin{array}{r}-236^{* * *} \\
(64)\end{array}$ & $\begin{array}{r}-242^{\text {*** }} \\
(63)\end{array}$ \\
\hline Year & $\begin{array}{r}-140 \\
(103)\end{array}$ & $\begin{array}{r}-146 \\
(103)\end{array}$ & $\begin{array}{r}-175^{*} \\
(92)\end{array}$ & $\begin{array}{r}-176^{*} \\
(90)\end{array}$ \\
\hline University Fixed Effects & Yes & Yes & Yes & Yes \\
\hline Year Fixed Effects & Yes & Yes & Yes & Yes \\
\hline Years & $2003-2015$ & $2003-2015$ & $2003-2015$ & $2003-2015$ \\
\hline Observations & 972 & 972 & 1249 & 1249 \\
\hline
\end{tabular}

Note: ${ }^{*} p<0.1,{ }^{* *} p<0.05,{ }^{* * *} p<0.01$. Robust standard errors in parentheses. Service academies omitted. The University of Texas and New Mexico University Systems omitted as they have multiple FBS teams. Coefficient estimates in the Conference Change row represent the ATE of a move to any conference. Estimates in the Conference Change Power 5 row represent the ATE of a move to a Power 5 conference (ACC, Big 10, Big 12, Pac 12, or SEC). 
Table 4.13: Private and Federal Funding and Conference Changes, Full Smaple

\begin{tabular}{|c|c|c|c|c|}
\hline & $\begin{array}{c}(1) \\
\text { Private }\end{array}$ & $\begin{array}{c}(2) \\
\text { Private }\end{array}$ & $\begin{array}{c}(3) \\
\text { Federal }\end{array}$ & $\begin{array}{c}(4) \\
\text { Federal }\end{array}$ \\
\hline Conference Change & $\begin{array}{r}-356 \\
(446)\end{array}$ & & $\begin{array}{r}126 \\
(281)\end{array}$ & \\
\hline Conference Change Power 5 & & $\begin{array}{r}-193 \\
(356)\end{array}$ & & $\begin{array}{r}141 \\
(252)\end{array}$ \\
\hline State Population (Mil) & $\begin{array}{l}535^{* *} \\
(212)\end{array}$ & $\begin{array}{l}527^{* *} \\
(215)\end{array}$ & $\begin{array}{r}-78 \\
(101)\end{array}$ & $\begin{array}{r}-75 \\
(102)\end{array}$ \\
\hline State RPCGDP (1000s) & $\begin{array}{r}-50 \\
(79)\end{array}$ & $\begin{array}{r}-51 \\
(79)\end{array}$ & $\begin{array}{r}-29 \\
(43)\end{array}$ & $\begin{array}{r}-30 \\
(43)\end{array}$ \\
\hline Cty RPC Inc (1000s) & $\begin{array}{c}208^{*} \\
(107)\end{array}$ & $\begin{array}{c}204^{*} \\
(106)\end{array}$ & $\begin{array}{r}22 \\
(31)\end{array}$ & $\begin{array}{r}23 \\
(29)\end{array}$ \\
\hline State Unemployment Rate & $\begin{array}{r}-75 \\
(133)\end{array}$ & $\begin{array}{r}-79 \\
(133)\end{array}$ & $\begin{array}{r}-38 \\
(75)\end{array}$ & $\begin{array}{r}-38 \\
(76)\end{array}$ \\
\hline Enrollment & $\begin{array}{r}-124^{* * *} \\
(45)\end{array}$ & $\begin{array}{r}-125^{* * *} \\
(46)\end{array}$ & $\begin{array}{l}-85^{*} \\
(44)\end{array}$ & $\begin{array}{l}-85^{*} \\
(45)\end{array}$ \\
\hline Year & $\begin{array}{r}-211 \\
(148)\end{array}$ & $\begin{array}{r}-207 \\
(148)\end{array}$ & $\begin{array}{r}21 \\
(66)\end{array}$ & $\begin{array}{r}20 \\
(65)\end{array}$ \\
\hline University Fixed Effects & Yes & Yes & Yes & Yes \\
\hline Year Fixed Effects & Yes & Yes & Yes & Yes \\
\hline Years & 2003-2015 & $2003-2015$ & $2003-2015$ & 2003-2015 \\
\hline Observations & 1206 & 1206 & 1260 & 1260 \\
\hline
\end{tabular}

Note: ${ }^{*} p<0.1,{ }^{* *} p<0.05,{ }^{* * *} p<0.01$. Robust standard errors in parentheses. Service academies omitted. The University of Texas and New Mexico University Systems omitted as they have multiple FBS teams. Private denotes private gifts, grants, and contracts. Federal is the amount of federal grants and contracts. All dependent variables are in 2014 dollars per FTE. Coefficient estimates in the Conference Change row represent the ATE of a move to any conference. Estimates in the Conference Change Power 5 row represent the ATE of a move to a Power 5 conference (ACC, Big 10, Big 12, Pac 12, or SEC). 
Table 4.14: Diff-in-Diff Estimates: Universities PS Matched on Switch Power 5

\begin{tabular}{lrlr}
\hline & Switch P5 & & Switch P5 \\
\hline Applications & 174.3 & Graduation Rate (\%) & 0.9 \\
& $(846.5)$ & & $(1.0)$ \\
Acceptance Rate (\%) & 1.3 & Retention Rate (\%) & 1.0 \\
& $(2.0)$ & & $(0.9)$ \\
State Appropriations & -114 & Total Research Spending & -34 \\
& $(417)$ & & $(441)$ \\
State and Local Grants and Contracts & -31 & Research Salaries & 159 \\
& $(440)$ & & $(206)$ \\
Private Gifts, Grants, and Contracts & 84 & Total Instructional Spending & 386 \\
& $(321)$ & & $(522)$ \\
Federal Grants and Contracts & 8 & Instructional Salaries & 220 \\
& $(457)$ & & $(201)$ \\
SAT Critical Reading Q1 & -1.1 & ACT Verbal Q1 & $-0.501^{*}$ \\
& $(2.6)$ & & $(0.289)$ \\
SAT Critical Reading Q3 & -1.5 & ACT Verbal Q3 & -0.167 \\
& $(2.9)$ & & $(0.413)$ \\
SAT Math Q1 & 0.5 & ACT Math Q1 & -0.266 \\
SAT Math Q3 & $(3.4)$ & & $(0.166)$ \\
& -1.1 & ACT Math Q3 & -0.107 \\
ACT Composite Q1 & $(3.0)$ & & $(0.211)$ \\
& -0.160 & ACT Composite Q3 & -0.166 \\
& $(0.253)$ & & $(0.170)$ \\
\hline
\end{tabular}

Note: ${ }^{*} p<0.1,{ }^{* *} p<0.05,{ }^{* * *} p<0.01$. Heteroskedasticity-robust standard errors in parenthesis. Each estimate represents a different model specification. PSM match based on logit estimation of treatment using averages of prior 5 years of bowl apperances, state population, state RPCGDP, state unemployment rate and university enrollment. 
Table 4.15: Applications, Retention, Graduation, and Conference Changes: 04/05 Cluster

\begin{tabular}{lrrrr}
\hline \hline & \multicolumn{1}{c}{$(1)$} & $(2)$ & $(3)$ & $(4)$ \\
& Applicants & Acceptance Rate & Graduation Rate & Retention Rate \\
\hline Conference Change & 193.2 & 3.2 & $5.4^{* * *}$ & $3.9^{* *}$ \\
& $(1277.3)$ & $(3.7)$ & $(1.0)$ & $(1.9)$ \\
State Population (Mil) & 363.5 & -0.7 & $1.0^{* * *}$ & 0.8 \\
State RPCGDP (1000s) & $(749.0)$ & $(1.7)$ & $(0.4)$ & $(0.6)$ \\
& -126.9 & 0.8 & $-0.5^{* * *}$ & -0.1 \\
Cty RPC Inc (1000s) & $(315.1)$ & $(0.5)$ & $(0.1)$ & $(0.2)$ \\
& -117.1 & -0.0 & $0.2^{* *}$ & -0.0 \\
State Unemployment Rate & $(213.8)$ & $(0.2)$ & $(0.1)$ & $(0.1)$ \\
& $-1779.7^{* * *}$ & $3.9^{* * *}$ & 0.3 & $-0.5^{*}$ \\
Enrollment (1000s) & $(606.1)$ & $(1.4)$ & $(0.3)$ & $(0.3)$ \\
Year & & & $0.6^{* * *}$ & -0.2 \\
& & & $(0.2)$ & $(0.4)$ \\
& $734.7^{* *}$ & -0.7 & $0.4^{* *}$ & $0.4^{* *}$ \\
University FE & $(364.7)$ & $(1.0)$ & $(0.2)$ & $(0.2)$ \\
Year FE & Yes & Yes & Yes & Yes \\
Years & Yes & Yes & Yes & Yes \\
Adj R-Squared & $2003-2015$ & $2003-2015$ & $2002-2015$ & $2004-2015$ \\
Observations & 0.861 & 0.784 & 0.982 & 0.894 \\
\hline
\end{tabular}

Note: ${ }^{*} p<0.1,{ }^{* *} p<0.05,{ }^{* * *} p<0.01$. Robust standard errors in parentheses. Models include data from all members of Conference USA and Big East in 2003. Coefficient estimates in the conference change row represent the ATE of a change from Conference USA or the Big East to a more prestigious conference (CUSA to BE and BE to ACC) in 2004 and 2005. Models omit observations from schools that left CUSA or the $\mathrm{BE}$ at other times or to different conferences. 
Patrick A. Reilly Chapter 4. Big-Time Sports and University Outcomes

Table 4.16: ACT Scores and Conference Changes: 04/05 Cluster

\begin{tabular}{lrrrrrr}
\hline & \multicolumn{2}{c}{ Composite } & \multicolumn{2}{c}{ Verbal } & \multicolumn{2}{c}{ Math } \\
& \multicolumn{1}{c}{ Q1 } & \multicolumn{1}{c}{ Q3 } & \multicolumn{1}{c}{ Q1 } & \multicolumn{1}{c}{ Q3 } & \multicolumn{1}{c}{ Q1 } \\
\hline Conference Change & $0.909^{* *}$ & $0.977^{* * *}$ & $1.399^{* * *}$ & $1.418^{* * *}$ & $1.556^{* * *}$ & $1.509^{* * *}$ \\
& $(0.380)$ & $(0.370)$ & $(0.469)$ & $(0.441)$ & $(0.361)$ & $(0.404)$ \\
State Population (Mil) & 0.254 & $0.286^{* *}$ & $0.542^{* * *}$ & $0.437^{* *}$ & $0.436^{* *}$ & $0.360^{* *}$ \\
& $(0.153)$ & $(0.140)$ & $(0.188)$ & $(0.182)$ & $(0.179)$ & $(0.155)$ \\
State RPCGDP (1000s) & -0.105 & -0.030 & -0.085 & -0.102 & $-0.274^{* * *}$ & -0.111 \\
& $(0.077)$ & $(0.061)$ & $(0.106)$ & $(0.077)$ & $(0.092)$ & $(0.073)$ \\
Cty RPC Inc (1000s) & 0.041 & 0.007 & 0.043 & 0.017 & $0.095^{*}$ & -0.051 \\
& $(0.052)$ & $(0.037)$ & $(0.080)$ & $(0.053)$ & $(0.057)$ & $(0.054)$ \\
State Unemployment Rate & 0.081 & 0.125 & 0.104 & 0.054 & -0.051 & -0.091 \\
& $(0.093)$ & $(0.098)$ & $(0.141)$ & $(0.151)$ & $(0.114)$ & $(0.132)$ \\
Enrollment (1000s) & $0.139^{* *}$ & $0.217^{* * *}$ & $0.180^{*}$ & -0.026 & $0.414^{* * *}$ & 0.066 \\
& $(0.068)$ & $(0.078)$ & $(0.104)$ & $(0.105)$ & $(0.095)$ & $(0.115)$ \\
Year & 0.110 & 0.022 & 0.013 & 0.101 & 0.042 & $0.322^{* *}$ \\
& $(0.074)$ & $(0.111)$ & $(0.139)$ & $(0.125)$ & $(0.106)$ & $(0.128)$ \\
\hline County FE & Yes & Yes & Yes & Yes & Yes & Yes \\
Year FE & Yes & Yes & Yes & Yes & Yes & Yes \\
Years & $2002-2015$ & $2002-2015$ & $2002-2015$ & $2002-2015$ & $2002-2015$ & $2002-2015$ \\
Adj R-Squared & 0.972 & 0.952 & 0.964 & 0.960 & 0.968 & 0.960 \\
Observations & 137 & 137 & 115 & 115 & 115 & 115 \\
\hline
\end{tabular}

Note: $* p<0.1,{ }^{* *} p<0.05,{ }^{* * *} p<0.01$. Robust standard errors in parentheses. Models include members of Conference USA and the Big East Conference in 2003. Coefficient estimates in the Conference Change row represent the ATE of a move from Conference USA or the Big East to a more prestigious conference (CUSA to BE and BE to ACC) in 2004 and 2005. Data from schools that left CUSA or the BE at other times or to different conferences omitted. 
Table 4.17: SAT Scores and Conference Changes: 04/05 Cluster

\begin{tabular}{lrrrr}
\hline & \multicolumn{2}{c}{ Math } & \multicolumn{2}{c}{ Critical Reading } \\
& \multicolumn{1}{c}{ Q1 } & \multicolumn{1}{c}{ Q3 } & \multicolumn{1}{c}{ Q1 } & Q3 \\
\hline Conference Change & $23.2^{* * *}$ & $21.7^{* * *}$ & $22.2^{* * *}$ & $11.7^{*}$ \\
& $(6.130)$ & $(4.067)$ & $(4.344)$ & $(6.513)$ \\
State Population (Mil) & $9.1^{* * *}$ & $8.7^{* * *}$ & $5.8^{* * *}$ & $6.7^{* *}$ \\
& $(2.3)$ & $(2.0)$ & $(1.6)$ & $(2.7)$ \\
State RPCGDP (1000s) & $-3.2^{* * *}$ & -0.8 & $-2.8^{* * *}$ & -0.7 \\
& $(1.0)$ & $(0.8)$ & $(0.8)$ & $(0.9)$ \\
Cty RPC Inc (1000s) & 0.7 & $0.8^{*}$ & $1.4^{* *}$ & $1.1^{* *}$ \\
& $(0.6)$ & $(0.5)$ & $(0.6)$ & $(0.5)$ \\
State Unemployment Rate & -3.2 & -2.3 & -2.4 & 1.3 \\
& $(2.1)$ & $(1.4)$ & $(1.5)$ & $(1.9)$ \\
Enrollment (1000s) & 1.1 & $1.8^{* *}$ & $1.2^{*}$ & $2.5^{* *}$ \\
Year & $(1.1)$ & $(0.7)$ & $(0.7)$ & $(1.2)$ \\
& 1.6 & -0.8 & 0.3 & -1.4 \\
& $(1.3)$ & $(1.4)$ & $(1.0)$ & $(1.7)$ \\
\hline University FE & Yes & Yes & Yes & Yes \\
Year FE & Yes & Yes & Yes & Yes \\
Years & $2002-2015$ & $2002-2015$ & $2002-2015$ & $2002-2015$ \\
Adj R-Squared & 0.947 & 0.952 & 0.959 & 0.917 \\
Observations & 174 & 174 & 174 & 174 \\
\hline
\end{tabular}

Note: ${ }^{*} p<0.1,{ }^{* *} p<0.05,{ }^{* * *} p<0.01$. Robust standard errors in parentheses. Models include members of Conference USA and the Big East Conference in 2003. Coefficient estimates in the Conference Change row represent the ATE of a move from Conference USA or the Big East to a more prestigious conference (CUSA to BE and BE to ACC) in 2004 and 2005. Data from schools that left CUSA or the BE at other times or to different conferences omitted. 
Table 4.18: University Funding and Conference Changes: 04/05 Cluster

\begin{tabular}{lrrrr}
\hline & $(1)$ & $(2)$ & $(3)$ & $(4)$ \\
& State & State and Local & Private & \multicolumn{2}{c}{ Federal } \\
\hline Conference Change & -148 & -151 & 370 & -561 \\
& $(232)$ & $(308)$ & $(451)$ & $(463)$ \\
State Population (Mil) & $391^{* * *}$ & $476^{* * *}$ & 331 & -137 \\
& $(93)$ & $(115)$ & $(254)$ & $(195)$ \\
State RPCGDP (1000s) & $114^{*}$ & $95^{*}$ & 135 & -68 \\
& $(59)$ & $(48)$ & $(83)$ & $(93)$ \\
Cty RPC Inc (1000s) & 9 & 1 & 60 & 139 \\
& $(22)$ & $(41)$ & $(51)$ & $(84)$ \\
State Unemployment Rate & 121 & 52 & 72 & $279^{*}$ \\
& $(105)$ & $(82)$ & $(225)$ & $(144)$ \\
Enrollment (1000s) & $-305^{* * *}$ & $-344^{* * *}$ & -16 & $-181^{* *}$ \\
& $(59)$ & $(46)$ & $(68)$ & $(73)$ \\
Year & $-221^{* * *}$ & $-145^{* *}$ & -124 & -167 \\
& $(71)$ & $(65)$ & $(111)$ & $(129)$ \\
\hline University FE & Yes & Yes & Yes & Yes \\
Year FE & Yes & Yes & Yes & Yes \\
Years & $2003-2015$ & $2003-2015$ & $2003-2015$ & $2003-2015$ \\
Adj R-Squared & 0.982 & 0.980 & 0.927 & 0.972 \\
Observations & 124 & 161 & 161 & 161 \\
\hline
\end{tabular}

Note: ${ }^{*} p<0.1,{ }^{* *} p<0.05,{ }^{* * *} p<0.01$. Robust standard errors in parentheses. Models include members of Conference USA and the Big East Conference in 2003. Coefficient estimates in the Conference Change row represent the ATE of a move from Conference USA or the Big East to a more prestigious conference (CUSA to BE and BE to ACC) in 2004 and 2005. Data from schools that left CUSA or the BE at other times or to different conferences omitted. 
Table 4.19: Research, Instructional Expenditures, and Conference Changes: 04/05 Cluster

\begin{tabular}{lrrrr}
\hline & \multicolumn{2}{c}{ Research } & \multicolumn{2}{c}{ Instructional } \\
& Total & Salaries & Total & Salaries \\
\hline Conference Change & 99 & 105 & -129 & -181 \\
State Population (Mil) & $(341)$ & $(163)$ & $(457)$ & $(258)$ \\
State RPCGDP (1000s) & -76 & 8 & $499^{* *}$ & $(132)$ \\
& $(148)$ & $(47)$ & $(222)$ & $-87^{* *}$ \\
County RPC Inc (1000s) & 79 & 28 & $-127^{*}$ & $(42)$ \\
& $(65)$ & $(24)$ & $(65)$ & $99^{* * *}$ \\
State Unemployment Rate & 5 & 12 & 55 & $(26)$ \\
& $(45)$ & $(17)$ & $(35)$ & $408^{* * *}$ \\
Enrollment (1000s) & 153 & $144^{* * *}$ & $608^{* * *}$ & $(103)$ \\
& $(120)$ & $(41)$ & $(193)$ & $-253^{* * *}$ \\
Year & -73 & -14 & $-296^{* * *}$ & $(54)$ \\
& $(49)$ & $(18)$ & $(77)$ & 37 \\
\hline University FE & -1 & -45 & $255^{* * *}$ & $(47)$ \\
Year FE & $(86)$ & $(34)$ & $(84)$ & Yes \\
Years & Yes & Yes & Yes & Yes \\
Adj R-Squared & Yes & Yes & Yes & $2003-2015$ \\
Observations & 0.977 & 0.981 & 0.979 & 0.973 \\
\hline
\end{tabular}

Note: ${ }^{*} p<0.1,{ }^{* *} p<0.05,{ }^{* * *} p<0.01$. Robust standard errors in parentheses. Models include members of Conference USA and the Big East Conference in 2003. Coefficient estimates in the Conference Change row represent the ATE of a move from Conference USA or the Big East to a more prestigious conference (CUSA to BE and BE to ACC) in 2004 and 2005. Data from schools that left CUSA or the BE at other times or to different conferences omitted. 
Patrick A. Reilly Chapter 4. Big-Time Sports and University Outcomes

Table 4.20: Admissions, Student Outcomes, and Conference Changes: 11/12/13 Cluster

\begin{tabular}{lrrrr}
\hline & $(1)$ & $(2)$ & $(3)$ & $(4)$ \\
& Applicants & Acceptance Rate & Graduation Rate & Retention Rate \\
\hline Conference Change & 582.5 & 2.1 & 0.2 & 0.5 \\
State Population (Mil) & $(678.1)$ & $(2.4)$ & $(1.0)$ & $(0.8)$ \\
& $2497.8^{* * *}$ & $-5.1^{* * *}$ & $1.6^{* *}$ & $1.9^{* * *}$ \\
State RPCGDP (1000s) & $(797.9)$ & $(1.1)$ & $(0.6)$ & $(0.3)$ \\
& $200.2^{*}$ & 0.1 & $-0.6^{* * *}$ & $-0.7^{* * *}$ \\
Cty RPC Inc (1000s) & $(118.1)$ & $(0.5)$ & $(0.2)$ & $(0.2)$ \\
State Unemployment Rate & $550.4^{* * *}$ & 0.5 & $0.8^{* * *}$ & $0.9^{* *}$ \\
& $(187.8)$ & $(0.8)$ & $(0.3)$ & $(0.4)$ \\
Enrollment (1000s) & $729.3^{* *}$ & $2.0^{*}$ & -0.5 & -0.1 \\
& $(335.4)$ & $(1.1)$ & $(0.4)$ & $(0.4)$ \\
Year & & & $0.3^{* *}$ & -0.3 \\
& & & $(0.1)$ & $(0.2)$ \\
\hline University FE & $-788.9^{* * *}$ & -1.3 & -0.2 & -0.8 \\
Year FE & $(245.1)$ & $(1.2)$ & $(0.4)$ & $(0.5)$ \\
Years & Yes & Yes & Yes & Yes \\
Adj R-Squared & Yes & Yes & Yes & Yes \\
N & $2005-2015$ & $2005-2015$ & $2005-2015$ & $2005-2015$ \\
\hline
\end{tabular}

Note: ${ }^{*} p<0.1,{ }^{* *} p<0.05,{ }^{* * *} p<0.01$. Robust standard errors in parentheses. Models include members of the Mountain West Conference and the Big East Conference in 2007. Coefficient estimates in the Conference change row represent the ATE of a move from the Mountain West Conference or the Big East to a more prestigious conference (MWC to Pac 12 or Big 12 and BE to ACC) between 2011 and 2013. 
Table 4.21: ACT Scores and Conference Changes: 11/12/13 Cluster

\begin{tabular}{lrrrrrr}
\hline & \multicolumn{2}{c}{ Composite } & \multicolumn{2}{c}{ Verbal } & \multicolumn{2}{c}{ Math } \\
& \multicolumn{1}{c}{ Q1 } & \multicolumn{1}{c}{ Q3 } & \multicolumn{1}{c}{ Q1 } & \multicolumn{1}{c}{ Q3 } & \multicolumn{1}{c}{ Q1 } & \multicolumn{1}{c}{ Q3 } \\
\hline Conference Change & -0.109 & -0.038 & $-0.588^{* *}$ & -0.307 & -0.383 & 0.252 \\
& $(0.203)$ & $(0.141)$ & $(0.288)$ & $(0.385)$ & $(0.272)$ & $(0.191)$ \\
State Population (Mil) & 0.178 & $0.214^{* *}$ & 0.293 & 0.122 & 0.200 & 0.129 \\
& $(0.138)$ & $(0.104)$ & $(0.219)$ & $(0.153)$ & $(0.292)$ & $(0.232)$ \\
State RPCGDP (1000s) & -0.072 & -0.043 & -0.114 & $-0.102^{*}$ & -0.133 & -0.062 \\
& $(0.059)$ & $(0.033)$ & $(0.075)$ & $(0.057)$ & $(0.089)$ & $(0.048)$ \\
Cty RPC Inc (1000s) & $0.137^{*}$ & 0.082 & 0.159 & -0.004 & $0.290^{* *}$ & 0.064 \\
& $(0.079)$ & $(0.053)$ & $(0.115)$ & $(0.081)$ & $(0.122)$ & $(0.081)$ \\
State Unemployment Rate & 0.006 & $-0.122^{*}$ & -0.141 & $-0.254^{* *}$ & 0.014 & -0.064 \\
& $(0.077)$ & $(0.067)$ & $(0.138)$ & $(0.102)$ & $(0.130)$ & $(0.106)$ \\
Enrollment (1000s) & 0.039 & -0.040 & 0.004 & -0.070 & 0.072 & -0.030 \\
& $(0.085)$ & $(0.050)$ & $(0.084)$ & $(0.053)$ & $(0.097)$ & $(0.073)$ \\
Year & -0.020 & 0.047 & 0.010 & $0.350^{* * *}$ & -0.199 & 0.046 \\
& $(0.093)$ & $(0.082)$ & $(0.155)$ & $(0.111)$ & $(0.156)$ & $(0.120)$ \\
\hline University FE & Yes & Yes & Yes & Yes & Yes & Yes \\
Year FE & Yes & Yes & Yes & Yes & Yes & Yes \\
Years & $2005-2015$ & $2005-2015$ & $2005-2015$ & $2005-2015$ & $2005-2015$ & $2005-2015$ \\
Adj R-Squared & 0.919 & 0.938 & 0.912 & 0.923 & 0.906 & 0.906 \\
N & 131 & 131 & 114 & 114 & 114 & 114 \\
\hline
\end{tabular}

Note: ${ }^{*} p<0.1,{ }^{* *} p<0.05,{ }^{* * *} p<0.01$. Robust standard errors in parentheses. Models include members of the Mountain West Conference and the Big East Conference in 2007. Coefficient estimates in the Conference change row represent the ATE of a move from the Mountain West Conference or the Big East to a more prestigious conference (MWC to Pac 12 or Big 12 and BE to ACC) between 2011 and 2013. 
Table 4.22: SAT Scores and Conference Changes: 11/12/13 Cluster

\begin{tabular}{lrrrr}
\hline & \multicolumn{2}{c}{ Math } & \multicolumn{2}{c}{ Critical Reading } \\
& Q1 & \multicolumn{1}{c}{ Q3 } & \multicolumn{1}{c}{ Q1 } & \multicolumn{1}{c}{ Q3 } \\
\hline Conference Change & 1.2 & -0.1 & $-6.0^{*}$ & $-7.5^{*}$ \\
State population (Mil) & $(3.5)$ & $(3.9)$ & $(3.5)$ & $(4.1)$ \\
& 2.0 & 1.3 & 3.3 & 1.3 \\
State RPCGDP (1000s) & $(2.1)$ & $(1.7)$ & $(2.0)$ & $(1.7)$ \\
& $-1.7^{*}$ & -0.3 & $-1.8^{*}$ & -0.1 \\
Cty RPC Inc (1000s) & $(0.9)$ & $(0.9)$ & $(1.0)$ & $(0.8)$ \\
& $2.5^{*}$ & 1.5 & $2.3^{*}$ & 0.4 \\
State Unemployment Rate & $(1.3)$ & $(1.0)$ & $(1.3)$ & $(1.0)$ \\
& $-3.8^{* *}$ & -2.2 & $-4.1^{* * *}$ & $-2.6^{*}$ \\
Enrollment (1000s) & $(1.6)$ & $(1.4)$ & $(1.5)$ & $(1.3)$ \\
& $-1.2^{*}$ & $-2.1^{* * *}$ & $-1.8^{* *}$ & $-1.5^{* * *}$ \\
Year & $(0.7)$ & $(0.6)$ & $(0.7)$ & $(0.5)$ \\
& -1.5 & -0.9 & -0.9 & 0.9 \\
University FE & $(1.6)$ & $(1.4)$ & $(1.7)$ & $(1.4)$ \\
Year FE & Yes & Yes & Yes & Yes \\
Years & Yes & Yes & Yes & Yes \\
Adj R-Squared & $2005-2015$ & $2005-2015$ & $2005-2015$ & $2005-2015$ \\
N & 0.927 & 0.918 & 0.927 & 0.933 \\
\hline
\end{tabular}

Note: ${ }^{*} p<0.1,{ }^{* *} p<0.05$, *** $p<0.01$. Robust standard errors in parentheses. Models include members of the Mountain West Conference and the Big East Conference in 2007. Coefficient estimates in the Conference change row represent the ATE of a move from the Mountain West Conference or the Big East to a more prestigious conference (MWC to Pac 12 or Big 12 and BE to ACC) between 2011 and 2013. 
Table 4.23: University Funding and Conference Changes: 11/12/13 Cluster

\begin{tabular}{lrrrr}
\hline & \multicolumn{1}{c}{$(1)$} & $(3)$ & \multicolumn{1}{c}{$(4)$} \\
& State & State and Local & Private & Federal \\
\hline Conference Change & $-936^{* *}$ & -116 & -370 & -46 \\
State Population (Mil) & $(366)$ & $(528)$ & $(417)$ & $(292)$ \\
State RPCGDP (1000s) & $-1529^{* * *}$ & $-628^{*}$ & $836^{* * *}$ & $334^{* * *}$ \\
& $(339)$ & $(371)$ & $(279)$ & $(116)$ \\
Cty RPC Inc (1000s) & $320^{* * *}$ & $315^{*}$ & -21 & -8 \\
& $(115)$ & $(170)$ & $(60)$ & $(46)$ \\
State Unemployment Rate & -94 & $-374^{*}$ & -95 & -102 \\
& $(159)$ & $(200)$ & $(134)$ & $(64)$ \\
Enrollment (1000s) & 66 & $-405^{* *}$ & -84 & 18 \\
& $(180)$ & $(184)$ & $(148)$ & $(84)$ \\
Year & $-382^{* * *}$ & 54 & -22 & $89^{* *}$ \\
& $(143)$ & $(170)$ & $(40)$ & $(42)$ \\
& -86 & 290 & 266 & 49 \\
University FE & $(236)$ & $(246)$ & $(205)$ & $(91)$ \\
Year FE & Yes & Yes & Yes & Yes \\
Years & Yes & Yes & Yes & Yes \\
Adj R-Squared & 110 & 138 & 141 & 143 \\
N & 20.969 & $2005-2015$ & $2005-2015$ & $2005-2015$ \\
\hline
\end{tabular}

Note: ${ }^{*} p<0.1,{ }^{* *} p<0.05,{ }^{* * *} p<0.01$. Robust standard errors in parentheses. Models include members of the Mountain West Conference and the Big East Conference in 2007. Coefficient estimates in the Conference change row represent the ATE of a move from the Mountain West Conference or the Big East to a more prestigious conference (MWC to Pac 12 or Big 12 and BE to ACC) between 2011 and 2013. 
Table 4.24: University Expenditures and Conference Changes: 11/12/13 Cluster

\begin{tabular}{lrrrr}
\hline & \multicolumn{2}{c}{ Research } & \multicolumn{2}{c}{ Instruction } \\
& Total & Salaries & Total & Salaries \\
\hline Conference Change & -79 & $186^{*}$ & $516^{*}$ & $424^{* * *}$ \\
& $(231)$ & $(102)$ & $(278)$ & $(161)$ \\
State population (Mil) & -33 & 25 & -74 & -126 \\
& $(130)$ & $(47)$ & $(147)$ & $(82)$ \\
State RPCGDP (1000s) & -21 & -4 & -28 & $64^{*}$ \\
& $(74)$ & $(21)$ & $(64)$ & $(33)$ \\
Cty RPC Inc (1000s) & 76 & -11 & -37 & $-95^{*}$ \\
& $(91)$ & $(31)$ & $(96)$ & $(50)$ \\
State Unemployment Rate & -86 & $-60^{* *}$ & 21 & 2 \\
& $(69)$ & $(30)$ & $(97)$ & $(51)$ \\
Enrollment (1000s) & 85 & 27 & -76 & -42 \\
& $(80)$ & $(30)$ & $(72)$ & $(43)$ \\
Year & -102 & 13 & $257^{*}$ & $174^{* *}$ \\
& $(118)$ & $(43)$ & $(136)$ & $(68)$ \\
\hline University FE & Yes & Yes & Yes & Yes \\
Year FE & Yes & Yes & Yes & Yes \\
Years & $2005-2015$ & $2005-2015$ & $2005-2015$ & $2005-2015$ \\
Adj R-Squared & 0.983 & 0.988 & 0.938 & 0.945 \\
N & 143 & 143 & 143 & 143 \\
\hline
\end{tabular}

Note: ${ }^{*} p<0.1,{ }^{* *} p<0.05,{ }^{* * *} p<0.01$. Robust standard errors in parentheses. Models include members of the Mountain West Conference and the Big East Conference in 2007. Coefficient estimates in the Conference change row represent the ATE of a move from the Mountain West Conference or the Big East to a more prestigious conference (MWC to Pac 12 or Big 12 and BE to ACC) between 2011 and 2013. 


\section{Appendix Figures and Tables}

Figure 4.2: Propensity Score Distribution: Power 5 Conference Changes

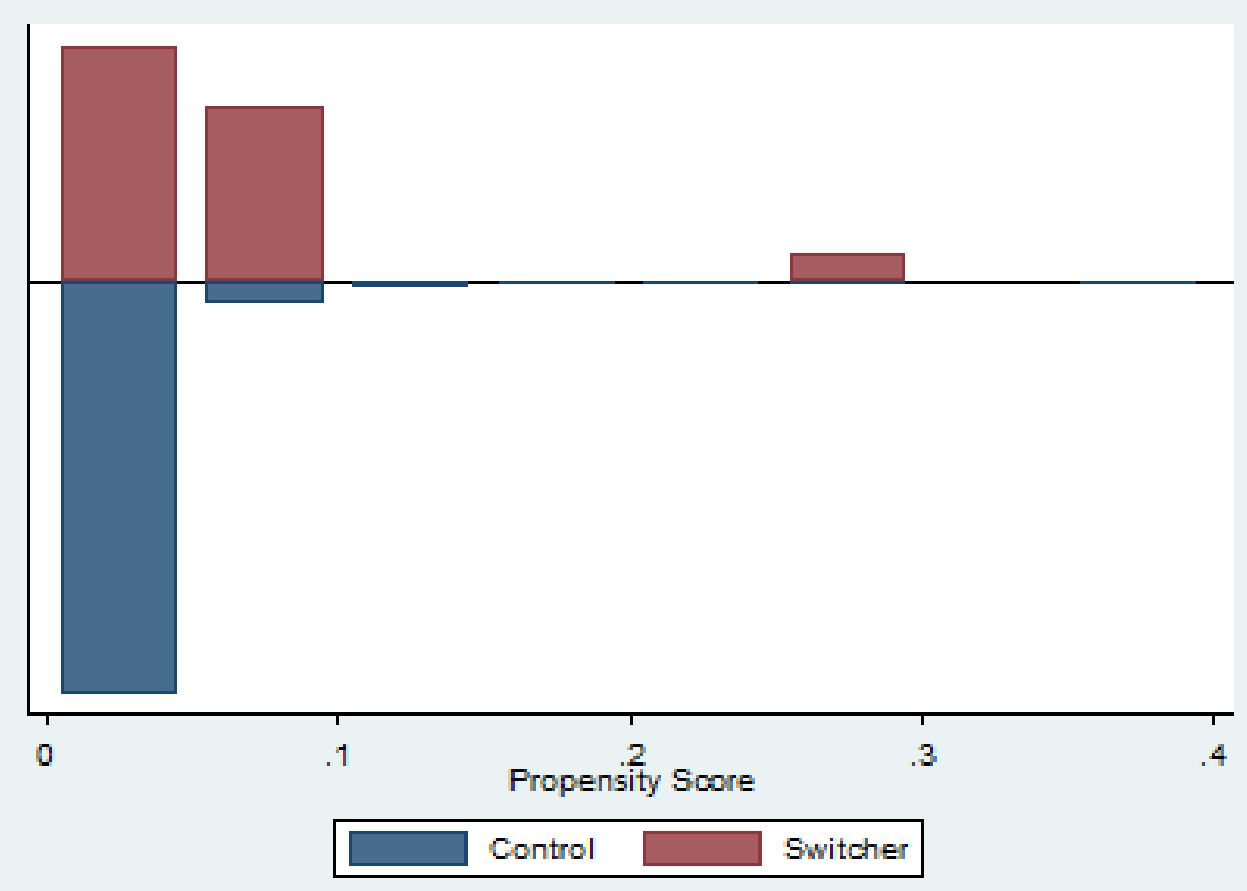


Patrick A. Reilly Chapter 4. Big-Time Sports and University Outcomes

Table 4.25: Summary Statistics, 2004/05 Clusters

\begin{tabular}{|c|c|c|c|c|c|}
\hline & Mean & St Dev & Min & Max & Obs \\
\hline Conference Change & 0.358 & 0.481 & 0 & 1 & 162 \\
\hline Applicants & 15089 & 8200 & 4205 & 43815 & 162 \\
\hline Total Enrollment & 25884 & 10887 & 10125 & 58182 & 161 \\
\hline Acceptance Rate & 59.9 & 17.3 & 25 & 94 & 162 \\
\hline Graduation Rate & 0.633 & 0.165 & 0.333 & 0.924 & 162 \\
\hline Retention Rate & 0.838 & 0.072 & 0.71 & 0.96 & 140 \\
\hline ACT Comp. 25 & 22.2 & 3.7 & 18 & 30 & 129 \\
\hline ACT Comp. 75 & 27.1 & 3.1 & 22 & 33 & 129 \\
\hline ACT English 25 & 21.8 & 4.1 & 16 & 30 & 110 \\
\hline ACT English 75 & 27.89 & 3.7 & 22 & 34 & 110 \\
\hline ACT Math 25 & 21.2 & 4.0 & 16 & 29 & 110 \\
\hline ACT Math 75 & 27.2 & 3.5 & 22 & 33 & 110 \\
\hline SAT Verbal 25 & 515.8 & 58.0 & 420 & 640 & 162 \\
\hline SAT Verbal 75 & 622.0 & 51.7 & 540 & 730 & 162 \\
\hline SAT Math 25 & 531.5 & 62.1 & 425 & 650 & 162 \\
\hline SAT Math 75 & 636.0 & 51.9 & 550 & 740 & 162 \\
\hline Total Research & 6828 & 5052 & 745 & 20591 & 162 \\
\hline Research Salaries & 3212 & 2246 & 406 & 9265 & 162 \\
\hline Instructional Expenditures & 13611 & 5827 & 6617 & 32143 & 162 \\
\hline Instructional Salaries \& Wages & 8741 & 3216 & 4340 & 18473 & 162 \\
\hline State Appropriations & 6897 & 3939 & 28 & 13789 & 146 \\
\hline State \& Local Grants \& Contracts & 8749 & 4695 & 357 & 18091 & 162 \\
\hline Private Gifts, Grants, \& Contracts & 3683 & 3950 & 7 & 18689 & 162 \\
\hline Federal Grants \& Contracts & 7470 & 5828 & 1671 & 23303 & 162 \\
\hline
\end{tabular}

Notes: Data from 2003 to 2015. The data include those universities from Conference USA and the Big East in 2003 with the exception of TCU. We focus on schools switching to more prestigious conferences in 2004 and 2005. So we drop those observations where teams change conference after 2005. 
Table 4.26: Admissions and Enrollment and Realignment, No Institutional Groupings

\begin{tabular}{lrrrr}
\hline & \multicolumn{1}{c}{$\begin{array}{c}(1) \\
\text { Applicants }\end{array}$} & $\begin{array}{c}(2) \\
\text { Applicants }\end{array}$ & $\begin{array}{c}\text { Acceptance } \\
\text { Rate }(\%)\end{array}$ & $\begin{array}{c}\text { Acceptance } \\
\text { Rate }(\%)\end{array}$ \\
& & & 1.4 \\
Conference Change & $-3146.7^{* * *}$ & & $(1.8)$ & 2.6 \\
Conference Change Power 5 & $(827.8)$ & & & $(2.1)$ \\
& & -1379.1 & -0.6 \\
State Population (Mil) & $1697.3^{* * *}$ & $1586.1^{* *}$ & -0.6 & $(0.8)$ \\
State RPCGDP (1000s) & $(592.2)$ & $(617.1)$ & $(0.9)$ & 0.1 \\
& 99.8 & 93.9 & 0.1 & $(0.2)$ \\
Cty RPC Inc (1000s) & $(121.8)$ & $(122.2)$ & $(0.2)$ & -0.2 \\
State Unemployment Rate & $196.4^{* *}$ & $160.9^{*}$ & -0.2 & $(0.2)$ \\
Year & $(84.6)$ & $(92.3)$ & $(0.2)$ & $0.8^{*}$ \\
& 30.1 & 12.8 & $0.8^{*}$ & $(0.5)$ \\
\hline University FE & $(273.0)$ & $(284.6)$ & $(0.5)$ & -0.4 \\
Year FE & 244.5 & 273.7 & -0.4 & $(0.4)$ \\
Years & $(180.6)$ & $(186.2)$ & $(0.4)$ & Yes \\
Observations & Yes & Yes & Yes & Yes \\
\hline
\end{tabular}

Note: ${ }^{*} p<0.1,{ }^{* *} p<0.05,{ }^{* * *} p<0.01$. Robust standard errors in parentheses. Universities part of institutional groupings or systems and service academies omitted. Coefficient estimates in the Conference Change row represent the ATE of a switch to any conference. Estimates in the Conference Change Power 5 row represent the ATE of a switch to a Power 5 conference (ACC, Big 10, Big 12, Pac 12, or SEC). 
Patrick A. Reilly

Table 4.27: ACT Composite Scores and Realignment, No Institutional Groupings

\begin{tabular}{lrrrr}
\hline & \multicolumn{1}{c}{$(1)$} & \multicolumn{1}{c}{$(2)$} & \multicolumn{1}{c}{$(3)$} & \multicolumn{1}{c}{$(4)$} \\
& Q1 & \multicolumn{1}{c}{ Q1 } & \multicolumn{1}{c}{ Q3 } & \multicolumn{1}{c}{ Q3 } \\
\hline Conference Change & -0.150 & & 0.190 & \\
& $(0.259)$ & & $(0.218)$ & \\
Conference Change Power 5 & & -0.369 & & -0.013 \\
& & $(0.347)$ & & $(0.225)$ \\
state population millions & $0.198^{* *}$ & $0.211^{* *}$ & 0.109 & 0.113 \\
& $(0.091)$ & $(0.092)$ & $(0.077)$ & $(0.080)$ \\
State RPCGDP Thousands & $-0.070^{*}$ & $-0.070^{*}$ & -0.020 & -0.021 \\
& $(0.038)$ & $(0.039)$ & $(0.023)$ & $(0.023)$ \\
County RPC Income Thousands & $0.063^{* * *}$ & $0.061^{* * *}$ & 0.018 & 0.021 \\
& $(0.021)$ & $(0.020)$ & $(0.019)$ & $(0.019)$ \\
State Unemployment Rate & 0.001 & -0.004 & -0.038 & -0.038 \\
& $(0.048)$ & $(0.047)$ & $(0.037)$ & $(0.038)$ \\
total full time thousands & 0.052 & 0.053 & $0.072^{*}$ & $0.075^{* *}$ \\
& $(0.048)$ & $(0.047)$ & $(0.037)$ & $(0.037)$ \\
Year & $0.082^{* *}$ & $0.085^{* *}$ & $0.089^{* *}$ & $0.087^{* *}$ \\
& $(0.040)$ & $(0.040)$ & $(0.042)$ & $(0.042)$ \\
\hline University Fixed Effects & Yes & Yes & Yes & Yes \\
Year Fixed Effects & Yes & Yes & Yes & Yes \\
Years & 835 & 835 & 835 & 835 \\
Observations & $2002-2015$ & $2002-2015$ & $2002-2015$ & $2002-2015$ \\
\hline
\end{tabular}

Note: ${ }^{*} p<0.1,{ }^{* *} p<0.05,{ }^{* *} p<0.01$. Robust standard errors in parentheses. Universities part of institutional groupings or systems and service academies omitted. Coefficient estimates in the Conference Change row represent the ATE of a Conference Changement to any conference. Estimates in the Conference Change Power 5 row represent the ATE of a Conference Changement to a Power 5 conference (ACC, Big 10, Big 12, Pac 12, or SEC). 
Patrick A. Reilly

Table 4.28: ACT Verbal Scores and Realignmen, No Institutional Groupingst

\begin{tabular}{|c|c|c|c|c|}
\hline & $\begin{array}{l}\text { (1) } \\
\text { Q1 }\end{array}$ & $\begin{array}{l}(2) \\
\text { Q1 }\end{array}$ & $\begin{array}{l}(3) \\
\text { Q3 }\end{array}$ & $\begin{array}{l}\text { (4) } \\
\text { Q3 }\end{array}$ \\
\hline Conference Change & $\begin{array}{r}-0.264 \\
(0.253)\end{array}$ & & $\begin{array}{r}0.118 \\
(0.243)\end{array}$ & \\
\hline Conference Change Power 5 & & $\begin{array}{r}-0.486 \\
(0.338)\end{array}$ & & $\begin{array}{r}0.331 \\
(0.347)\end{array}$ \\
\hline State Population (Mil) & $\begin{array}{c}0.266^{*} \\
(0.133)\end{array}$ & $\begin{array}{c}0.261^{*} \\
(0.134)\end{array}$ & $\begin{array}{r}0.166 \\
(0.142)\end{array}$ & $\begin{array}{r}0.166 \\
(0.139)\end{array}$ \\
\hline State RPCGDP (1000s) & $\begin{array}{l}-0.074^{*} \\
(0.041)\end{array}$ & $\begin{array}{l}-0.076^{*} \\
(0.041)\end{array}$ & $\begin{array}{l}-0.045 \\
(0.033)\end{array}$ & $\begin{array}{c}-0.044 \\
(0.033)\end{array}$ \\
\hline Cty RPC Inc (1000s) & $\begin{array}{r}0.078^{* * *} \\
(0.024)\end{array}$ & $\begin{array}{r}0.076^{* * *} \\
(0.024)\end{array}$ & $\begin{array}{r}0.013 \\
(0.022)\end{array}$ & $\begin{array}{r}0.014 \\
(0.022)\end{array}$ \\
\hline State Unemployment Rate & $\begin{array}{l}-0.010 \\
(0.052)\end{array}$ & $\begin{array}{l}-0.018 \\
(0.051)\end{array}$ & $\begin{array}{r}-0.004 \\
(0.047)\end{array}$ & $\begin{array}{r}0.001 \\
(0.048)\end{array}$ \\
\hline Enrollment & $\begin{array}{r}0.050 \\
(0.057)\end{array}$ & $\begin{array}{r}0.056 \\
(0.057)\end{array}$ & $\begin{array}{r}0.041 \\
(0.051)\end{array}$ & $\begin{array}{r}0.036 \\
(0.052)\end{array}$ \\
\hline Year & $\begin{array}{r}0.096^{*} \\
(0.054)\end{array}$ & $\begin{array}{r}0.099^{*} \\
(0.055)\end{array}$ & $\begin{array}{r}0.188^{* * *} \\
(0.051)\end{array}$ & $\begin{array}{r}0.186^{* * *} \\
(0.050)\end{array}$ \\
\hline University Fixed Effects & Yes & Yes & Yes & Yes \\
\hline Year Fixed Effects & Yes & Yes & Yes & Yes \\
\hline Years & $2002-2015$ & $2002-2015$ & $2002-2015$ & $2002-2015$ \\
\hline Observations & 747 & 747 & 747 & 747 \\
\hline
\end{tabular}


Patrick A. Reilly

Table 4.29: ACT Math Scores and Realignment, No Institutional Groupings

\begin{tabular}{|c|c|c|c|c|}
\hline & $\begin{array}{l}\text { (1) } \\
\text { Q1 }\end{array}$ & $\begin{array}{l}\text { (2) } \\
\text { Q1 }\end{array}$ & $\begin{array}{l}\text { (3) } \\
\text { Q3 }\end{array}$ & $\begin{array}{l}\text { (4) } \\
\text { Q3 }\end{array}$ \\
\hline Conference Change & $\begin{array}{r}0.037 \\
(0.267)\end{array}$ & & $\begin{array}{r}0.003 \\
(0.222)\end{array}$ & \\
\hline Conference Change Power 5 & & $\begin{array}{r}-0.390 \\
(0.269)\end{array}$ & & $\begin{array}{c}-0.133 \\
(0.284)\end{array}$ \\
\hline State Population (Mil) & $\begin{array}{l}0.256^{* *} \\
(0.096)\end{array}$ & $\begin{array}{l}0.264^{* *} \\
(0.100)\end{array}$ & $\begin{array}{l}0.216^{* *} \\
(0.099)\end{array}$ & $\begin{array}{l}0.219^{* *} \\
(0.098)\end{array}$ \\
\hline State RPCGDP (1000s) & $\begin{array}{r}-0.016 \\
(0.035)\end{array}$ & $\begin{array}{r}-0.018 \\
(0.034)\end{array}$ & $\begin{array}{r}-0.032 \\
(0.029)\end{array}$ & $\begin{array}{r}-0.033 \\
(0.029)\end{array}$ \\
\hline Coty RPC Inc (1000s) & $\begin{array}{l}0.037^{* *} \\
(0.018)\end{array}$ & $\begin{array}{l}0.038^{* *} \\
(0.017)\end{array}$ & $\begin{array}{r}0.029 \\
(0.019)\end{array}$ & $\begin{array}{r}0.029 \\
(0.019)\end{array}$ \\
\hline State Unemployment Rate & $\begin{array}{r}-0.059 \\
(0.046)\end{array}$ & $\begin{array}{r}-0.065 \\
(0.046)\end{array}$ & $\begin{array}{r}-0.052 \\
(0.047)\end{array}$ & $\begin{array}{c}-0.054 \\
(0.047)\end{array}$ \\
\hline Enrollment (1000s) & $\begin{array}{r}0.070 \\
(0.063)\end{array}$ & $\begin{array}{r}0.076 \\
(0.062)\end{array}$ & $\begin{array}{r}0.035 \\
(0.045)\end{array}$ & $\begin{array}{r}0.037 \\
(0.044)\end{array}$ \\
\hline Year & $\begin{array}{r}0.031 \\
(0.047) \\
\end{array}$ & $\begin{array}{r}0.033 \\
(0.047) \\
\end{array}$ & $\begin{array}{c}0.070^{*} \\
(0.041) \\
\end{array}$ & $\begin{array}{r}0.070^{*} \\
(0.040) \\
\end{array}$ \\
\hline University Fixed Effects & Yes & Yes & Yes & Yes \\
\hline Year Fixed Effects & Yes & Yes & Yes & Yes \\
\hline Years & $2002-2015$ & $2002-2015$ & $2002-2015$ & $2002-2015$ \\
\hline Observations & 748 & 748 & 748 & 748 \\
\hline $\begin{array}{l}\text { Note: }{ }^{*} p<0.1,{ }^{* *} p<0.05,{ }^{* * *} \\
\text { part of institutional groupings or } \\
\text { the realign row represent the ATI } \\
\text { Power } 5 \text { row represent the ATE o } \\
\text { Pac } 12 \text {, or SEC). }\end{array}$ & $\begin{array}{l}<0.01 . \text { Ro } \\
\text { ems and se } \\
\text { f a realignn } \\
\text { realignmer }\end{array}$ & $\begin{array}{l}\text { standard } \\
\text { e academie } \\
\text { to any col } \\
\text { a Power } 5\end{array}$ & $\begin{array}{l}\text { rs in paren } \\
\text { itted. Co } \\
\text { nce. Estin } \\
\text { ference (A }\end{array}$ & $\begin{array}{l}\text { Universities } \\
\text { estimates in } \\
\text { the Realign } \\
10 \text {, Big } 12 \text {, }\end{array}$ \\
\hline
\end{tabular}


Patrick A. Reilly

Table 4.30: SAT Critical Reading Scores and Realignment, No Institutional Groupings

\begin{tabular}{|c|c|c|c|c|}
\hline & $\begin{array}{l}\text { (1) } \\
\text { Q1 }\end{array}$ & $\begin{array}{l}\text { (2) } \\
\text { Q1 }\end{array}$ & $\begin{array}{l}\text { (3) } \\
\text { Q3 }\end{array}$ & $\begin{array}{l}\text { (4) } \\
\text { Q3 }\end{array}$ \\
\hline Conference Change & $\begin{array}{r}0.1 \\
(3.4)\end{array}$ & & $\begin{array}{r}1.8 \\
(3.3)\end{array}$ & \\
\hline Conference Change Power 5 & & $\begin{array}{r}-0.5 \\
(3.6)\end{array}$ & & $\begin{array}{c}-0.2 \\
(3.9)\end{array}$ \\
\hline State Population (Mil) & $\begin{array}{l}4.6^{* *} \\
(2.0)\end{array}$ & $\begin{array}{l}4.7^{* *} \\
(2.0)\end{array}$ & $\begin{array}{c}3.1^{*} \\
(1.6)\end{array}$ & $\begin{array}{c}3.1^{*} \\
(1.7)\end{array}$ \\
\hline State RPCGDP (1000s) & $\begin{array}{r}-1.0 \\
(0.6)\end{array}$ & $\begin{array}{l}-1.0 \\
(0.6)\end{array}$ & $\begin{array}{r}-0.7 \\
(0.6)\end{array}$ & $\begin{array}{r}-0.7 \\
(0.6)\end{array}$ \\
\hline County RPC Inc (1000s) & $\begin{array}{l}0.7^{* *} \\
(0.3)\end{array}$ & $\begin{array}{l}0.7^{* *} \\
(0.3)\end{array}$ & $\begin{array}{l}0.7^{* *} \\
(0.3)\end{array}$ & $\begin{array}{l}0.7^{* *} \\
(0.3)\end{array}$ \\
\hline State Unemployment Rate & $\begin{array}{r}1.3 \\
(1.1)\end{array}$ & $\begin{array}{r}1.3 \\
(1.1)\end{array}$ & $\begin{array}{r}-0.0 \\
(0.9)\end{array}$ & $\begin{array}{r}-0.0 \\
(0.9)\end{array}$ \\
\hline Enrollment (1000s) & $\begin{array}{r}-0.6 \\
(1.1)\end{array}$ & $\begin{array}{r}-0.6 \\
(1.1)\end{array}$ & $\begin{array}{r}-0.0 \\
(0.9)\end{array}$ & $\begin{array}{r}-0.0 \\
(0.9)\end{array}$ \\
\hline Year & $\begin{array}{r}0.7 \\
(0.8)\end{array}$ & $\begin{array}{r}0.7 \\
(0.8)\end{array}$ & $\begin{array}{r}0.4 \\
(0.7)\end{array}$ & $\begin{array}{r}0.4 \\
(0.7)\end{array}$ \\
\hline University Fixed Effects & Yes & Yes & Yes & Yes \\
\hline Year Fixed Effects & Yes & Yes & Yes & Yes \\
\hline Years & $2002-2015$ & $2002-2015$ & $2002-2015$ & $2002-2015$ \\
\hline Observations & 839 & 839 & 839 & 839 \\
\hline $\begin{array}{l}\text { Note: }{ }^{*} p<0.1,{ }^{* *} p<0.05,{ }^{* * *} \\
\text { part of institutional groupings or } \\
\text { the realign row represent the ATH } \\
\text { Power } 5 \text { row represent the ATE o } \\
\text { Pac } 12 \text {, or SEC). }\end{array}$ & $\begin{array}{l}<0.01 \text {. Rob } \\
\text { tems and ser } \\
\text { f a realignm } \\
\text { realignment }\end{array}$ & $\begin{array}{l}\text { standard } \\
\text { e academie } \\
\text { to any cor } \\
\text { a Power } 5\end{array}$ & $\begin{array}{l}\text { rs in paren } \\
\text { nitted. Coe } \\
\text { ence. Estin } \\
\text { ference (A }\end{array}$ & $\begin{array}{l}\text { Universities } \\
\text { t estimates in } \\
\text { n the Realign } \\
\text { ig } 10 \text {, Big } 12 \text {, }\end{array}$ \\
\hline
\end{tabular}


Patrick A. Reilly

Table 4.31: SAT Math Scores and Realignment, No Institutional Groupings




Table 4.32: Graduation and Retention Rates and Realignment, No Institutional Groupings

\begin{tabular}{lrrrr}
\hline & $\begin{array}{c}(1) \\
\text { Graduation } \\
\text { Rate }\end{array}$ & $\begin{array}{c}\text { Graduation } \\
\text { Rate }\end{array}$ & $\begin{array}{c}\text { r } \\
\text { Retention } \\
\text { Rate }\end{array}$ & $\begin{array}{c}\text { Retention } \\
\text { Rate }\end{array}$ \\
\hline Conference Change & $0.023^{* *}$ & & $0.009^{*}$ & \\
Conference Change Power 5 & $(0.009)$ & & $(0.005)$ & 0.010 \\
& & 0.017 & & $(0.010)$ \\
State Population (Mil) & 0.001 & $(0.011)$ & & 0.002 \\
& $(0.004)$ & $(0.004)$ & $(0.002)$ & $(0.002)$ \\
State RPCGDP (1000s) & $-0.003^{* *}$ & $-0.003^{* *}$ & $-0.002^{*}$ & $-0.002^{*}$ \\
& $(0.001)$ & $(0.001)$ & $(0.001)$ & $(0.001)$ \\
Cty RPC Inc (1000s) & 0.001 & 0.001 & 0.001 & 0.001 \\
& $(0.001)$ & $(0.001)$ & $(0.001)$ & $(0.001)$ \\
State Unemployment Rate & -0.001 & -0.001 & -0.001 & -0.001 \\
& $(0.002)$ & $(0.002)$ & $(0.001)$ & $(0.001)$ \\
Enrollment (1000s) & $0.005^{* * *}$ & $0.005^{* * *}$ & 0.002 & 0.002 \\
Year & $(0.002)$ & $(0.002)$ & $(0.001)$ & $(0.001)$ \\
& $0.006^{* * *}$ & $0.006^{* * *}$ & $0.002^{* *}$ & $0.002^{* *}$ \\
& $(0.002)$ & $(0.002)$ & $(0.001)$ & $(0.001)$ \\
\hline University Fixed Effects & Yes & Yes & Yes & Yes \\
Year Fixed Effects & Yes & Yes & Yes & Yes \\
Observations & 937 & 937 & 787 & 787 \\
\hline
\end{tabular}

Note: ${ }^{*} p<0.1,{ }^{* *} p<0.05,{ }^{* * *} p<0.01$. Robust standard errors in parentheses. Universities part of institutional groupings or systems and service academies omitted. Coefficient estimates in the realign row represent the ATE of a realignment to any conference. Estimates in the Realign Power 5 row represent the ATE of a realignment to a Power 5 conference (ACC, Big 10, Big 12, Pac 12, or SEC) 
Table 4.33: Instructional Expenditures and Realignment, No Institutional Groupings

\begin{tabular}{|c|c|c|c|c|}
\hline & $\begin{array}{c}(1) \\
\text { Total }\end{array}$ & $\begin{array}{c}(2) \\
\text { Total }\end{array}$ & $\begin{array}{c}(3) \\
\text { Salaries } \\
\text { and Wages }\end{array}$ & $\begin{array}{c}(4) \\
\text { Salaries } \\
\text { and Wages }\end{array}$ \\
\hline Conference Change & $\begin{array}{r}-1726^{*} \\
(915)\end{array}$ & & $\begin{array}{r}-852^{* *} \\
(402)\end{array}$ & \\
\hline Conference Change Power 5 & & $\begin{array}{c}-686 \\
(683)\end{array}$ & & $\begin{array}{c}-275 \\
(327)\end{array}$ \\
\hline State Population (Mil) & $\begin{array}{r}415 \\
(328)\end{array}$ & $\begin{array}{r}356 \\
(328)\end{array}$ & $\begin{array}{r}167 \\
(167)\end{array}$ & $\begin{array}{r}137 \\
(168)\end{array}$ \\
\hline State RPCGDP (1000s) & $\begin{array}{r}-12 \\
(87)\end{array}$ & $\begin{array}{r}-16 \\
(88)\end{array}$ & $\begin{array}{r}-26 \\
(58)\end{array}$ & $\begin{array}{r}-28 \\
(58)\end{array}$ \\
\hline Cty RPC Inc (1000s) & $\begin{array}{r}285 \\
(174)\end{array}$ & $\begin{array}{r}264 \\
(176)\end{array}$ & $\begin{array}{r}117^{*} \\
(63)\end{array}$ & $\begin{array}{r}107 \\
(65)\end{array}$ \\
\hline State Unemployment Rate & $\begin{array}{l}356^{* *} \\
(136)\end{array}$ & $\begin{array}{l}347^{* *} \\
(133)\end{array}$ & $\begin{array}{c}104 \\
(80)\end{array}$ & $\begin{array}{r}100 \\
(78)\end{array}$ \\
\hline Enrollment (1000s) & $\begin{array}{r}-90 \\
(129)\end{array}$ & $\begin{array}{r}-95 \\
(137)\end{array}$ & $\begin{array}{r}-80 \\
(79)\end{array}$ & $\begin{array}{r}-83 \\
(82)\end{array}$ \\
\hline Year & $\begin{array}{r}-179 \\
(260) \\
\end{array}$ & $\begin{array}{r}-160 \\
(265) \\
\end{array}$ & $\begin{array}{r}-23 \\
(101) \\
\end{array}$ & $\begin{array}{r}-14 \\
(104) \\
\end{array}$ \\
\hline University Fixed Effects & Yes & Yes & Yes & Yes \\
\hline Year Fixed Effects & Yes & Yes & Yes & Yes \\
\hline Years & 2003-2015 & 2003-2015 & 2003-2015 & 2003-2015 \\
\hline Observations & 870 & 870 & 870 & 870 \\
\hline
\end{tabular}

Note: ${ }^{*} p<0.1,{ }^{* *} p<0.05,{ }^{* * *} p<0.01$. Robust standard errors in parentheses. Universities part of institutional groupings or systems and service academies omitted. Coefficient estimates in the Conference Change row represent the ATE of a switch to any conference. Estimates in the Conference Change Power 5 row represent the ATE of a switch to a Power 5 conference (ACC, Big 10, Big 12, Pac 12, or SEC). 
Patrick A. Reilly

Table 4.34: Research Expenditures and Realignment, No Institutional Groupings

\begin{tabular}{|c|c|c|c|c|}
\hline & $\begin{array}{c}(1) \\
\text { Total }\end{array}$ & $\begin{array}{c}(2) \\
\text { Total }\end{array}$ & $\begin{array}{c}(3) \\
\text { Salaries } \\
\text { and Wages }\end{array}$ & $\begin{array}{c}(4) \\
\text { Salaries } \\
\text { and Wages }\end{array}$ \\
\hline Conference Change & $\begin{array}{r}-109 \\
(400)\end{array}$ & & $\begin{array}{r}-35 \\
(205)\end{array}$ & \\
\hline Conference Change Power 5 & & $\begin{array}{r}316 \\
(483)\end{array}$ & & $\begin{array}{r}299 \\
(180)\end{array}$ \\
\hline State Population (Mil) & $\begin{array}{r}225 \\
(157)\end{array}$ & $\begin{array}{r}216 \\
(155)\end{array}$ & $\begin{array}{r}67 \\
(79)\end{array}$ & $\begin{array}{r}61 \\
(78)\end{array}$ \\
\hline State RPCGDP (1000s) & $\begin{array}{r}16 \\
(60)\end{array}$ & $\begin{array}{r}13 \\
(60)\end{array}$ & $\begin{array}{r}17 \\
(21)\end{array}$ & $\begin{array}{r}14 \\
(21)\end{array}$ \\
\hline Cty RPC Inc (1000s) & $\begin{array}{c}83^{*} \\
(48)\end{array}$ & $\begin{array}{c}81^{*} \\
(48)\end{array}$ & $\begin{array}{r}41 \\
(37)\end{array}$ & $\begin{array}{r}40 \\
(37)\end{array}$ \\
\hline State Unemployment Rate & $\begin{array}{r}19 \\
(82)\end{array}$ & $\begin{array}{r}18 \\
(82)\end{array}$ & $\begin{array}{r}-7 \\
(31)\end{array}$ & $\begin{array}{r}-8 \\
(30)\end{array}$ \\
\hline Enrollment (1000s) & $\begin{array}{r}-136^{*} \\
(75)\end{array}$ & $\begin{array}{r}-140^{*} \\
(73)\end{array}$ & $\begin{array}{r}-70^{* *} \\
(30)\end{array}$ & $\begin{array}{r}-73^{* *} \\
(29)\end{array}$ \\
\hline Year & $\begin{array}{r}-71 \\
(76)\end{array}$ & $\begin{array}{r}-69 \\
(77)\end{array}$ & $\begin{array}{r}-63 \\
(54)\end{array}$ & $\begin{array}{r}-61 \\
(55)\end{array}$ \\
\hline University Fixed Effects & Yes & Yes & Yes & Yes \\
\hline Year Fixed Effects & Yes & Yes & Yes & Yes \\
\hline Years & $2003-2015$ & $2003-2015$ & $2003-2015$ & $2003-2015$ \\
\hline Observations & 856 & 856 & 852 & 852 \\
\hline
\end{tabular}

Note: ${ }^{*} p<0.1,{ }^{* *} p<0.05,{ }^{* * *} p<0.01$. Robust standard errors in parentheses. Universities part of institutional groupings or systems and service academies omitted. Coefficient estimates in the Conference Change row represent the ATE of a switch to any conference. Estimates in the Conference Change Power 5 row represent the ATE of a switch to a Power 5 conference (ACC, Big 10, Big 12, Pac 12, or SEC). 
Table 4.35: State and Local Funding and Realignment, No Institutional Groupings

\begin{tabular}{|c|c|c|c|c|}
\hline & $\begin{array}{c}(1) \\
\text { State } \\
\text { Appropr- } \\
\text { iations }\end{array}$ & $\begin{array}{c}(2) \\
\text { State } \\
\text { Appropr- } \\
\text { iations }\end{array}$ & $\begin{array}{c}(3) \\
\text { State and } \\
\text { Local } \\
\text { Grants } \\
\text { and } \\
\text { Contracts }\end{array}$ & $\begin{array}{l}(4) \\
\text { State and } \\
\text { Local } \\
\text { Grants } \\
\text { and } \\
\text { Contracts }\end{array}$ \\
\hline Conference Change & $\begin{array}{r}563 \\
(607)\end{array}$ & & $\begin{array}{r}119 \\
(452)\end{array}$ & \\
\hline Conference Change Power 5 & & $\begin{array}{c}973^{*} \\
(532)\end{array}$ & & $\begin{array}{r}585 \\
(421)\end{array}$ \\
\hline state population millions & $\begin{array}{c}-102 \\
(331)\end{array}$ & $\begin{array}{l}-104 \\
(328)\end{array}$ & $\begin{array}{r}294 \\
(257)\end{array}$ & $\begin{array}{r}301 \\
(247)\end{array}$ \\
\hline State RPCGDP Thousands & $\begin{array}{r}194^{* *} \\
(84)\end{array}$ & $\begin{array}{r}198^{* *} \\
(80)\end{array}$ & $\begin{array}{l}136 \\
(90)\end{array}$ & $\begin{array}{l}133 \\
(90)\end{array}$ \\
\hline County RPC Income Thousands & $\begin{array}{r}-137^{*} \\
(75)\end{array}$ & $\begin{array}{r}-130^{*} \\
(73)\end{array}$ & $\begin{array}{r}-10 \\
(43)\end{array}$ & $\begin{array}{r}-10 \\
(39)\end{array}$ \\
\hline State Unemployment Rate & $\begin{array}{r}-120 \\
(156)\end{array}$ & $\begin{array}{r}-104 \\
(149)\end{array}$ & $\begin{array}{r}-72 \\
(111)\end{array}$ & $\begin{array}{r}-73 \\
(110)\end{array}$ \\
\hline total full time thousands & $\begin{array}{r}-344^{* * *} \\
(97)\end{array}$ & $\begin{array}{r}-353^{* * *} \\
(96)\end{array}$ & $\begin{array}{r}-466^{* * *} \\
(104)\end{array}$ & $\begin{array}{r}-472^{* * *} \\
(101)\end{array}$ \\
\hline Year & $\begin{array}{r}-146 \\
(149)\end{array}$ & $\begin{array}{r}-161 \\
(145)\end{array}$ & $\begin{array}{r}-215^{* *} \\
(98)\end{array}$ & $\begin{array}{r}-215^{* *} \\
(95)\end{array}$ \\
\hline University Fixed Effects & Yes & Yes & Yes & Yes \\
\hline Year Fixed Effects & Yes & Yes & Yes & Yes \\
\hline Years & $2003-2015$ & $2003-2015$ & $2003-2015$ & $2003-2015$ \\
\hline Observations & 595 & 595 & 859 & 859 \\
\hline
\end{tabular}

Note: ${ }^{*} p<0.1,{ }^{* *} p<0.05,{ }^{* * *} p<0.01$. Robust standard errors in parentheses. Universities part of institutional groupings or systems and service academies omitted. Coefficient estimates in the realign row represent the ATE of a realignment to any conference. Estimates in the Realign Power 5 row represent the ATE of a realignment to a Power 5 conference (ACC, Big 10, Big 12, Pac 12, or SEC). 
Table 4.36: Private and Federal Funding and Realignment, No Institutional Groupings

\begin{tabular}{lrrrr}
\hline \hline & $(1)$ & $(2)$ & $(3)$ & \multicolumn{1}{c}{$(4)$} \\
& Private & Private & \multicolumn{1}{c}{ Federal } & \multicolumn{1}{c}{ Federal } \\
\hline Conference Change & -710 & & 262 & \\
& $(634)$ & & $(385)$ & 240 \\
Conference Change Power 5 & & -341 & & $(342)$ \\
& & $(556)$ & & -119 \\
State Population (Mil) & $455^{*}$ & 429 & -126 & $(120)$ \\
& $(254)$ & $(259)$ & $(118)$ & 9 \\
State RPCGDP (1000s) & -51 & -51 & 9 & $(49)$ \\
& $(103)$ & $(103)$ & $(49)$ & 24 \\
Cty RPC Inc (1000s) & $243^{*}$ & $234^{*}$ & 21 & -54 \\
& $(128)$ & $(127)$ & $(36)$ & $(90)$ \\
State Unemployment Rate & -83 & -86 & -55 & $-164^{* * *}$ \\
& $(167)$ & $(164)$ & $(89)$ & $(45)$ \\
Enrollment (1000s) & -117 & -119 & $-164^{* * *}$ & -1 \\
Year & $(71)$ & $(73)$ & $(44)$ & $(71)$ \\
\hline University Fixed Effects & -200 & -194 & 1 & Yes \\
Year Fixed Effects & $(163)$ & $(166)$ & $(73)$ & Yes \\
Years & Yes & Yes & Yes & 870 \\
Observations & Yes & Yes & Yes & $2003-2015$ \\
\hline
\end{tabular}

Note: ${ }^{*} p<0.1,{ }^{* *} p<0.05,{ }^{* * *} p<0.01$. Robust standard errors in parentheses. Universities part of institutional groupings or systems and service academies omitted. Coefficient estimates in the Conference Change row represent the ATE of a switch to any conference. Estimates in the Conference Change Power 5 row represent the ATE of a switch to a Power 5 conference (ACC, Big 10, Big 12, Pac 12, or SEC). 
Table 4.37: Log Odds of Joining a Power 5 Conference

\begin{tabular}{lr}
\hline & \multicolumn{1}{c}{$(1)$} \\
& Switch Power 5 \\
\hline Bowl Appearance & $3.121^{* * *}$ \\
& $(1.123)$ \\
State Population (Millions) & -0.0433 \\
& $(0.0279)$ \\
State RPCGDP (Thousands) & $0.1387^{* * *}$ \\
& $(0.0413)$ \\
State Unemployment & -0.0046 \\
& $(0.1601)$ \\
Enrollment (Thousands) & 0.0230 \\
& $(0.0202)$ \\
\hline Pseudo R-Squared & 0.1605 \\
Observations & 802 \\
\hline Note: Standard errors in parentheses. ${ }^{*} p<0.1,{ }^{* *} p<$ \\
$0.05,{ }^{* * *} p<0.01 . \quad$ Variables are all averages of the \\
previous 5 years.
\end{tabular}


Table 4.38: PSM with Rutgers and Maryland

\begin{tabular}{lrrr}
\hline \hline & Switch P5 & & Switch P5 \\
\hline Applications & 324.5 & Graduation Rate (\%) & 0.7 \\
& $(820.8)$ & Retention Rate (\%) & $0.9)$ \\
Acceptance Rate (\%) & 1.6 & 0.8 & $(0.8)$ \\
& $(2.0)$ & Total Research Spending & -33 \\
State Appropriations & 115 & & $(446)$ \\
& $(481)$ & Research Salaries & 166 \\
State and Local Grants and Contracts & 267 & & $(212)$ \\
& $(554)$ & & 398 \\
Private Gifts, Grants, and Contracts & 100 & Total Instructional Spending & $(501)$ \\
& $(265)$ & & 242 \\
Federal Grants and Contracts & 24 & Instructional Salaries & $(204)$ \\
& $(428)$ & & -0.465 \\
SAT Critical Reading Q1 & -3.3 & ACT Verbal Q1 & $(0.272)$ \\
SAT Critical Reading Q3 & $(2.6)$ & ACT Verbal Q3 & -0.252 \\
& -3.4 & & $(0.376)$ \\
SAT Math Q1 & $(2.8)$ & ACT Math Q1 & -0.258 \\
& -0.9 & & $(0.166)$ \\
SAT Math Q3 & $(3.5)$ & ACT Math Q3 & -0.130 \\
& -2.5 & & $(0.208)$ \\
ACT Composite Q1 & $(3.0)$ & ACT Composite Q3 & -0.247 \\
& -0.211 & & $(0.174)$ \\
\hline
\end{tabular}

Note: ${ }^{*} p<0.1,{ }^{* *} p<0.05, * * * p<0.01$. Heteroskedasticity-robust standard errors in parenthesis. Each estimate represents a different model specification. PSM match based on logit estimation of treatment using averages of prior 5 years of bowl apperances, state population, state RPCGDP, state unemployment rate and university enrollment. 
References

\section{References}

Alexander, D. L. and Kern, W. (2009). The impact of athletic performance on tuition rates. International Journal of Sport Finance, 4(4):240-254.

Alexander, D. L. and Kern, W. (2010). Does athletic success generate legislative largess from sports-crazed representatives? The impact of athletic success on state appropriations to colleges and universities. International Journal of Sport Finance, 5(4):253-267.

Amel, D. (1993). State laws affecting the geographic expansion of commercial banks. Unpublished manuscript, Board of Governors of the Federal Reserve System.

Anderson, M. L. (2017). The benefits of college athletic success: An application of the propensity score design. Review of Economics and Statistics, 99(1):119-134.

Beck, T., Levine, R., and Levkov, A. (2010). Big bad banks? The winners and losers from bank deregulation in the United States. The Journal of Finance, 65:1637-67.

Becker, G. (1957). The Economics of Discrimination. University of Chicago Press, Chicago.

Bedard, K. (2001). Human capital versus signaling models: University access and high school dropouts. Journal of Political Economy, 109:749-75.

Benmelech, E., Bergman, N., and Seru, A. (2011). Financing labor. Working Paper 17144, NBER.

Betts, J. R. (1998). The impact of educational standards on the level and distribution of earnings. The American Economic Review, 88(1):266-275.

Black, D., McKinnish, T., and Sanders, S. (2005). Tight labor markets and the demand for education: Evidence from the coal boom and bust. Industrial and Labor Relations Review, 59:3-16.

Black, S. and Strahan, P. (2002). Entrepreneurship and bank credit availability. The Journal of Finance, 57:2807-33. 
Blankmeyer, E. (2006). How robust is linear regression with dummy variables? Faculty Publications - Finance and Economics, 2:1-14.

Bostock, M., Carter, S., and Quealy, K. (2013). Tracing the history of N.C.A.A. conferences. New York Times. http://www.nytimes.com/newsgraphics/2013/11/30/footballconferences/index.html. Retrieved 05/16/18.

Boustanifar, H. (2014). Finance and employment: Evidence from U.S. banking reforms. Journal of Banking and Finance, 46:343-54.

Bremmer, D. S. and Kesselring, R. G. (1993). The advertising effect of university athletic success: A reappraisal of the evidence. The Quarterly Review of Economics and Finance, $33(4): 409-421$.

Bridgeland, J., Dilulio, and Morison, K. B. (2006). The Silent Epidemic: Perspectives of High School Dropouts. Civic Enterprises.

Bui, Q. and Miller, C. C. (2015). The typical american lives only 18 miles from mom. NY Times.

Cameron, S. V. and Heckman, J. J. (1993). The nonequivalence of high school equivalence. Journal of Labor Economics, 11:1-47.

Cameron, S. V. and Heckman, J. J. (2001). The dynamics of educational attainment for black, hispanic, and white males. Journal of Political Economy, 109:455-99.

Card, D. and Payne, A. A. (2002). School finance reform, the distribution of school spending, and the distribution of student test scores. Journal of Public Economics, 83:49-82.

Carneiro, P. and Heckman, J. J. (2002). The evidence on credit constraints in postsecondary schooling. The Economic Journal, 112:705-34.

Carroll, K. and Humphreys, B. R. (2016). Opportunistic behavior in a cartel setting: Effects of the 1984 Supreme Court decision on college football television broadcasts. Journal of Sports Economics, 17(6):601-628. 
Caucutt, E. M. and Lochner, L. (2012). Early and late human capital investments, borrowing constraints, and the family. Working Paper 18493, NBER.

Caudill, S. B., Hourican, S., and Mixon, F. G. (2018). Does college football impact the size of university applicant pools and the quality of entering students? Applied Economics, 50(17):1885-1890.

Cetorelli, Nicola, P. E. S. (2006). Finance as a barrier to entry: Bank competition and industry structure in local U.S. markets. The Journal of Finance, 61(1):437-461.

Chapman, C., Laird, J., Ifill, N., and Ramani, A. K. (2011). Trends in high school dropout and completion rates in the United States: 1972-2009. Technical Report NCES 2012-006, National Center for Education Statistics.

Clarke, M. Z. (2004). Geographic deregulation of banking and economic growth. Journal of Money, Credit, and Banking, 36:929-42.

Dee, T. S. (2004). Are there civic returns to education? Journal of Public Economics, $88: 1697-1720$.

Evans, W. N. and Kim, W. (2006). The impact of local labor market conditions on the demand for education: Evidence from Indian casinos. Technical report, U.S. Census Bureau Center for Economic Studies.

Fulks, D. L. (1998). Revenues and expenses of divisions I and II intercollegiate athletics programs: Financial trends and relationships, 1997. Research report, National Collegiate Athletic Association.

Glaeser, E. L., Kahn, M. E., and Rappaport, J. (2008). Why do the poor live in cities? The role of public transportation. Journal of Urban Economics, 63:1-24.

Goff, B. (2000). Effects of university athletics on the university: A review and extension of empirical assessment. Journal of Sport Management, 14(2):85-104.

Grembi, V., Nannicini, T., and Troiano, U. (2016). Do fiscal rules matter? American Economic Journal: Applied Economics, 8(3):1-30. 
Hahn, J., Todd, P., and der Klaauw, W. V. (2001). Identification and estimation of treatment effects with a regression-discontinuity design. Econometrica, 69:201-209.

Hansen, G. (2016). UA, ASU made tough decision to bolt WAC for Pac. Arizona Daily Star. http://tucson.com/sports/ua-asu-made-tough-decision-to-bolt-wac-forpac/article_167ed5ad-5a2b-5c6b-8447-1291ecaefc17.html. Retrieved 05/16/18.

Hernández-Julián, R. and Rotthoff, K. W. (2014). The impact of college football on academic achievement. Economics of Education review, 43:141-147.

Hickman, D. C. and Meyer, A. G. (2017). Does athletic success influence persistence at higher education institutions? New evidence using panel data. Contemporary Economic Policy, 35(4):658-676.

Hoffer, A. J. and Pincin, J. A. (2015). The effects of conference realignment on NCAA athletic departments. Applied Economics Letters, 22(15):1209-1223.

Huang, R. R. (2008). Evaluating the real effect of bank branching deregulation: Comparing contiguous counties across US state borders. Journal of Financial Economics, 87(3):678705.

Humphreys, B. R. (2006). The relationship between big-time college football and state appropriations for higher education. International Journal of Sport Finance, 1(2):119128.

Humphreys, B. R. and Mondello, M. (2007). Intercollegiate athletic success and donations at NCAA Division I institutions. Journal of Sport Management, 21(2):265-280.

Illinois Department of Financial \& Professional Regulation (2015). Illinois bank branching history. https://www.idfpr.com/banks/cbt/stats/br-hist.asp [Accessed: 04-28-2018].

Jaquette, O. and Parra, E. (2016). The problem with the Delta Cost project database. Research in Higher Education, 57:630-651.

Jayaratne, J. and Strahan, P. E. (1996). The finance-growth nexus: Evidence from bank branch deregulation. The Quarterly Journal of Economics, 111:639-70. 
Jerzmanowski, M. and Nabar, M. (2013). Financial development and wage inequality: Theory and evidence. Economic Inquiry, 51:211-34.

Kearney, T. D. (2014). Three essays on intercollegiate athletics and the financial relationship with institutions of higher education. PhD thesis, University of Illinois at UrbanaChampaign.

Kerr, W. R. and Nanda, R. (2009). Democratizing entry: Banking deregulation, financing constraints, and entrepreneurship. Journal of Financial Economics, 94:124-49.

Kramer II, D. A. (2014). Making the Switch: Factors Affecting and Theoretical Considerations about Athletic Conference Realignment in FBS Institutions. PhD thesis, University of Georgia.

Kroszner, R. S. and Strahan, P. E. (1999). What drives deregulation? Economics and politics of the relaxation of bank branching restrictions. Quarterly Journal of Economics, 114:1437-67.

Kroszner, R. S. and Strahan, P. E. (2014). Regulation and deregulation of the U.S. banking industry: Causes consequences, and implications for the future. In Rose, N. L., editor, Economic Regulation and Its Reform: What Have We Learned?, pages 485-543. University of Chicago Press, Chicago.

Krueger, A. O. (1974). The political economy of the rent-seeking society. The American Economic Review, 64:291-303.

Lang, K. and Ruud, P. (1986). Returns to schooling, implicit discount rates and black-white wage differentials. The Review of Economics and Statistics, 68(1):41-47.

Levine, R. and Rubinstein, Y. (2013). Liberty for more: Finance and educational opportunities. Cato Papers on Public Policy, 3:55 - 94.

Lindo, J. M., Swensen, I. D., and Waddell, G. R. (2012). Are big-time sports a threat to student achievement? American Economic Journal: Applied Economics, 4(4):254-74. 
Lleras-Muney, A. (2002). Were compulsory attendance and child labor laws effective? An analysis from 1915 to 1939. Journal of Law and Economics, 45:401 - 435.

Lochner, L. and Moretti, E. (2004). The effect of education on crime: Evidence from prison inmates, arrests, and self-reports. American Economic Review, 94:155 - 189.

Long, M. C., Goldhaber, D., and Huntington-Klein, N. (2015). Do completed college majors respond to changes in wages? Economics of Education Review, 49:1-14.

McChesney, F. S. (1987). Rent extraction and rent creation in the economic theory of regulation. The Journal of Legal Studies, 16(1987):101-118.

McCormick, R. E. and Tinsley, M. (1987). Athletics versus academics? Evidence from SAT scores. Journal of Political Economy, 95(5):1103-1116.

Milligan, K., Moretti, E., and Oreopoulos, P. (2004). Does education improve citizenship. Journal of Public Economics, 88(9-10):1667 - 1695.

Mincer, J. (1958). Investment in human capital and personal income distribution. Journal of Political Economy, 66(4):281-302.

Mixon, F. G., Treviño, L. J., and Minto, T. C. (2004). Touchdowns and test scores: Exploring the relationship between athletics and academics. Applied Economics Letters, 11(7):421424.

Mixon Jr, F. G. (1995). Athletics versus academics? Rejoining the evidence from SAT scores. Education Economics, 3(3):277-283.

Mixon Jr, F. G. and Ressler, R. W. (1995). An empirical note on the impact of college athletics on tuition revenues. Applied Economics Letters, 2(10):383-387.

Mixon Jr, F. G. and Trevino, L. J. (2005). From kickoff to commencement: The positive role of intercollegiate athletics in higher education. Economics of Education Review, 24(1):97102. 
Murnane, R. J. (2013). U.S. high school graduation rates: Patterns and explanations. Journal of Economic Literature, 51:370-422.

Murphy, R. G. and Trandel, G. A. (1994). The relation between a university's football record and the size of its applicant pool. Economics of Education Review, 13(3):265-270.

Oreopoulos, P. (2007). Do dropouts drop out too soon? Wealth, health and happiness from compulsory schooling. Journal of Public Economics, 91:2213-29.

Oreopoulos, P. and Salvanes, K. G. (2011). Priceless: The nonpecuniary benefits of schooling. Journal of Economic Perspectives, 25:159 - 184.

Pope, D. G. and Pope, J. C. (2009). The impact of college sports success on the quantity and quality of student applications. Southern Economic Journal, pages 750-780.

Pope, D. G. and Pope, J. C. (2014). Understanding college application decisions: Why college sports success matters. Journal of Sports Economics, 15(2):107-131.

Powdthavee, N. (2010). Does education reduce the risk of hypertension? Estimating the biomarker effect of compulsory schooling in england. Journal of Human Capital, 4:173202.

Rees, D. I. and Mocan, H. N. (1997). Labor market conditions and the high school dropout rate: Evidence from New York State. Economics of Education Review, 16:103-09.

Rishe, P. J. (2003). A reexamination of how athletic success impacts graduation rates: Comparing student-athletes to all other undergraduates. American Journal of Economics and Sociology, 62(2):407-427.

Rumberger, R. W. (1987). High school dropouts: A review of issues and evidence. Review of Educational Research, 57:101-21.

Sanderson, A. R. and Siegfried, J. J. (2015). The case for paying college athletes. Journal of Economic Perspectives, 29(1):115-38. 
Sanderson, A. R. and Siegfried, J. J. (2018). The National Collegiate Athletic Association cartel: Why it exists, how it works, and what it does. Review of Industrial Organization, $52(2): 185-209$.

Segura, J. and Willner, J. (2016). The game is good at the top. Journal of Sports Economics, pages $1-32$.

Siedler, T. (2010). Schooling and citizenship in a young democracy: Evidence from postwar Germany. Scandinavian Journal of Econonmics, 112:315 - 338.

Smith, D. R. (2008). Big-time college basketball and the advertising effect: Does success really matter? Journal of Sports Economics, 9(4):387-406.

Smith, D. R. (2012). The curious (and spurious?) relationship between intercollegiate athletic success and tuition rates. International Journal of Sport Finance, 7(1):3-18.

Stiroh, K. J. and Strahan, P. E. (2003). Competitive dynamics of deregulation: Evidence from U.S. banking. Journal of Money, Credit, and Banking, 35:801-28.

Sweitzer, K. V. (2009). Institutional ambitions and athletic conference affiliation. New Directions for Higher Education, 2009(148):55-63.

Sylla, R., Legler, J. B., and Wallis, J. J. (1987). Banks and state public finance in the republic: The United States, 1790-1860. Journal of Economic History, 47:391-403.

Teng Sun, S. and Yannelis, C. (2016). Credit constraints and demand for higher education: Evidence from financial deregulation. Review of Economics and Statistics, 98:12-24.

Tewari, I. (2014). The distributive impacts of financial development: Evidence from mortgage markets during US bank branch deregulation. American Economic Journal: Applied Economics, 6(4):175-196.

Tucker, I. B. (1992). The impact of big-time athletics on graduation rates. Atlantic Economic Journal, 20(4):65-72. 
Tucker, I. B. (2004). A reexamination of the effect of big-time football and basketball success on graduation rates and alumni giving rates. Economics of Education Review, 23(6):655661.

Tucker, I. B. (2005). Big-time pigskin success: Is there an advertising effect? Journal of Sports Economics, 6(2):222-229.

Tucker, I. B. and Amato, L. (1993). Does big-time success in football or basketball affect SAT scores? Economics of Education Review, 12(2):177-181.

Tucker, I. B. and Amato, L. T. (2006). A reinvestigation of the relationship between big-time basketball success and average SAT scores. Journal of Sports Economics, 7(4):428-440.

Tullock, G. (1967). The welfare costs of tariffs, monopolies, and theft. Economic Inquiry, $5: 224-32$.

White, L. J. (1991). The SÉL Debacle: Public Policy Lessons for Bank and Thrift Regulation. Oxford University Press, New York. 